\title{
LNG Annotated Bibliography
}

H. J. Bomelburg

C. A. Counts

C. E. Cowan

W. E. Davis

J. G. Desteese

P. J. Pelto

September 1982

Prepared for the U.S. Department of Energy under Contract DE-AC06-76RLO 1830

Pacific Northwest Laboratory Operated for the U.S. Department of Energy by Battelle Memorial Institute 


\title{
DISCLAIMER
}

This report was prepared as an account of work sponsored by an agency of the United States Government. Neither the United States Government nor any agency thereof, nor any of their employees, makes any warranty, express or implied, or assumes any legal liability or responsibility for the accuracy, completeness, or usefulness of any information, apparatus, product, or process disclosed, or represents that its use would not infringe privately owned rights. Reference herein to any specific commercial product, process, or service by trade name, trademark, manufacturer, or otherwise, does not necessarily constitute or imply its endorsement, recommendation, or favoring by the United States Government or any agency thereof. The views and opinions of authors expressed herein do not necessarily state or reflect those of the United States Government or any agency thereof.

\author{
PACIFIC NORTHWEST LABORATORY \\ operated by \\ BATTELLE \\ for the \\ UNITED STATES DEPARTMENT OF ENERGY \\ under Contract DE-AC06-76RLO 1830
}

\begin{tabular}{|c|c|}
\hline \multicolumn{2}{|c|}{$\begin{array}{l}\text { Printed in the United States of America } \\
\text { Available from } \\
\text { National Technical Information Service } \\
\text { United States Department of Commerce } \\
5285 \text { Port Royal Road } \\
\text { Springfield, Virginia } 22151\end{array}$} \\
\hline \multicolumn{2}{|c|}{$\begin{array}{l}\text { NTIS Price Codes } \\
\text { Microfiche A01 }\end{array}$} \\
\hline \multicolumn{2}{|c|}{ Printed Copy } \\
\hline Pages & $\begin{array}{l}\text { Price } \\
\text { Codes }\end{array}$ \\
\hline $001-025$ & $\mathrm{~A} 02$ \\
\hline 026-050 & $\mathrm{A} 03$ \\
\hline 051-075 & $\mathrm{A} 04$ \\
\hline $076-100$ & A05 \\
\hline $10:-125$ & A06 \\
\hline $126-150$ & $\mathrm{~A} 07$ \\
\hline $151-175$ & $\mathrm{~A} 08$ \\
\hline $176-200$ & A09 \\
\hline $201-225$ & A010 \\
\hline $226-250$ & A011 \\
\hline $251-275$ & A012 \\
\hline $276-300$ & A013 \\
\hline
\end{tabular}


LNG ANNOTATED BIBLIOGRAPHY

H. J. Bomelburg

C. A. Counts

C. E. Cowan

W. E. Davis

J. G. DeSteese

P. J. Pelto

September 1982

Prepared for

the U.S. Department of Energy Office of

Environmental Protection, Safety and Emergency Preparedness Under Contract DE-AC-06-76RLO 1830

Pacific Northwest Laboratory

Richland, Washington 99352 



\section{FOREWORD}

This report is one of a series prepared by Pacific Northwest Laboratory (PNL) to communicate results of the Liquefied Gaseous Fue1s (LGF) Safety Studies Project, being performed for the U.S. Department of Energy, Office of Environmental Protection, Safety and Emergency Preparedness (DOE/EP). The DOE/EP Office of Operational Safety, Environmental and Safety Engineering Division (ESED), is conducting the DOE Liquefied Gaseous Fuels Safety and Environmental Control Assessment Program. The LGF Safety Studies Project contributes research, technical surveillance and program development information in support of the ESED Assessment Program. This LNG annotated bibliography benefited from the technical direction and guidance provided by Dr. John M. Cece and Dr. Henry F. Walter of ESED.

Completed effort in other tasks of the PNL project are reported in:

1. Assessment of Research and Development (R\&D) Needs in LPG Safety and Environmental Control (PNL-3991)

2. Assessment of Research and Development (R\&D) Needs in Ammonnia Safety and Environmental Control (PNL-4006)

3. An Overview Study of LNG Release Prevention and Control Systems (PNL-4014)

4. Applications of Human Factors Engineering to LNG Release Prevention and Control (PNL-4090)

5. Analysis of LNG Import Terminal Release Prevention Systems (PNL-4152)

6. Analys is of LNG Peakshaving Facility Release Prevention Systems (PNL-4153)

7. LNG Fire and Vanor Control System Technologies (PNL-4398)

8. Comparative Safety Analys is of LNG Storage Tanks (PNL-4399) 


\section{ACKNOWLEDGMENTS}

The authors gratefully acknowledge the assistance provided by individuals at Battelle-Institute e.V. (BIeV) in Frankfurt, West Germany, and at Pacific Northwest Laboratory (PNL) during the course of this work and preparation of the final report. Dr. W. Geiger, Dr. M. Stock and staff from the Safety Technologies Department at BIeV provided abstracts of European technical literature related to safety hazards associated with production, transportation, storage and use of LNG. Nancy Burleigh and Karen Rodriguez of PNL provided editorial support throughout the study and in preparation of the final report. Finally, Marlene Hale and Michele Thielges contributed their word processing skills in the preparation of the final manuscript. 


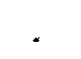


TABLE OF CONTENTS

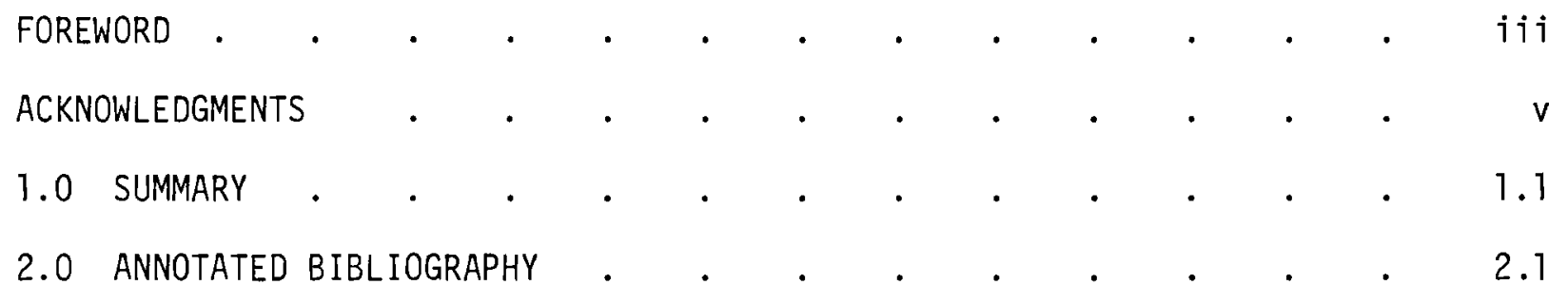

vii 


\subsection{SUMMARY}

The U.S. Department of Energy, Office of the Assistant Secretary for Environmental Protection, Safety and Emergency Preparedness (DOE/EP) has a responsibility for identifying, characterizing and mitigating environmental, safety and health issues associated with the commercial use of specific enerqy materials. The Environmental and Safety Engineering Division (ESED), in the DOE/EP Office of Operational Safety, is responsible for assessing some of these materials. To fulfill this responsibility, the ESED is conducting an R\&D program that includes safety and environmental control assessments of 1 iquefied gaseous fuels (LGF). The overall objective of this program is to gather, analyze and disseminate technical information that will aid future decisions made by industry, regulatory agencies and the general public on facility siting, system operations and accident prevention and mitigation. This effort is known as the DOE Liquefied Gaseous Fuels Safety and Environmental Control Assessment Program.

In support of the DOE Program, Pacific Northwest Laboratory (PNL) undertook the LGF Safety Studies Project to provide research, technical surveillance and program development information to DOE. As part of the PNL project, an LNG Technical Surveillance Task was established to assist ESED in maintaining surveillance of technical literature reporting R\&D activities related to LNG safety and environmental control.

Under the LNG Technical Surveillance Task an annotated bibliography was continuously updated and submitted to ESED on a quarterly basis. Periodically, the information developed under this task was complied and included in status reports of the ESED Program. Preceding documents which included LNG annotated bibliographies are DOE/EV-0002 (February 1978), D0E/EV-0036 (May 1979), DOE.EV0085 (October 1980) and PNL-4172 (March 1982). This document updates the bibliography published in Liquefied Gaseous Fuels Safety and Environmental Control Assessment Program: Third Status Report (PNL-4172) and is a complete listing of literature reviewed and reported under the LNG Technical Surveillance Task. The bibliography is organized alphabetically by author. 


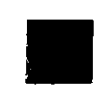




\subsection{LNG ANNOTATED BIBL IOGRAPHY}

Adkins, R. E. "LNG: New Driving Force." Pipeline \& Gas J. 209(13):45-52, 1981.

The history of using liquefied methane as motor fuel is briefly outlined. The advantages as well as safety problems of LNG in automobile propulsion are discussed. The "Methane Transportation Use and Demonstration Act of 1980" indicates the intent of the U.S. Congress to encourage the use of LNG in automobile, aircraft and ship propulsion.

Affleck, W. S., Harrow, G. A. and Mills, W. D., "Converting a Small Car to LivG: What Are the Problems and What Can It Do for Economy and Emissions," She11 Research Ltd., United Kingdom, SAE Preprint \#760376, February 1976.

The results of a comparison between a two-liter compact car run on gasoline and one converted to LNG are discussed. Fuel economy improvements for both normal road use and taxi service on the LNGpowered car are described.

Alger, A. S., Corlett, R. C., Gordon, A. S. and Williams, F. A., Some Aspects of Structures of Turbulent Pool Fires. WSS/C1 76-46, October $197 \overline{6 .}$

Results are reported on the burning of JP-5 and methanol pools $305 \mathrm{~cm}$ in dia. Measurements made include radiant energy fluxes outside and within the fire, temperatures and chemical compositions within the fire and rates of weight loss of the pool. Results emphasize structural differences between JP-5 and methanol fires and importance of radiant feedback of energy to the pool surface in controlling rates of burning.

Allan, D., Atallah, S., Drake, E., Hinckley, R. and Mathias, S., Technology and Current Practices for Processing, Transferring and Storing Liquefied Natural Gas. Department of Transportation/OST, Office of Pipeline Safety, Washington, DC, (prepared by Arthur D. Littie, Inc., Report No. C-76971) December 1974.

Current state-of-the-art safety information related to the design, location, construction, operation and maintenance of facilities required for liquefaction, transfer, storage, and revaporization of natural gas is assembled and summarized. A detailed review of codes, standards and practices pertaining to LNG installations is presented along with an evaluation of present trends in LNG safety requirements. LNG safety research programs completed or in progress are described and key research results summarized. Finally a methodology for quantitative assessment of risks associated with LNG facilities is outlined. 
Allen, D. S., R. L. Phani Raj, P. Athens, E. G. Pollack, N. M. Laurendeau, R. N. Caron, and A. A. Fowle. The Feasibility of Methods and Systems for Reducing LNG Tanker Fire Hazards. DOE/EV/04734-T1, Department of Energy, Washington, D.C., 1980.

Various methods have been analyzed for their suitability of reducing LNG tanker fire hazards. None of them appear to be promising, nevertheless, the feasibility studies should be continued to include some test work.

Almgren, D. W. and Smith, J. L., Jr., "The Inception of Nucleate Boiling With Liquid Nitrogen." Journal of Engineering for Industry. pp. 1211-1216, November 1969.

The phenomena of patchwise boiling are discussed, and the significant parameters restricting the growth of a boiling patch are analytically determined to be: a high nucleate boiling heat-transfer coefficient; a low total heat flux; the absence of cavities with a trapped liquid vapor interface outside the boiling patch; an appropriate value of wall thermal conductivity; a high vapor enthalpy per bubble.

American Gas Association, LNG Fact Book. Planning and Analysis Group, AGA Arlington, VA 22209, 1977.

This report summarizes the American Gas Association view of LNG importation and its advantages. Issues and project status at the time of publication are also reviewed.

An Economic Analysis of Imported LNG in Selected End Use Markets. Prepared for the American Gas Association by Booz Allen and Hamilton, Inc., May 1978.

Economics of LNG usage in space heating, with and without advanced equipment, and in industrial applications is reviewed.

An Experimental Study of the Mitigation of Flammable Vapor Dispersion and Fire Hazards Immediately Following LNG Spills on Land. A report by University Engineers, Inc., to the American Gas Association, February 1974.

A series of fire control, fire extinguishment and vapor dispersion tests were conducted under the high boil-off rates which occur immediately following an LNG spill on land. Correlations of the results provide fire control and extinguishment times with dry chemical agents and high expansion foams. The magnitude of the reduction in downwind concentrations of methane vapors by the application of high expansion foam on the spill was also determined. 
Analysis of Risk in the Water Transportation of Hazardous Materials. U.S. Coast Guard Report, CG-D-39-76. NTIS No. AD/A025298, January 1976.

This report assesses the utility and feasibility of using risk analysis to assist in management decisions regarding the regulation of water transportation of bulk hazardous materials. A number of risk analysis studies were surveyed. Barge transportation on inland waterways was chosen for special study, and a probabilistic model of risk was selected. It was concluded that the greatest utility of the methodology lies in answering specific questions with output of a specific predetermined nature.

Andersen, W. H., Garfinkle, D. R., Carpenter, G. E. and Brown, R. E., "Energy Absorption Near and Below the Burning Surface of Hydrocarbon Pools. "Paper presented at the 1969 Meeting, Central States Section, The Combustion Institute, March 18-19, 1969.

The burning behavior of a liquid fuel pool is discussed in terms of the heat feedback from the flame that is transported into and through the fuel via conduction and radiation. It is shown that the radiant flux contribution to the total heat flux input is greatest for benzene, and decreases consecutively for gasoline, kerosene, and alcohol.

Anderson, A. D., "Analytical Modeling of Practical Combustion Systems." DOE/Final Report FE-2589-TI, Department of Energy, Washington, D.C., 1978.

The author applies Spaulding's approach to model a two-dimensional, steady-state, recirculating and reacting flow. An attempt is made to incorporate the effect of turbulence on the reaction rate through a two-equation turbulence model $(K-E)$. Analytical and experimental results are compared with fair to good agreement.

Anderson, J. and Smith, M., "Safety-Guided Design of LNG Termina1." $0 i 1$ and Gas Journal, 77(25):93-97, 1979.

Safety was the basic consideration in the design of Southern Energy's LNG import terminal at Elba Island, Alabama. The terminal sits on an island in the Savannah River. Its three storage tanks can each store $400,000 \mathrm{bbl}$ of LNG. Nine $125,000 \mathrm{~m}^{3}$ tankers supply the terminal from Algeria.

Anderson, P. J., "Recent Developments in Regulations for LNG Storage in the United States." CONF-790985-1, 1979.

The paper reports on the ongoing debate for a new version of the principal standard for LNG facilities: NFPA-59A. A target date for final approval was set for November 1979. 
Anderson, P. J., "Steady Growth Seen in Next Decade for World Trade in LNG." Pipeline and Gas Journa 1, 121(3):39-45, 1980.

It is expected that until the mid-1980's, the size of world trade in LNG will more than double, with an annual growth rate of about 16\%. However, this must be compared with an annual growth rate of an average $23.5 \%$ for the last 15 years.

Anderson, P. J. "The Potential for LNG World Trade." Chem. Eng. Progr. 77( 1$): 73-79,1981$.

Statistical data on production and trade of natural gas are presented. The LNG industry registered an average $23 \%$ annual growth during the last 20 years. Future growth is expected to continue at a measured pace, at least for this decade.

Anderson, R. P. and Armstrong, D. R., "Experimental Studies of Vapor Explosions." 3rd International Conference on Liquefied Natural Gas, paper 3 of Session VI, Chicago, 1972.

Small scale experiments with molten salts and molten metals, injected into water, are described. In some cases ensuing reactions can turn into vapor explosions.

Anderson, R. P. and Armstrong, D. R., "Experimental Study of Vapor Explosions." Paper presented at the Third International Conference and Exhibition on Liquefied Natural Gas, September 24-28, 1972, Washington, DC.

Present knowledge about various aspects of vapor explosions is summarized. Particular emphasis is placed on methods of evaluating the destructive kinetic energy release from a specified accident. A theoretical method of calculating the maximum destructive energy is outlined.

Andrews, G. E. and Bradley, D., "The Burning Velocity of Methane-Air Mixtures." Combustion and Flame. 19:275-288, 1972.

Results are presented for the variation of burning velocity with equivalence ratio for methane-air mixtures at one atmosphere pressure. values were determined by the bomb-hot wire and corrected density ratio techniques, for combustion during the pre-pressure period. The former of these methods gives a maximum burning velocity of $45 \pm 2 \mathrm{~cm} / \mathrm{sec}$, at an equivalence ratio of 1.07 .

Androulakis, J. G., "Thermal Barrier System for a Liquefied Gas Tank." U.S. patent 4,140,073 (to Frigitemp, New York), 1979.

It is claimed that radiation is the main contributor for heat transfer to an LNG cargo tank. Therefore, it is proposed to surround the tank with a high reflectance material acting as a thermal shield for radiation. 
Anonymous. "Nickel Steels in Construction of Liquid Methane Carriers." (in German), Masch. u. Werkz. 80(7):34-40, 1979.

Various $\mathrm{Ni}$-steels and corrosion resistant austenitic steel are used for ship containers for the storage of liquid methane up to $130,000 \mathrm{~m}^{3}$. The criteria for the choice of the material are discussed like resistance against low temperature brittleness, fracture toughness, thermal expansion coefficient, weldability and corrosion resistance.

Anselmann, H. H. and R. Bellemann. "Test Run of Safety Valves for LNG." $0 i 1$ and Gas J., pp. 68-69, October 6, 1980.

The temperature gradients in an LNG safety relief valve were experimentally determined by tests with liquid nitrogen under simulated operating conditions. These measurements provide criteria for selecting the proper materials for the valve components.

Anspach, G., Baseler, R. and Glasfeld, R., "A Floating LNG Receiving Terminal." Chem. Eng. Progr. 75(10):86-91, 1979.

The paper presents the floating LNG terminal as a practical alternative to land-based storage and regasification facilities. Lower cost and independence of seismic restraints are its prime advantages. However, so far no such terminal has been designed or ordered.

Anthony, E. J., "Some Aspects of Unconfined Gas and Vapor Cloud Explosions," Journal of Hazardous Materials. 1:284-301, 1975-77.

A critical review is presented of experimental and theoretical work on unconfined vapor explosions with emphasis on modeling studies.

Arkharov, A. M., Yu. A. Berestyanskiy, "Natural Gas Liquefaction Plants with Expanders in the Return Flow." In: Problems of Modern Cryogenics.

NASA TT F-16, 841, 1976.

A theoretical study shows the possibility of using a Le Rouge cycle with a turbo-expander in the return flow for liquefying natural gas. The pressure differential between the main supply line and the distribution network is sufficient for 6-15\% liquefaction.

Arnoni, Y. G., "The Marriage of LNG and Offshore Facilities." Chem. Eng. Progr. 75(10):60-65, 1979.

The article deals with the advantages and problems of an LNG offshore facility on technical, economic and sociological grounds. Even though no such facilities have been built, several are in the planning and engineering phase. 
Aronson, J. D. and Westermeyer W. "U.S. Public and Private Regulation of LNG Transport." Marine Policy. 6:11-26, 1982.

A wide-ranging critical review of the current status of the LNG industry is given, with emphasis on existing regulations by twelve different agencies. The pros and cons of shifting the regulatory responsibilities back to the industrial and financial community are discussed.

Arthur D. Little, Inc., A Report on LNG Safety Research, Vol. I. to A.G.A., A.G.A. Project I U-2-1, A.G.A. Catalog No. M19771, January 37, 1971.

It is concluded that smaller reieases are rather rare and usually not damaging; probability is low that a large spill will occur from currently constructed facilities; spills from containers may have acceptable probability but some additional protection should be provided; risk of transfer line failure requires higher level of protection; further consideration should be given to hazards involved with LNG transport.

Asselineau, P. R., "Experience With LNG as a Vehicle Fuel for the Public Transport System of Paris." Paper No. A3.11 presented at the 14 th International Congress of Refrigeration, Moscow, (in French), September 20-29, 1975.

This paper discusses the results and recommendations of field tests conducted by Gas de France to assess the economic and practical aspects of operating LNG-powered vehicles. Three buses from the Paris public transport network were used in the testing.

Atallah, S. and Allen, D. S., "Safe Separation Distances From Liquid Fuel Spill Fires." Paper presented at Central States Section, Combustion Institute Meeting on Disaster Hazards, Houston, TX, Apri1 1970.

This paper critically reviews the methods generally used to calculate safe separation distances from liquid fuel spill fires. Correlations for predicting flame height and other radiative properties are reviewed. Distances at which the thermal radiation flux falls below the minimum level needed to ignite cellulosic materials are calculated and the results are presented in convenient graphical form.

Atallah, S. and Raj, P., "Thermal Radiation From LNG Spill Fires." Paper P-3 presented at the Cryogenic Engineering Conference, Atlanta, GA, August 10, 1973 .

This paper reviews the present state of knowledge relating to thermal radiation from LNG fires. Utilizing data from recent AGA-sponsored LNG fires in seven 6-ft, six 20-ft, and one 80-ft diameter pools, equations were derived for predicting LNG flame height and the angle of tilt of LNG flames in the presence of wind. A model for predicting the thermal radiative flux at various locations away from an LNG fire is presented. 
Atallah, S., E. Drake and R. Reid. Summary of LNG Safety Research. PB273.278, 1974.

A critical comprehensive overview of LNG safety. The document goes into considerable technical details with an extensive bibliography.

Atallah, S. "LNG Safety Research Overview." (in English), Paper presented at the 8th International LNG/LPG Conference and Exhibition, Hamburg, West Germany, October 20-23, 1981.

This paper summarizes current LNG Safety research projects sponsored by the Gas Research Institute - a not-for-profit organization which plans and implements research for the benefit of the U.S. gas consumer. The LNG Safety research program is coordinated with the U.S. Department of Energy and Other European and Japanese organizations. It addresses the assessment, prevention and control of hazards.

Auton, T. R. and J. H. Pickles. The Calculation of Blast Waves from the Explosion of Pancake-Shaped Vapor Clouds. Central Electricity Research Laboratories, Laboratory Note No. RD/L/N 210/78.

A theoretical model for the explosion of a circular pancake-shaped cloud of inflammable vapor is proposed. The model is an extension of the piston model familiar in the treatment of spherical or hemispherical clouds.

Backhaus, H., "LNG - A Fuel for Motor Vehicles." Gas Warme Int. 21:257-64, (in German), June 1972.

The merits and advantages of converting motor vehicles to compressed or liquefied natural gas to reduce pollution are discussed. Present and future costs of LNG in West Germany and an incentive to encourage private conversion of fleet vehicles to LNG are also discussed.

Backhaus, H. and Wieske, P. "Liquefied Natural Gas Pipelines in the Sea." (in German), Meerestechn.-Mar.Techno1. 8(6):208-212, 1977.

The paper presents a new concept to prevent offshore hazards due to collisions between tanker and liquefaction platform. construction and technical performance of a submerged LNG-pipeline in a tunnel are discussed. Expenses and risks are compared to those of normal LNG-pipelines.

Backhaus, H. "Submerged Joint for Cryogenic Liquefied Gases. A Constituent of the Transfer System in Offshore Natural Gas Liquefaction." Meerestechn.-Mar. Technol. 11(4):133-137, 1980.

The article describes the technique of a cardanic beam similar to that used in offshore oil loading but with separated joint to prevent low temperature brittleness. 
Baier, E. "Cryogenic Materials in Ship Building: Nickel-Steels." (in German), Kîl te-u. Klimatechnik. 33(5):209-214, 1980.

This paper gives criteria for the construction of storage tanks for LNG-carriers and a number of material parameters of various nickel steels that can be used for this purpose.

Bailey, F. B., "Status of United States Codes and Regulations Affecting Land Based LNG Facilities." 1978 Operating Section Proceedings, American Gas Association, Montreal, Quebec, May 1978.

This report summarizes current safety and non-safety regulations, and activities concerning regulations. NEPA59A versions and applications are listed.

Baitis, A. E., Bales, S. L. and Meyers, W. G., Prediction of Lifetime Extreme Accelerations for Design of LNG Cargo Tanks. U.S. Coast Guard Report CG-D-89-74. NTIS No. AD/779635, March 1974.

A procedure is developed to predict the extreme accelerations needed for design of the cargo tanks in LNG vessels. The validity of the prediction tool is discussed. Comparisons are made with accelerations measured in model and full scale experiments.

The results of a pilot study on a single, large typical LNG ship are presented. Acceleration response variations due to changes in ship load conditions and changes due to longitudinal, lateral and vertical locations are examined.

naibis, A. E., Meyers W.G. and Bales S. L. Summary of Development for LNG Tank Design Acceleration Rules. U.S. Coast Guard Report SPD-517-03, DTIC Accession No. AD A037652, 1976.

Design accelerations for LNG tankers are estimated for extreme storm conditions. Vertical accelerations have a higher impact on design than longitudinal and lateral accelerations.

Baker, C. R., H. Cheung. Ethylene Production with Utilization of LNG Refrigeration. U.S. Patent 4,121,917; to Union Carbide Corporation, 1978.

Union Carbide Corporation suggests using the cold energy available in LNG as a source of refrigeration in an ethylene plant. By closely matching the cooling curve of the ethylene plant with the LNG warming curve, a highly efficient utilization of the LNG refrigeration is obtained.

Baker, C. R., and H. Cheung. Ethylene Production with Utilization of LNG Refrigeration. U.S. Patent 4,121,917, 1978.

By closely matching the cooling curve of the ethylene plant with the LNG warming curve, highly efficient utilization of the LNG refrigeration is achieved. 
Baker, J. Microcomputer Firmware Description, LGF Data Acquistion System. UCID $18745,1980$.

Two firmware systems (a weather system and a gas and turbulence system) for data acquisition in the LNG dispersion test at China Lake are described.

Barbre, R. and Schmidt, H. "Experimental Investigations with the Spherical Pressure Storage Tank for Gas of the Municipal Works Braunschweig." (in German), Stahlbau 45(11):321-330, 1976 .

Results are given for a strain control of a spherical LPG storage tank and its supporting pillars during pressure and load tests.

Baringeer and Davies J. R. "Electro-Optical Techniques for Remote Sensing." Proceedings of Current Research on Methane Detection and Measurement Symposium, pp. 163-173. Environment Safety and Distribution Division, Gas Research Institute, Chicago, Illinois, 1979.

This paper describes an electro-optical technique for true remote sensing of methane and ethane by detecting the characteristic absorption spectra in the infrared of these gases in incoming radiation.

Bartels, B. "Design of a $40000 \mathrm{~m}^{3} \mathrm{LPG} / \mathrm{NH}_{3}$ Tanker with Large Pressure Vesse1s." (in German), Hansa. 115 (20):1695, 1978.

The design of the tankship with 4 pressure tanks, each in the form of a "lying eight" (IMCO tank type C) aided by finite element calculations according to IMCO regulations is described. The problems to combine ship construction with tank construction are discussed. (Shipyard: AG Weser, Seebeckwerft, Bremerhaven).

Bartels, B. "Development of a $40,000 \mathrm{~m}^{3}$ Gas Tanker with the Consideration of the Use of Large Pressure Vessels." (in German), Schiff u. Hafen 30(10):922-925, 1978.

The project to develop an $L P G / N_{3}$-tanker with the construction and installation of large pressure vessels is promoted by the German Ministry of Research and Technology. Described are design criteria, load conditions, model tests and calculations.

Bartknecht, T. W. "The Course of Gas and Dust Explosions and their Control." First International Loss Prevention Symposium, 1974, 159-174.

The paper describes the course of explosions in vessels and in pipelines. The author discusses the different probabilities of applied explosion protection. 
Partinä, F. "Interactions between Reaction Fronts and Gasdynamic Discontinuties." (in German), Proc. ICT-Jahrestagung, 421-439, 1979.

This paper outlines the results of a systematic study of the most important interaction phenomena under the assumption that the flame can be described in an approximation as a planar front ("reaction front"). However, these are not mere heating fronts; instead, the chemical reaction is simulated by a single-step reaction. This preserves one characteristic property of the flame, i.e., the dependence of its rate of propagation on the condition of the unburnt mixture.

It is seen that the reaction front may change its mode under certain conditions. Slow combustion (deflagration) may suddenly turn into a detonation or vice versa.

Bartlmä, F. "The Transition from Slow Burning to Detonation." (in English), Acta Astronautica 6:435-447, 1979.

The transition from slow burning to detonation in a premixed gas is re-examined. Applying a simple law for the turbulent flame propagation, the acceleration of a flame and the formation of a detonation wave in a tube of constant cross section is predicted for different cases. The flame acceleration which is mainly governed by interaction processes between the flame and gasdynamic discontinuities reveals a strong influence of the heat liberated by chemical reaction. It is not so sensitive to changes of the turbulent transport coefficients. Different possible ways of generating a detonation wave are shown.

Basevich, Y. Ya., Volodin, V. P., Kogarko, S. M. and Peregadov, N. I., "Calculation of Turbulent Flame in the One-Dimensional Approach." Combustion and Flame, 36(1): September 1979.

The authors model the effect of turbulence on flame structure (e.g., flame thickness and propagation velocity) in imperfectly mixed deflagrations. Good agreement between their experimental and analytical results were presented. The approach outlined is somewhat obscure but deserves careful scrutiny because of the importance of deflagrations in large, partially mixed LNG vapor clouds for safety considerations.

Baysinger, F. R. Liquefied Natural Gas Tank Construction, U.S. Patent 4,181,235, assigned to Kaiser ATuminum, 1980.

An improved method for fabricating a spherical storage tank for liquefied or compressed natural gas is described. This method results in a reduction of scrap losses and in a reduced number of weldments. 
Becker, H. and Liang, D., "Viable Length of Vertical Tree Turbulent Diffusion Flames." Combustion and Flame. 32:11-137, 1978.

The authors of this paper propose and review correlations for the visible length of turbulent diffusion flames. This paper may be useful for determining the magnitude of thermal radiation from LNG pool fires.

Beer, J. M., "Methods for Calculating Radiative Heat Transfer from Flames in Combustors and Furnaces." Heat Transfer in Flames. Chapter 2, John Wiley and Sons, 1974.

Recent advances in methods for predicting radiative heat flux distribution in furnaces and combustors are reviewed with special reference to the zone method of analysis and the flux methods. Recent experimental studies specially designed to test these prediction procedures under sufficiently severe conditions are discussed.

Bellus, F., Cochard, H., Vincent, R. and Mauger, J., Controlling the Hazards from LNG Spills on the Ground LNG Firefighting Methods and Their Effects Application to Gaz de France Terminals. Gaz de France, DOE-Tr-18.

Three basic areas are examined in this paper. A mathematical model to calculate vapor dispersion from accidental LNG spills on land is described. This model is used to investigate various types of impounding areas and their minimization of methane cloud travel. A method to calculate water spray rates for the protection of LNG tank walls from the energy radiated by an adjacent fire is described and a numerical example is given. The authors describe the details of design and construction of the new $80,000 \mathrm{~m}^{3} \mathrm{LNG}$ tank at the Fos Terminal.

Bellus, F., Vincent, R., Cochard, H. and Mauger, J., "Controlling the Hazards from LNG Spills on Land." Fifth International Conference on LNG, Session III, paper 5, Institute of Gas Technology (in French), 1977.

A new mathematical model is described which allows the calculation of vapor dispersion from accidental spills of LNG on land.

Bellus, F. and Humbert--Basset, R., "LNG as Motor Fuel: French Studies and Results." Paper presented at The Fourth International Conference on Liquefied Natural Gas, Algiers, Algeria, (in French), June 24-27, 1974.

Gas de France's comparison studies and test results with gas-fueled engines over motors using gasoline or diesel-oil, and their arrangements for cryogenic equipment that is necessary for storing and vaporizing the LNG on the vehicle, are described. 
Benedick, W. B., "High-Exposure Initiation of Methane-Air Detonations." Combustion and Flame." 35:89-93, 1979.

The detonation limits of a stoichimetric methane-air mixture have been determined under "free-field" and "confined" conditions. Such a mixture is generally more difficult to detonate than an LNG vapor cloud.

Benner, R. E. and Chang R. K. "Point Monitoring of Gaseous Hydrocarbons by Spontaneous Raman Scattering." Proceedings of Current Research on Methane Detection and Measurement Symposium, pp. 69-83. Environment Safety and Distribution Division, Gas Research Institute, Chicaqo, Illinois, 1979.

The Raman calibrational spectrum produced by laser irradiation of the various chemical gas species are used to detect the presence of several hydrocarbons simultaneously. The technique can detect the presence of hydrocarbons of similar composition and at low concentrations.

Bennett, C. P., "Marine Transportation of LNG at Intermediate Temperature." Chartered Mechanical Engineer. 26(3):63-66, 1979.

The paper details advantages of transporting LNG at intermediate temperatures in pressure vessels.

rennett, C. P. "Marine Transportation of LNG at Intermediate Temperature." Adv. Cryo. Eng. 25:751, 1979.

For economic reasons it is proposed to carry LNG in tankers at high pressures $(450 \mathrm{psi})$ and intermediate temperatures $\left(-140^{\circ} \mathrm{F}\right)$. However, safety considerations speak against such a concept.

Bensesh, M. E., "The Use of Gas Hydrates in Improving the Load Factor of Gas Supply Systems." U.S. Patent 2,090,163 (to Chicago By-Products Corp), 1942.

This method recommended using excess natural gas, during low demand periods, for hydrate formation and storage. The natural gas would be regenerated for peak demand.

Berge, H. and Pol1, J. "10 Years LNG-Storage Tank in Stuttgart." (in German), Gas U. Wasserfach - Gas/Erdgas. 123(2):53-56, 1982.

In 10 years of operation, the Stuttgart LNG storage facility has proved the rentability and safety of its technical concept. The article reports the experiences during this period of operation. 
Bergen, K. "Transportation of LNG in Germany." (in German), Gas u. Wasserfach Gas/Erdgas. 123(4):169-175, 1982.

In Germany, LNG is produced in three plants. Statistical data, regulations, guidelines and concepts are presented for the transportation of LNG on road, rail and waterways in Germany.

Berger, E. "Installations for the Offshore Liquefaction of Natural Gas." (in German), Linde Ber. Techn. Wiss. 42:3-10, 1977.

A description is given about the projects ARGE 76 and CONSORTIUM

76. LNG is produced on floating platforms and transferred to

storage buoys at a distance of about $600 \mathrm{~m}$ from the platform.

Berger, E. "LNG-Plants on Floating Platforms." (in German), Meerestechn.-Mar. Technol. 8 $(6): 193-201,1977$.

The article describes the projects ARGE 76 and CONSORTIUM 76 for the offshore liquefaction of natural gas.

Berger, E. "LNG from Floating Platforms. A Project Study of ARGE 76." (in German) 1st Part: Meerestechn.-Mar. Technol. 10(5):153-158, 1979; 2nd Part: Meerestechn.-Mar. Technol. 10(6):201-205, 1979.

The first part of the article gives a general description of the project of an LNG-production plant on floating platforms in the north sea.

The second part deals with experimental investigations on components of the plant and safety aspects.

Berger, E., "LNG Plants on Floating Structures - Intermediate Reports on an Extensive Test Program." Chemical Economy and Engineering Review. 10(10):22-29, 1978.

The paper reports on progress in designing floating LNG liquefaction plants which could be used for marginal offshore gas fields where subsurface pipelines are not economical.

Bernard, H. "Measurement of Mass Flow with Vortex Path Flow Meters." (in German), Ind.-Anz. 100(58):11-13, 1978.

Methods and functions of vortex path flow meters are described. They can be used to measure the mass flow in all liquids and gases, but they are especially useful for liquefied gases because they are not susceptible to rapid overload. 
Bernert, R. E., "Technical Aspects of Ambient Vaporizers and Superheaters." Applications of Cryogenic Technology. Vol. 6. Proc. Cryo 173 Conf. 6th Los Angeles, CA, October 2-4, 1973, pp. 85-93, 1974.

This paper discusses aspects governing the performance of ambient water and air cryogenic vaporizers and superheaters. This paper also includes some design limits due to ice and frost formation.

Beychok, M. R., "How Accurate are Dispersion Predictions?" Hydrocarbon Processing. pp. 113-116, October, 1979.

This paper cautions the reader against assuming that generalized dispersion models have a fixed accuracy in all applications. Examples of the variability are shown.

Bijl, P., Vet, P. N., "Novel Approach Required for LNG Peakshaving Plant in the Netherlands." 0il and Gas Journal. pp. 81-85, November 28, 1977.

This article describes a unique peakshaving facility which produces both $L N G$ and liquid nitrogen, $L N_{2}$. Because of the high $\mathrm{N}_{2}$ content of the gas in the Netherlands, a slightly modified expander liquefaction cycle was designed which allowed separation of $L N_{2}$ from the LNG.

Bingham, G. E., Gillespie, J. H. and McOuaid, J. H., Small Battery-Powered Infrared Absorption Sensor for Methane, Ethane, and Other Hydrocarbons. UCID-17968-79-1, pp. 23-42 Lawrence Livermore Laboratory 1979.

The concept for a portable gas sensor capable of measuring LNG vapor concentrations is described. It is based on infrared absorption by hydrocarbons between 3 and $4 \mathrm{pm}$.

Bingham, G. E., Gillespie C. H. and McQuaid J. H. "A Battery-Powered, Differential Infrared Absorption Sensor for Methane, Ethane and Other Hydrocarbons." Proceedings of Current Research or Methane Detection and Measurement Symposium, pp. 87-106, Environment Safety and Distribution Division, Gas Research Institute, Chicago, I11inois, 1979.

This report describes the performance goals and design considerations of a light-weight, battery powered, portable, self-contained infrared absorption sensor for detecting the presence of hydrocarbons.

Biro, P., "Fire Protection for LNG Storage, Transportation and Distribution Facilities." gwf-gas/erdgas. 118(8):344-346, 1977 (in German).

The requirements for fire protection of LNG facilities are described. Specifically, liquefaction plants, storage facilities, LNG terminals and LNG tankers are addressed. 
Blackmore, D. R., Eyre, J. Homer and Martin, J. A. "Refrigerated Gas Safety Research." Paper presented at the AGA Transmission Conference, Atlanta, Georgia, 1981.

A brief general review is presented on Shell's most recent R\&D programs relating to LNG/LPG safety which were carried out at various laboratories and test facilities in England and Holland.

Blackmore, D.R., Colenbrander, G.W. and Puttock, J.S. "Maplin Sands Experiments 1980: Dispersion Results from Continuous Releases of Refrigerated Liquified Propane." (in English), Paper on the 2nd Symposium on Heavy Gases and Risk Assessment, Frankfurt May 25-26, 1982.

The paper describes briefly the technical equipment and setup in the Maplin Sands dispersion experiments. Results of the variation of concentration with place and time are given for different spills and compared with model predictions.

Blackshear, P. L., ed., Heat Transfer in Fire: Thermophysics, Social Aspects, Economic Impact. John Wiley \& Sons, 1974.

The book, in five parts, considers social and economic aspects of fires; geometric parameters for classifying full-scale fires; heat and mass transfer in gaseous and condensed phases; radiative heat transfer associated with fire problems, and radiative transfer parameters.

Blanchard, R. L., A. E. Sherburn, J. L. Middleton. "An LNG Cargo System Simulator for Crew Training." Presented at Gastech 78 LNG/LPG Conference, Monte-Carlo, Monaco, November 7-10, 1978.

This paper describes an LNG Cargo System Simulator that has been built and is used for training crews for large LNG tankers.

Blau, H. and Kegabian P. "The ERT Methane Meter." Proceedings of Current Research on Methane Detection and Measurement Symposium, pp. 7-24, Environment Safety and Distribution Division, Gas Research Institute, Chicago, Illinois, 1979.

The ERT methane meter, which is more sensitive to methane than conventional meters and less sensitive to other organic hydrocarbons, measures methane by using a single laser system and measuring absorbance.

Blinov, V. I. and Khudyakov, G. N., "Certain Laws Governing Diffusion Burning of Liquids." Doklady Akademi i Nauk U.S.S.R. 113:1094-1098, 1957.

An investigation of the burning of gasoline, diesel oil, solar oil and a number of other petroleum products in containers having different diameters enabled the authors to determine some important relationships for diffusion of burning liquids. 
Board, S. J., Farmer, C. L. and Poole, D. H., "Fragmentation in Thermal Explosions." International Journal of Heat and Mass Transfer. 17:331-339, 1974.

Experiments involving explosions between molten tin and water are described. Results indicate that thermal explosions usually involve several distinct interactions; a small disturbance can escalate by successive growth and collapse cycles; vapor collapse is the main cause of dispersion in many thermal explosions, and the jet penetration hypothesis can account for both the time scales and energy transfer rates.

Bongers, A., TenBrink, G. Rulkans, P. "Release of a Pressurized Hydrocarbon from a Pilot-Plant-Scale Pressure Vessel; Experiments and Theory." Third International Loss Prevention Symposium, 1980, 16/1198-16/1209.

This paper describes experiments concerning the unsteady release of pure propylene from a $20-\ell$ pressure vessel through an $8 \mathrm{~mm}$ opening in the top of the vessel.

Boni, A. A., Wilson, C. W., Chapman, M. and Cook, J. L., "A Study of Detonation in Methane/Air Clouds." Acta Astron. 5:1153-1169, 1978.

A numerical simulation of the detonation in unconfined, gaseous mixtures of methane/oxygen/nitrogen is attempted. Results show that initiation of such detonations requires very large trigger charges (10 to $1000 \mathrm{t}$ of tetryl).

Booth, S. H. and Vance, R. W. (ed.), Applications of Cryogenic Technology, Vol. 8. Scholium International, Inc., New York, 1976.

This text presents papers comparing Cryogenic Applications Symposia on Liquefied National Gas (LNG) presented at CRYO'75 and CRYO '76, conferences of the Cryogenic Society of America.

Boulanger, A., "Method of Storing Liquefied Gases at Low Temperature in a Subterranean Cavity." U.S. patent 4,140,423 (to Geostock, Paris, France), 1979.

It is claimed that leak tightness of the underground cavity can be obtained by freezing the surrounding ground. Fissures that might be generated during the cooling process can be plugged by spraying water into them. For this purpose, the cavity must be under visual observation during the initial cooling program.

Bourguet, J. M. "LNG Cold: Still a Problem." Hydrocarb. Proc. 60(1):167-172, 1981 .

A wide variety of possibilities is discussed on how to use the "cold" energy of LNG in energy-saving applications. Many of these possibilities are still beset with technical problems. 
Bowman, B. R., "Dispersion Model Comparisons." Report B, Liquefied Gaseous Fuels Safety and Environmental Control Assessment Proaram: A Status Report. DOE/EV-0036, Department of Energy, Washington DC, 1979.

Various mathematical models for the dispersion process following an LNG spill are evaluated. Deficiencies are pointed out and needs for further work are outlined.

Bowman, B. R., Sutton, S. B. and Comfort, W. J., "The Impact of LNG Spills on the Environment: A Comparison of Dispersion Models and Experimental Models." Proceedings of the 25th annual technical meeting of the Institute of Environmental Sciences, Seattle, WA, April 1979.

A Gaussian and Three-Dimensional Navier-Stokes model for LNG spills and subsequent dispersion are compared. Data including hydrocarbon concentrations from three 5-m LNG spill tests are used to evaluate the models.

Boyle, G. J., "Vapor Production From LNG Spills on Water." American Gas Association Distribution Conference, May 1973.

The results indicate that LNG spilled onto water will spread outward with a rate that decreases with time; vapor production will equal the discharge rate as long as the discharge is occurring; with a batch spill it is necessary to take into account the LNG which evaporates to calculate the maximum pool and the peak vapor production rate; the dispersion plume from a large LNG spill on water will be wide and shallow.

Boyle, G. J. and Kneebone, A., Laboratory Investigation into the Characteristics of LNG Spills on Water, Evaporation, Spreading and Vapor Dispersion. Re 6Z32, She11 Research Limited, Released by the American Petroleum Institute, March 1973.

This is a laboratory and small-scale wind tunnel investigation of the characteristics of LNG spills on water. One characteristic investigated, that has not been studied by others, is the appreciable incorporation of water in the vapor cloud.

Bradford, R. H. Supporting Structure for Containers Used in Storing Liquefied Gas. U.S. Patent 4,136,493, assigned to: NRG Inc., 1979.

Land-based storage vessels for LNG are thermally insulated all around with a solid insulating material which must carry the total weight of the tank. The patented structure design minimizes the squeezing of the insulating material from the space below the tank bottom. 
Bradley, D. and Mitcheson, A., "The Venting of Gaseous Explosions in Spherical Vessels I, II." Combustion and Flame. 32:221-237, 1978.

The authors present various theoretical analyses of the pressure rise in partially confined reactive systems. The results of these investigations are then compared with experimental data and recommendations are made for proper venting procedures.

Brecht, Ch. "LNG-Perspectivities for the German Natural Gas Supply." (in German), Schiff u. Hafen. 29(8):703-704, 1977.

Current data are presented on the German natural gas supply. Future growth is expected in the second half of the eighties and some major projects on LNG are reported to increase experience and to develop the infrastructure.

Brecht, C. "Gas - Energy of the Future." Hydrocarbon Process. 59:76-0-76-UU, November 1980.

Since proven reserves of natural gas are more plentiful than those for oil, natural gas will play an increasingly important role in the future energy supply, particularly in Europe. LNG will be restricted primarily to world areas which are not close enough to be reached by pipeline.

Briscoe, F. and Vaughn, G. J., "LNG/Water Vapor Explosions--Estimates of Pressures and Yields." Paper presented at the Gastech 78 LNG/LPG Conference, Monte Carlo, November 1978.

The essentials for the occurrence of LNG vapor explosions are discussed. The maximum possible yields and pressures in such explosions are determined by various theoretical approaches.

Briscoe, F. and Fog, G. F., A Guide to the Use of BKWAVE - A Computer Program for the Calculation of One-Dimensional Shock Wave Propagation from Explosions. United Kingdom Energy Authority, SRO-R-104, Calceth Warrington, U.K., May 1978.

This report is a description of a computer code, BKWAVE, which can calculate the shock wave resulting from an explosion of known strength. The reaction is assumed to be over instantaneously. 
Briscoe, F., Curtress, N., Farmer, C. L., Fogg, G. F. and Vaughan, G. J. EECSponsored Theoretical Studies of Gas Cloud Explosion Pressure Loadings (in English), SRD-Final Report, EUR 6119, 1979.

Estimates of the pressure loadings produced by unconfined gas cloud explosions on the surface of structures are required to assist the design of strong secondary containments in countries where the protection of nuclear installations against these events is considered to be necessary. At the present time, one difficulty in the specification of accurate pressure loadings arises from our lack of knowledge concerning the interaction between the incident pressure waves produced by unconfined gas cloud explosions and large structures. Preliminary theoretical studies of this important problem are described, which has previously only received experimental attention in Germany. These studies include 1) general theoretical considerations, especially with regard to scaling, 2) investigations of the deflagration wave interaction with a wall based on an analytic solution for situations with planar symmetry and the application of an SRD gas cloud explosion code (GASEX 1) for situations with planar and spherical symmetry, and 3) investigations of the interaction between shock waves and structures for situations with two-dimensional symmetry based on the application of another SRD gas cloud explosion code (GASEX 2).

Britter, R. E., "The Spread of a Negatively Buoyant Plume in a Calm Environment." Atm. Envir. 13:1241-1247, 1979.

The paper presents the results of a laboratory experiment to study the spread of a negatively buoyant plume in a calm environment including semiempirical relation for the cloud leading edge. Under conditions where the effects of wall frictions and ambient wind can be neglected, most or all mixing occurs at the cloud leading edge.

Brossard, J., Duco, J., Gobert, T., Lannoy, A. and Perrot, J., "Experimental Study of the Overpressures Generated by the Detonation of Spherical AirHydrocarbon Gaseous Mixtures" (in English), Paper presented at the ENS/ANS Int. Top. Meeting on Nuclear Power Reaktor Safety, Brussels, October 1978.

The characteristics of the pressure waves transmitted by detonation of gaseous mixtures to the surrounding air were measured by tests made near the ground level in 1- to $54-m^{3}$ spherical balloons containing air-acetylene or air-ethylene mixtures.

As concerns the peak overpressure $\Delta p$, a theoretical dimensional analysis in accordance with the experimental results shows that $\Delta p$ can be expressed as a function of two independent variables, which are the radial distance $R$ and the volume $V$ of the balloon. A semiempirical formula, including ground effects, is proposed and its present validity range is given. 
Bröty, W., Schössbucher, A., Scheller, V. and Kettler, A., "Electronically Produced Equidensities From Time Exposures and Instantaneous Photographs in the Investigation of Pool Flames." Combustion and Flame, 37(1): January 1980.

This paper essentially describes an experimental method by which information on the temperature, soot formation, turbulence and other fire phenomenon may be obtained photographically. Some experimental data are also presented.

Brown, G. H. "Wisconsin National Gas Makes Successful LNG Turnaround." Pipeline \& Gas J. 209(13):41-43, 1981.

The modification of an LNG peakshaving plant built in 1965 required taking the storage tank out of service, inspecting it, increasing LNG pumping capacity, adding regasification capacity, adding instrumentation and building a new containment dike.

Brown, L. E. and Romine, L. M. , "Liquefied Gas Fires: Which Foam?" Hydrocarbon Proc. 58 $(9): 321-332,1979$.

Six different types of foam were evaluated for their effectiveness in controlling liquefied gas fires. Medium and high expansion foams proved to be most efficient.

Brown, L. E., Martinsen, W. E., Muhlenkamp, S. P. and Puckett, G. L., Small Scale Tests on Control Methods for Some Liquefied Natural Gas Hazards. Final Report, prepared by University Engineers, Inc., Norman, Oklahoma, for the U.S. Coast Guard, Report No. CG-D-95-86. NTIS No. AD/A033522, May 1976.

A report of results of small scale (100 $\left.\mathrm{ft}^{2}\right)$ tests of some liquefied natural gas (LNG) hazard control methods and concepts. Tests of water spray screens showed that the concept is practical and effective for small LNG spills. Tests of water spray screens to reduce radiant heating of exposures demonstrated no practical value.

Brown, T. T. and Hubbard, J. K., Application of Gas Turbine/Compressors in LNG Plants. 1979.

This paper discusses key considerations associated with selection of Gas Turbine Driven LNG Turbo Compressors. Use of gas driven versus steam driven compressors is compared.

Browning, R. L., "Estimating Loss Probabilities." Chemical Engineerina. pp. 135-140. December 15, 1969.

This article presents a technique for analyzing industrial risks. Methods for obtaining the loss incident frequencies are described and the relative probabilities of loss incidents are included. 
Brueschweiler, C. and Burg, H., "The Risks of Transportation of Hazardous Goods on Roads." (in German), Chem. Rdsch. 32(6):11, 1979.

This report of the colloquy of the commission of experts for safety in the Swiss chemical industry (ESCIS) on Sept. 5, 1978. The hazard potential of tank trucks is discussed on the background of international and Swiss (SDR) regulations for the transportation of hazardous goods on road.

Brzustowski, T. A., "A New Criterion for the Length of a Gaseous Turbulent Diffusion Flame." Combustion Science and Technology. 6:313-319, 1973.

The flame tip is identified with the point on the axis of maximum fuel concentrations where the fuel has been diluted to the lean flammability limit. Flame-length equations are derived using the new criterion, together with data from the literature on entrainment of air into flames, transverse concentration profiles in turbulent jets, and flammability limits.

Brzustowski, T. A., "The Hydrocarbon Turbulent Diffusion Flame in Subsonic Cross-Flow." AIAA Paper 77-222, January 1977.

The flame is modeled as a bent-over initially vertical circular jet with top-hat profiles of composition, temperature, and velocity. The hydrocarbon pyrolyzes in a zero-order reaction and the pyrolysis products are oxidized at a rate proportional to the rate of entrainment of air into the flame.

Buch, E., "Utilizing the Cold of LNG for Power Generation." Energie. 29:182-183, 1977 (in German).

When vaporizing $L N G$, it would be economical to take advantage of the low temperature of the LNG as a heat sink in a closed gas turbine cycle. Such a scheme could recover $14 \%$ of the total LNG energy, which otherwise could be lost in the vaporization process.

Buchholz, C. D. and Senkowski, E., "Unique Design and Operating Features of Philadelphia Electric Company's LNG Plant." Paper presented to Seminar and Study Tour on LNG Peakshaving, Washington DC, March 5-9, 1979.

The design and operating experience of the West conshohocken LNG Plant is reviewed. The plant utilized a nitrogen expansion cycle for liquefaction, a double-walled, double-roofed above ground storage tank, and submerged combustion vaporizers.

Bukacek, R. F., "Operating Characteristics of LNG Storage Tanks." CONF 780457-1, 1978.

The interactions which exist among the various operating parameters of an LNG storage tank are elucidated in a quantitative way. The origination of a "rollover" incident is explained. 
Bu11, D. C., Ellsworth, J. E., Hooper, G. and Quinn, C. P., "A Study of Spherical Detonation in Mixtures of Methane and Oxygen Diluted by Nitrogen." J. Phys.

D: Apply. Phys. 9:1991-2000, 1976.

Experiments are described which examine the behavior of spherically propagating detonation waves in methane/oxygen/nitrogen mixtures. Such tests have a bearing on the safety question of $L N G$.

Bu11, D. C., Ellsworth, J. E. and Hooper, G., "Susceptibility of MethaneEthane Mixtures to Gaseous Detonation in Air." Combustion and Flame. $34: 327-330,1979$.

Experiments are described which determine the detonation limits of methane-ethane-air mixtures. The presence of even small amounts of the heavier hydrocarbons has a significant effect on these limits.

Bu11, D. C., Elsworth J. E. and Shuff P. J. "Detonation Cell Structures in Fuel/Air Mixtures." Combustion and Flame. 45:7-22, 1982.

Measurements of cell sizes in detonation waves indicate that planar-tospherical detonation transition at the end of a pipe carrying methane gas cannot occur unless the pipe diameter exceeds $4 \mathrm{~m}$.

Bureau Veritas. "The 'GASTOR', 122,000 m³ Methane Carrier." (in French), Bull. Techn. Bur. Veritas. $58(9): 226,1976$.

This article describes the latest technical standard for the construction of $L N G / L P G$ tankers by the example of the 'Gastor' classified for the transport of gases with a temperature of $-162{ }^{\circ} \mathrm{C}$ and a maximum density of 0.6 .

Bureau Veritas. "Liquefied Gas Carriers-Damage, Stability, Investigation." Guidance Note NI 162 A BM.1, März 1977.

The paper describes the proceeding at the classification of liquefied gas carriers.

Burgess, D., Biordi, J. and Murphy, J., Hazards of Spillage of LNG into Water. PMSRC Report No. 4177 , U.S. Department of the Interior, Bureau of Mines, Pittsburgh, PA, 1972.

These are reports of experimental investigations of LNG spills on water. The pool spread, evaporation rate, vapor gravity spread, downwind drift and dispersion were studied in spill sizes up to $0.5 \mathrm{~m}^{3}$. In unconfined spills coherent ice flow formation was not observed. In several cases small scale physical explosions were observed but no attempt was made to study the initiation or burning of the cloud. 
Burgess, D. S. and Hertzberg, M., "Radiation From Pool Flames." Heat Transfer in Flames. Chapter 27, John Wiley \& Sons, 1974.
Some radiation data from pool flames is summarized and our understand- ing of the problem is reviewed. Spectral data yield a $1500^{\circ} \mathrm{K}$ tem- perature for hydrocarbon pool fires, which is consistent with the 40 percent maximum in the fraction of combustion energy radiated, and with limited flame temperatures for the mixing limited systems. A revised correlation of mass burning rate with $\Delta H_{C} / \Delta H_{V}$ is presented, and derived fundamentally.

Burgess, D. S., Murphy, J. N. and Zabetakis, M. G., Hazards Associated with the Spillage of Liquefied Natural Gas on Water. Report RI 7448, U.S. Department of the Interior, Bureau of Mines, November 1970.

The hazard of spilling LNG onto water is discussed. After spillage, the initial vaporization rate of LNG was determined to be $0.037 \mathrm{Ib} /$ ft 2 sec. If the LNG was confined, this rate was modified by the formation of ice on the water surface. Using a 2000-gallon LNG sample, the maximum diameter (in feet) of the spreading pool was calculated at $6.3 \mathrm{w}_{0} 1 / 3$ where $w_{O}$ is the weight of LNG in pounds.

Burgess, D. S., Murphy, J. N. and Zabetakis, M. G., Hazards of LNG Spillage in Marine Transportation Final Report. NTIS No. A0/70578, for USCG, Office of Research Development, February 1970.

The hazard of spilling LNG onto water is discussed. After spillage onto water, the initial vaporization rate of LNG was determined to be $0.037 \mathrm{lb} / \mathrm{ft}^{2} \mathrm{sec}$. If the LNG was confined, this rate was modified by the formation of ice on the water surface. Using a 2000-gal LNG sample, the maximum diameter (in feet) of the spreading pool was calculated at $6.3 w_{O} 1 / 3$ where $w_{O}$ is the weight of LNG in pounds.

Burgess, D. S., Murphy, J. N., Zabetakis, M. G. and Perlee, H. E., "Volume of Flammable Mixture Resulting from the Atmospheric Dispersion of a Leak or Spi11." Application of Cryogenic Technology, Vol. 8. Combustion Institute 15th Symposium on Combustion, 1976.

The paper discusses atmospheric dispersion of flammable vapors, the struture of gas clouds and the explosion potential of flammable mixtures.

Burgess, D. S., Strasser, A. and Gumer, J., "Diffusive Burning of Liquid Fue1s in Open Trays." Fire Research Abstracts and Reviews. 3(3):177-192, 1961.

The paper describes the effects of fuel temperature and wind on burning rate, discusses the problem of cryogenic fuels, and suggests that burning rate may be predicted from heats of vaporization and combustion of the fuel. Data on methanol, LNG, liquid hydrogen, amine fuels, and typical hydrocarbons are included. 
Burgess, D. S. and Zabetakis, M. G., Detonation of a Flammable Cloud Following Propane Pipel ine Break: The December 9, 1970 Explosion in Port Hudson, Missouri. Report RI 7752, U.S. Department of the Interior, Bureau of Mines, 1973.

This report summarizes the incidents that preceded the December 9, 1970, propane-air explosion in Port Hudson, MO. Both near- and far-field damage indicated that this explosion may be attributed to the detonation of propane in air with an energy release equivalent to that from about 50 tons of detonating TNT.

Burgess, D. and Zabetakis, M. G., Fire and Explosion Hazards Associated With Liquefied Natural Gas. Report RI 6099, U.S. Department of the Interior, Bureau of Mines, 1962 .

Factors that should be considered in evaluating the fire and explosion hazards relating to any fuel are discussed. These factors are utilized in the design of experiments to evaluate the hazards associated with LNG as compared to those hazards associated with other fuels.

Burgess, D. et al. "Volume of Flammable Mixture Resulting from the Atmospheric Dispersion of a Leak or Spi11." Proc. 15th Symp. (internat.) on Combustion, pp. 289-303, 1975 .

It is argued that the explosive yield of an LNG vapor cloud explosion is not more than about $10 \%$ of what would have been predicted from the heat of combustion of the fuel. Certain aspects of the commonly used vapor dispersion models are believed to be leading to the overly conservative predictions.

Buschmann, C. H., "Experiments on the Dispersion of Heavy Gases and Abatement of Chlorine Clouds." Proceedings of the Fourth International Symposium on Transport of Hazardous Cargoes by Sea and Inland Waterway, Jacksonville, FL, October 26-30, 1975, Report No. AD/A023505, pp. 475-488, October 1975.

The experiments comprised four different parts: dispersion of heavy gases offer an instantaneous release; penetration of heavy gases in buildings during the passage of a gas-cloud; influence of a chlorinecloud on motorized traffic, and suppression and abatement of chlorineclouds. 
Bush, S. H., "Pressure Vessel Reliability." Journal of Pressure Vessel Technology. $97(\mathrm{~J}): 54-70$, February 1975.

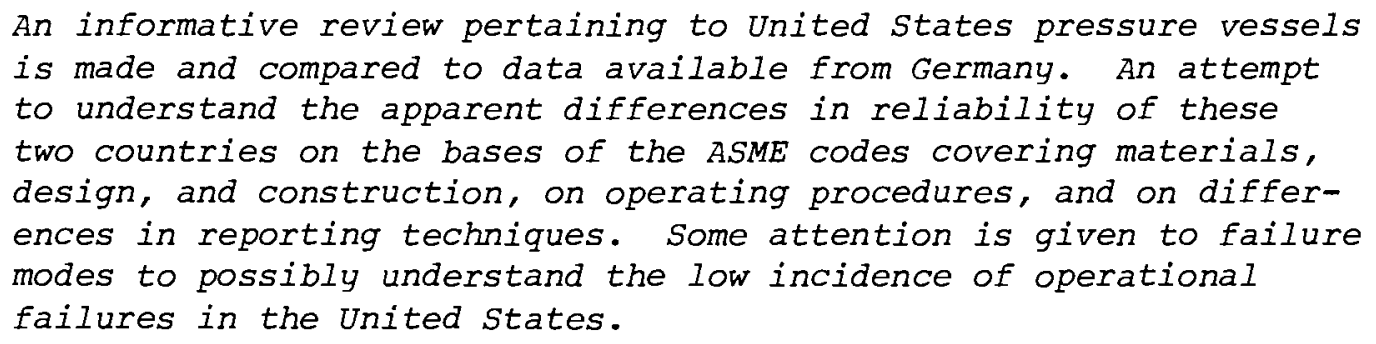

Byram, G. M., "Scaling Laws for Modeling Mass Fires." Pyrodynamics. 4:271-284, 1966.

The paper is concerned with the development of scaling laws necessary for modeling and is restricted to the stationary mass fire.

Byram, G. M. and Nelson, R. M., Jr., "Buoyancy Characteristics of a Fire Heat Source." Fire Technology. 10(1):68-79, 1974.

Buoyancy production rates for a pure heat source and for a fire heat source of burning woody fuels show that fire may be regarded as a pure source yielding heated air rather than heated combustion products.

Byram, G. M. and Nelson, R.M., Jr., "The Modeling of Pulsating Fires." Fire Technology. $\underline{6}(2): 102-110,1970$.

The authors present scaling relationships for modeling pulsating fires. Data gathered from various sizes of pulsating fires compared favorably with the predicted relationships between fire diameter and pulsation frequency.

Cahn, R. P., Johnston, P. H. and Plumstead, J. A., Transportation of Natural Gas Hydrate. U.S. Patent 3,514,274 (to Esso Research and Engineering Co.), 1970 .

Natural gas was combined at 25 to $40^{\circ} \mathrm{F}$ and $>80$ psia with a slurry of propane hydrate in propane. This mixture was cooled to $-40^{\circ} \mathrm{F}$ to give methane hydrate slurry in propane. Treating this product with propane gas at $25-40^{\circ} \mathrm{F}$ and $<80$ psia regenerated methane and propane hydrate. 
Carne, M., Thomas, J. R. and Hutchinson, E. A., Buxton Bund-Fire Tests. The Gas Counci1, December, 1971.

Ignition and burnout tests were conducted on LNG contained within walls of clay or pulverized fuel ash. The test objective was to establish whether walls of this construction would be damaged by a combination of cold LNG and flame radiation. Results showed no damage to the walls apart from a superficial calcining of the turf and slight spalling of the concrete covering. Flame radiation agreed reasonably well with predicted values.

Cermak, J. E., "Applications of Fluid Mechanics to Wind Engineering - A Freeman Scholar Lecture." Journal of Fluids Engineering. 97:9-38, March 1975.

The objectives of this review are to establish an initial subjectmatter base for wind engineering, to demonstrate current capabilities and deficiencies of this base for an engineering treatment of windeffect problems, and to indicate areas of research needed to broaden and strengthen the subject-matter base.

Champ, M., Montane11i, T., Deshaies, B. and Leyer, J. C. Effects of Pressure Generation due to the Propagation of Unconfined Deflagrations. (in French), Final Report, C.C.E. 463/78/9/ECI/F/, Universite de Poitiers, September 1979.

The report gives an overview on existing models for the deflagration of unconfined vapor clouds. Soap bubble experiments were performed to study the propagation of deflagration in inhomogeneous vapor clouds. The results of pressure generation and flame frond propagation are described and compared with theoretical models.

Chan, S. T. and Gresho, P. M., A Comparison of Hydrostatic and Nonhydrostatic Models as Applied to the Prediction of LNG Vapor Spread and Dispersion. UCID-18097, Lawrence Livermore Laboratory, March 1979.

Two mathematical models are described and after numerical implementation, results of a series of computations for LNG vapor dispersion are compared. Conclusions are drawn on how to further develop the less elaborate model into a more cost-effective code.

Chan, S. T., Gresho, P. M. and Lee, R. L., Simulation of LNG Vapor Spread and Dispersion by Finite Element Methods. UCRL-82441, Lawrence Livermore Laboratory, July 1979.

Two finite element models are described: one based on solving the time-dependent, two-dimensional conservation equations of mass, momentum, and energy, with buoyancy effects included via the Boussinesq approximation; the other based on solving the otherwise identical set of equations except using the hydrostatic assumption, and applied these models to predict some aspects of the vapor dispersion phenomena associated with LNG spills. 
Chan, S. T., P. M. Gresho, and R. L. Lee. "Simulation of LNG Vapour Spread and Dispersion by Finite Element Methods." App1. Math. Model. 4:335-344, 1980.

Two analytical models are described which predict the dispersion of vapour clouds after an LNG spill. These models appear to be slightly superior when compared with existing models.

Chang, H. R. and R. C. Reid. Simultaneous Boiling and Spreading of LPG on Water. DOE/EV/04548-1, Department of Energy, Washington, D.C., 1981.

Theoretical and experimental studies on the boiling and spreading of certain cryogenic fluids were conducted. A mathematical model was developed to describe the phenomena in the test apparatus. Its results agreed fairly well with actual observations.

Chang, R. K. and Brenner R. E. Laser Raman Point Monitoring of $\mathrm{CH}_{4}$ Vapor in the LNG Storage Field. Gas Research Institute Report 79/0050, December 1979.

The feasibility of using laser-Raman scattering techniques for detecting leaking LNG vapors has been demonstrated in laboratory experiments. Manufacture of large-scale instrumentation of this type is believed possible.

Chanue1, P. and Leyer, J. C. Characteristics of the Pressure Field Generated in an Unconfined Area by Accelerating Flames: Effect of Partial Confinement in the Vicinity of the Point of Ignition. (in French), Final Report, ECI 699-80-G, Universite de Poitiers, November 1981.

The report gives detailed experimental results on the generation of pressure fields in the presence of flame accelerating effects like jet ignition due to partial confinement in the vicinity of the ignition point and grid type obstacles in the vapor cloud. The experiments were performed with oxygen enriched propane-air mixtures. It has been shown that jet ignition can increase pressure in the unconfined area of the vapor cloud by orders of magnitude compared to normal central ignition of a hemispherical cloud, whereas noncentral ignition gives a decrease of pressure.

Chatterjee, N., Gaumer, L. S. and Geist, J. M., "Operational Flexibility of LNG Plants Using the Propane Precooled Multicomponent Refrigerant MCR Process." LNGS - International Conference on LNG, Duesseldorf, Germany, August 29September 1, 1977.

This paper discusses the operation of the MCR liquefaction process over a wide range of conditions. A computer program which models the porcess is described. 
Chatterjee, N. and Geist, J. M., Spontaneous Stratification in LNG Tanks Containing Nitrogen. ASME Publication 76-WA/PID-6, December 5, 1976.

LNG containing significant concentrations of nitrogen can stratify spontaneously during weathering in storage tanks. Mixing of stratified layers leads to an increase in boil-off rates, commonly referred to as "rollover". LNG storage tanks can be designed and operated safely if stratification and associated problems are taken into account.

Chatterjee, N. and Geist, J. M., "The Effects of Stratification on Boil-off Rates in LNG Tanks." Paper presented at the A.G.A. Distribution Conference, At1anta, GA, May 8-10, 1972.

The addition of LNG to a partially filled tank containing liquid of a different density may lead to the temporary formation of stratified layers. The physical phenomena associated with the mixing of stratified layers of LNG have been simulated on the computer. One method for mitigating potential hazards associated with stratification is by limiting the density and the temperature difference between fresh liquid and $L N G$ in the tanks.

Chevalier, L. and Inquimbert, L. "Intervention into a Cavity for the Storage of Natural Liquefied Gas at the Methane Terminal at Fos-sur-Mer." (in French), Gaz d'aujuourd'hui. p. 492, 1976.

In an cavity of $35,000 \mathrm{~m}^{3}$, a defect of a service installation was repaired. The procedures of emptying, warming, filling with nitrogen, performance of the repair crew, new refrigeration, and refilling are described.

Chippet, S. and Gray, W. A., "The Size and Optical Property of Soot Particles." Combustion and Flame. 31:149-159, 1978.

This paper presents the results of an experimental inventigation to determine the spectral transmissivity and size distribution of soot aggregates. Measured attenuation and light scattering were found to be in best agreement with theoretical results when the complex refractive index, $\bar{u}$, was taken to be 1.9-0.35i.

Chiu, Chen-Hwa, "Evaluate Separation for LNG Plants." Hydrocarbon Processing. pp. 266-272, September 1978.

Energy losses from various processes involved in separation of LNG components during liquefaction are discussed. Losses due to compression and liquefication were cited to show areas for improvement in energy use. 
Chiu, C. H. and C. L. Newton. "Second Law Analysis in Cryogenic Processes." Energy. 5:899-904, 1980.

Two different processes for liquefying natural gas are compared on the basis of conserving energy. It is shown that one of the processes (the propaneprecooled mixed refrigerant process) is clearly more effient for producing LNG than the other.

Clancey, V. J. "The Development of Hazardous Clouds." Second International Loss Prevention Symposium, 1977, 323-331.

Equations are presented to estimate the quantity of vapor generated and the growth and dispersion of a large cloud of inflammable vapor. The mechanism of flame acceleration and the generation of pressure pulses into the environment is discussed. The phenomenon of pressure propagation to yield shock waves at a distance is indicated.

Clancey, V.J. "The Effects of Explosions." (in English), Paper presented at 'The Assessment of Major Hazards', Manchester 14-16 Apri1 1982, I. Chem. E. Symposium Series 72:87-108, 1982.

In this general review, the propagation of ideal shock waves in air is outlined, together with the scaling laws which make it possible to estimate parameters from standard data. Propagation in water and in the ground are also described. The loading of structures by incident shock waves is given together with empirical data on the response of various structures to blast. Finally the topic of blast from exploding large unconfined clouds is reviewed in the light of experience, experiments and current theoretical treatments.

Clapp, M. B. and Litziner, L. F., "Marine Terminals for LNG, Ethylene, and LPG." A paper presented at the 68th National AICHE Meeting, Houston, Texas, February 28 - March 4, 1971.

The design and economics of marine terminals for LNG, Ethylene, and LPG are discussed. Some discussion of safety features is included.

Closner, J. J. and Parker, R.0., "A Careful Accident Assessment Key to LNG Storage Safety." Oil and Gas Journal. pp. 47-51, February 6, 1978.

This article discusses potential accidents and related hazards associated with LNG storage facilities. A list of mitigating measures which would prevent an accident or reduce its consequences is included.

Closner, J. J. and Parker, R. 0., "Safety of Storage Designs Compared." 0 i1 and Gas Journal. pp. 121-125, February 13, 1978.

Eight different types of LNG storage designs are compared with respect to the likelihood and potential consequences of a spill or accident. 
Coevert, K., Groethuizen, Th. M., Pasman, H. S., Trense, R. W. "Explosions of Unconfined Vapor Clouds." First International Loss Prevention Symposium, 1974, 145-157.

Accidental releases of combustible liquids or gases into the open air are associated with the hazard of subsequent ignition which initiates a large fire or an explosion. The paper presents a tentative evaluation of the problem. The basic concepts of deflagrative and detonative combustion are reviewed and current research studies are discussed, with particular regard to the blast wave generation by unconfined vapor-cloud explosions.

Cole, R. S. and Moulsley, T. J., "The Use of the Atmospheric Acoustic Sounder to Track Methane Gas Plumes." Atm. Envir. 13:1437-1441, 1979.

The usefulness of the acoustic sounder as a method of tracking elevated methane plumes is explored.

Colenbrander, G. W. "A Mathematical Model for the Transient Behaviour of Dense Vapor Clouds." Third International Loss Prevention Symposium, 1980, 15/1104$15 / 1132$.

On the basis of an existing steady-state model, a quasi-steady-state description has been developed for the atmospheric dispersion of heavy gases.

Colgate, S. A. and Sigurgeirsson, T., "Dynamic Mixing of Water and Lava." Nature. 244:552-555, August 31, 1973.

It is suggested that lava eruptions under the ocean might result in vapor explosions, similar to those which have been observed when liquid metals or LNG come into contact with water. Violent mixing of water and lava are believed to be the cause of such explosions.

Collins, M. H., et al. Method of Producing a Barrier in a Thermally Insulated Container. To Shell Internationale Research llaatschappij B.V. (U.S. Patent $\overline{4,120,413}) 1973$.

The Netherlands' Shell Internationale Research Maatschappij B.V. has developed an essentially pinhole-free barrier for LNG storage/transport tanks. The barrier consists of layers of an epoxy-resin formulation and glass-fiber material, applied in a special sequence to produce a barrier of superior quality.

Colton, J. W., Pretreatment of Raw Natural Gas Prior to Liquefaction. U.S. Patent $4,150,962,1979$.

A process for pre-treating raw wellhead gas is described that reduces the liquefaction refrigeration power requirements by expanding the gas through an expansion turbine, which in turn drives the liquefaction compressor. 
Conley, J. M., Simonds J. J., Britten R. A. and Sinha M. P. "A Four Band Differential Radiometer for Monitoring LNG Vapors." Published in Proceedings of Current Research on Methane Detection and Measurement Symposium, pp. 109-117, Environment Safety and Distribution Division, Gas Research Institute, Chicago, Illinois, 1979.

The Four Band Differential Radiometer (FBDR) measures methane, ethane and propane and allows for convections due to variations in source intensity or broad band extinction in the optical path. This paper describes the design consideration and estimated performance of the $F B D R$.

Conners, T. G., "LNG Primer." Hazardous Chemicals--Spi11s and Waterborne Transportation. AICHE Symp. Ser. 194, 76, pp. 62-69 1980.

The paper gives a brief description of the cargo operations of an LNG tanker and outlines the basic types of LNG containment and insulation systems.

Conrad, W. and Eberhard, R. "Explosion Protection in Gas Pressure Control and Measuring Devices." (in German), Gas U. Wasserfach-Gas/Erdgas. 118(6):215-217, 1977.

Rules and standards of gas pipeline operating conditions are explained. Primary and secondary measures of protection in pressure limit and leak prevention are described, and periodic checking for safety is considered.

Considine, M., Grint, G. C. and Holden, P. L. "Bulk Storage of LPG Factors Affecting Offsite Risk" (in English), Paper for The Assessment of Major Hazards, Manchester, Apri1 14-16 1982, I. Chem. E. Symposium Series 71:291-320, 1982.

Refrigerated storage of LPG is usually considered to be less hazardous than pressurized storage. In this paper, the offsite risks posed by a 3000-Te butane storage facility are examined. This quantity is such that either storage mode could be economically viable. Refrigerated storage in a single tank and pressurised storage in two equal capacity spheres are considered. Individual and societal risks are estimated for an urban site, with population encroaching to within $100 \mathrm{~m}$ of the site boundary, and for a remote site, with population excluded from within $1 \mathrm{~km}$ of the storage facility.

Constant, H. "Transportation of Liquefied Gases on Roads." (in French), Tech. Mod. 69(2):57-52, 1977.

An overview is given on the technical standards of the transport of liquefied gases in France. The volume capacity of large units is about 50,000 l. Propylen, aethylenoxide and natural gas are some of the transported liquids. 
Corbin, G. A. and Reid R. C. Liquefied Natural Gas Rapid Phase Transitions. Gas Research Institute Report 80/0031, January 1981.

This report summarizes the results of an investigation to determine if rapid phase transitions in methane-rich LNG spilled on water can be initiated by collapsing the vapor film with a shockwave. The shockwave was caused by helium overpressures up to 62 bar. No rapid phase transitions occurred for liquid nitrogen, liquid ethane, liquid methane or methane-rich LNG systems. Large scale vapor explosions did not occur in any of the experiments. The only observable effect was enhancement of boiloff.

Corlett, R. C., "Gas Fires With Pool-Like Boundary Conditions: Further Results of Interpretation." Combustion and Flame. 14:351-360, 1970.

A circular, upward-facing burner, supplying uniform flux of fuel gas from a water-cooled surface, preserves the essential features of a pool fire. Addition of up to $2 \%$ methyl bromide to several fuels had no effect on heat transfer. At high fuel supply rates, the data tend to correlate independently of the air requirement of the fuel; at low supply rates, the data tend to correlate independently of volumetric supply rate.

Corlett, R. C. and Fu, T. M., "Some Recent Experiments With Pool Fires." Pyrodynamics. $4: 253-269,1966$.

Steady burning rates of methanol, ethanol and acetone in thin-walled stainless steel burners of 0.6 to $30 \mathrm{~cm}$ diameter have been studied. Radiation levels were estimated and are found consistent with results of earlier experiments with water-cooled gas burners. Measured water absorption rates are in reasonable agreement with those inferred from burning rate data on the basis of heat and mass transfer similarity.

Cox, R.A. and Carpenter, R. J. "Further Development of a Dense Vapour Cloud Dispersion Model for Hazard Analysis." (in English), S. Hartwig (ed.), Heavy Gas and Risk Assessment, 55-87, Battelle-Institut e.V., Frankfurt am Main, Germany, 1980.

A mathematical model for the dispersion of dense gases is described, which is a development of a previously published model. The development concerns the kind of vapor release, the addition of heat to the cloud from the ground and the matching conditions between the gravity spreading phase and the Gaussian type dispersion phase. Parameters occurring in the model were calibrated by using the results of various spill tests. 
Cox, R. A., Roe, D. R. "A Model of the Dispersion of Dense Vapor Clouds." Second International Loss Prevention Symposium, 1977, 359-366.

This paper presents a model for the dispersion of dense vapor clouds and describes its particular application to LNG-Spills.

Crawford, D. B. and Eschenbrenner, G. P., "Heat Transfer Equipment for LNG." Chemical Engineering Progress. September 1972.

This article describes liquefaction heat exchangers and vaporizers for LNG facilities. Advantages, disadvantages, and relative costs for each type are included.

Crawley, F. K. "The Effects of the Ignition of a Major Fuel Spillage." (in English), Paper presented at The Assessment of Major Hazards, Manchester, April 14-16, 1982. I. Chem. E. Symposium Series 71:125-145, 1982.

This paper describes the various forms of damage which may result from the ignition of a major fuel spillage. The paper also tries to expand the understanding of Boiling Liquid Expanding Vapor Explosions, flash and pool fires and the events which happen during and after the ignition using facts from incidents and also a literature survey of experimental work.

Creighton, J. R., A Two Reaction Model of Methane Combustion for Rapid Numerical Calculations. UCRL-79669, Rev 1, Lawrence Livermore Laboratory, September 28, 1977.

Inclusion of chemical kinetics in the computational schemes for multi-dimensional thermo-hydrodynamic codes (involving flame propagation) results in prohibitively expensive computational time. The author of this report attempts to develop a simplified flame propagation model (of possible use in Langrangian-Eulerian hybrid codes) which yields acceptable values of flame velocity, temperature and pressure.

Crescittel1i, S., Russo, G., Tufano, V. "Mathematical Modeling of Relief Venting of Gas Explosions: Theory and Experiment." Third International Loss Prevention Symposium, 1980, 16/1187-16/1197.

Two different dimensionless models for the venting of gas explosions are presented which are based on the hypotheses that there is unburnt gas. The results are compared with experimental data. 
Crismen, E. E. and Genitsen H. J. "A Methane Detector Based on 'Tuned' Infrared Emitting Semiconductor Diodes." Proceedings of Current Pesearch on Methane Detection and i.easurement Symposium, Dp. 177-198, Environment Safety and Distribution Division, Gas Research Institute, Chicago, Illinois, 1979.

This paper describes semiconductor, infrared, electroluminescent diodes whose emission bands have been "tuned" to the o-band molecular absorption peak of the methane molecule. These diodes can be used to detect the presence of methane down to $.2 \%$ in dry nitrogen with a signal to noise ratio of twenty.

Crouch, W. W. and Hillver, J. C., "What Happens When LNG Spills?" Chem. Tech. 2(4):210-215, 1972.

Authors try to assuage certain exaggerated fears about the safety hazards of LNG spills. They stress, however, the need for more information on the behavior of large spills.

Culbertson, L. and Emery, W. B., "Liquefaction Plant Experience at Lenai." Presented at the 3rd International LNG Conference and Exhibition, Washington, DC, September 24-28, 1972.

This paper reviews the more significant problems encountered and solutions employed in the operation of the Alaska to Japan LNG project. This is a follow-up to earlier papers describing design and startup at the Kenai plant.

Dahncke, K. "The Transportation of LNG. The LNG-Transport from Libya." (in German), Drei R. Internat. 18(12):768-771, 1979.

The technical concept of LNG-transportation is demonstrated with the example of the LNG-project in Libya. The project includes a liquefaction plant in Libya, 4 LNG tankers with $40,000 \mathrm{~m}^{3}$ each and terminals in Spain and Italy.

Dailey, W. V. and Long, E. V., "Remote Sensing of Combustible and Toxic Gases." Analysis Instrumentation, Vol. 17. pp. 89-96, Pro. 1979 Symposium Measurement Technology for the $80^{\prime} \mathrm{s}$. Instru. Soc. Am., 1979.

Remote sensing systems with central control readout for detecting and monitoring levels of combustible gas (as, e.g., contained in LNG) are described. Detailed specifications are listed. The systems can be obtained from the Mine Safety Appliance Company. 
Danis, G. A., III, and Reid R. C. The Boiling and Spreading of Liquefied Natural Gas on Water. Gas Research Institute Report 80/0012, February 1981.

This report presents experimental data on boiling and spreading rates of LNG spilled on water. Comparison of the experimental data with existing models of LNG vaporization in an unconfined mode revealed that none of the models described all of the phenomena observed during the course of the experiment. Correction for the presence of vapor was necessary before reasonable agreement was obtained.

Daniels, E. J., K. G. Darrow, and H. R. Linden. "Energy Alternatives to LNG." Session I, Paper 4, Sixth International Conference on Liquefied Natural Gas, 1980.

\begin{abstract}
In addition to the economic competitiveness of LNG relative to the other energy-supply alternatives, this paper considers the relative impact on the balance of trade. It is debated how to price $L N G$ in a manner that adequately compensates the producer, but still makes it available to the ultimate consumer at a marginal price which is competitive with alternative energy sources.
\end{abstract}

Davenport, J. A., "A Survey of Vapor Cloud Incidents." Loss Prevention. 11:39-49, A CEP Technical Manual, 1977.

The paper gives a survey of open-air, unconfined vapor cloud explosions which have occurred during the last 25 years. The survey is taken from the viewpoint of a major insurance company and is primarily concerned with the property loss (in \$) in the various types of accidents. LNG accidents represent only a minor fraction of all reported cases.

Deaton, W. M. and Frost, E. M., "Gas Hydrate Composition and Equilibrium Data." Proc. Natural Gas Department, American Gas Association. pp. 49-56, 1946.

Phase diagrams as well as equilibrium data were presented.

DeFrondeville, B., "Reliability and Safety of LNG Shipping: Lessons from Experience." Paper presented to the Annual Meeting of the Socity of Naval Architects and Marine Engineers, New York, New York, November 10-12, 1977.

This paper reviews LNG shipping experience in Europe, Japan, and the United States. The review concentrates on reliability and safety aspects. The safety/reliability record for liquefaction/ loading ports and receiving are also summarized. 
Degenkolbe, J. and Haneke, M. "Low Temperature Embrittlement Resistent Steels for Transportation and Storage of Liquefied Gases." (in German), Drei R Internat. 17(8/9):514-420, 1978.

Overview on various nickel-steels and their application in transportation and storage of liquefied hydrocarbons. The influence of composition and processing on material properties are described as well as regulations and standards.

DeLeon, C. "An Overview of the Development of LNG Facility Regulations by MTB." LNG Terminals and Safety Symposium, pp. 287-292, in Applications of Cryogenic Technology 9. Scholium International, Flushing, New York, 1979.

A brief overview is given of the development of LNG facility safety regulations by the Materials Transportation Bureau of DOT. The need for Comprehensive new federal LNG safety standards is stressed.

Del Tatto, D. L., "LNG Satellite Peakshaving." Presented at the AGA Distribution Conference, Houston, Texas, May 6-9, 1968.

This paper presented by an engineer from Chicago Bridge and Iron describes one of the first LNG satellite operations in the U.S. Both primary liquefaction and peakshaving plant and the satellite peakshaving facility are discussed.

Department of Transportation, "Liquefied Natural Gas Facilities; Federal Safety Standards: Development of New Standards." Federal Register. pp. 8142-8182, Thursday, February 8, 1979.

The notice proposed establishment of a set of comprehensive safety standards governing design, site selection and construction of LNG facilities used in pipeline gas transportation or interstate or foreign commerece. Implications of the regulations and comments are also discussed.

Department of Transportation, "Liquefied Natural Gas Facilities; Federal Safety Standards; Final Rule and Proposed Rule Making." Federal Register. pp. 91849237, February 1980.

The final rule establishing a set of comprehensive safety standards governing the design and construction of liquefied natural gas facilities is given. A proposed rule establishing safety standards governing operation and maintenance is also described. 
Department of Transportation, "Liquefied Natural Gas Facilities, (LiVG); Federal Safety Standards: Development of New Standards, "Federal Register, pp. 7077670800, Thursday, Apri1 21, 1977.

The article sets forth proposed safety standards for LNG facilities. The proposed rules are based largely on National Fire Protection Association Rules (NFPA 59A 1975) and an Arthur D. Little Report summarizing LNG Technology.

Desbordes, D., Manson, N., and Brossard, J. "Explosion in Air of Unconfined Spherical Charges of Gas Reactive Mixtures." (in French), Acta Astronautica. 5:1009-1026, 1978.

Experimental results are presented on pressure waves generated by the explosion of spherical soap bubbles containing explosive gasoxygen mixtures. The changes of the relevant pressure wave characteristics (amplitude, duration, impulse) with distance are compared for deflagrations with various flame front velocities and detonation.

Desgroseilliers, G. J. Radiation from Burning Hydrocarbon Clouds. M.S. Thesis, MIT Department of Mechanical Engineers, p. 88, 1978.

Radiation test data from the combustion of methane, ethane and propane are reported. Tests are of small scale with the vapors initially contained in soap bubbles. A newly-developed mathematical model agrees fairly well with the experimental results.

Det Norske Veritas. Guidelines for the Classification of Floating Facilities for Gas Processing, Liquefaction and Storage. Classification Notes No. 8, Hovik, Norway, 1976.

The purpose of this note is to provide a uniforn guidance for those who intend to build or operate floating facilities for gas processing, liquefaction, and storage with classification by Det Norske Veritas. The note contains principles and criteria which will form the basis for classification of such facilities.

Det Norske Veritas. Programme for Gas Explosion Research. Exhibit A-Project Description, Hovik, Norway, 1980.

Det Norske Veritas proposes research to further understand: 1) Vented Gas Explosions, including flame accelerations, methods for practical scaling, and variation of geometry and 2) Coupled Explosions, including jet ignition of gas clouds and explosion propagation in interconnected rooms. 
Devanna, L. and Doulames, G., "Planning is the Key to LNG Tank Purging, Entry and Inspection." 0il and Gas Journal. pp. 74-82, September 8, 1975.

Procedures used by the Lowell Gas Co. to purge a one billion cu-ft tank out of service are described in detail. The article includes a drawing showing the piping, valves, and fittings on the tank which are used for purging.

Dewey, C. F. Jr. "The MIT Two-Wavelength Laser System for Measuring Atmosnheric Methane." Proceedings of Current Research on Methane Detection and Measurement Symposium, pp. 27-44, Environment Safety and Distribution Division, Gas Research Institute, Chicago, Illinois.

A methane monitoring system band on a two wavelength laser system is described. One wavelength is strongly absorbed by methane, the other is only weakly absorbed. The differential attenuation of the laser beams yields the concentration of methane in the absorption path.

Diller, D. E., "LNG Thermophysical Properties Data and Custody Transfer Measurements." American Gas Association Monthly. March 1979.

Measurement research for custody transfer discussed along with the economic reason for pursuing these studies. Publications in Thermophysical properties of LNG are referenced.

DiNapoli, R. N., "Design Needs for Base-load LNG Storage, Regasification." 0il and Gas Journal. pp. 67-70, October 22, 1970.

Design of base-load storage and vaporization equipment and facilities is described. The article contains particularly good information on the operation and control of sendout pumps and seawater vaporizers.

DiNapoli, R. N., "LNG Peakshaving Plants Require Careful Cost Estimating." Pipeline and Gas Journal. pp. 28-36, May 1978.

The paper reports a dearth of data on the costs of LNG peakshaving plant construction probably due to the competitive nature of the LNG construction industry. Generalized costs of peakshaving and satellite facilities are presented.

DiNapoli, R. N., "Gas Turbines Prove Effective as Drivers for LNG Plants." 0i] \& Gas J., 78(31):47-52, August 4, 1980.

Since fuel costs have risen dramatically, even small differences in the mechanical efficiencies of equipment drivers in LNG plants become important. Therefore, the substitution of gas turbines for steam turbines might be economically attractive now and in the foreseeable future. 
Dincer, A. K., Drake, E. M. and Reid, R. C., "Boiling of Liquid Nitrogen and Methane on Water. The Effect of Initial Water Temperature." Int J. Heat Mass Transfer. pp. 176-177, 1977.

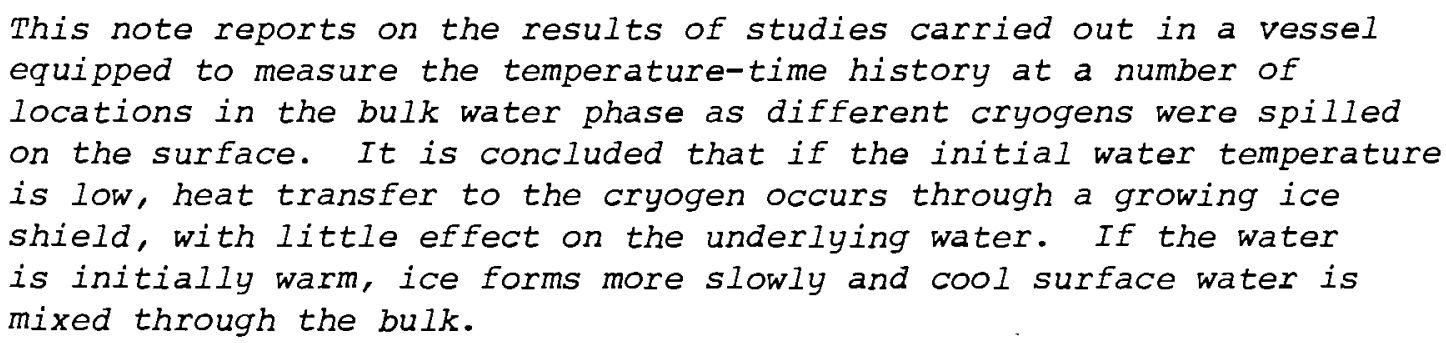

Dörge, K., Pangritz, D. and Wagner, H.Gg. "The Influence of Obstacles on the Propagation of Flames." (in English), 7 th Int. Coll. on Gasdynamics of Explosions and Reactive Systems, Göttingen, August 20-24, 1979; (in German), Proc. ICT-Jahrestagung, pp. 441-454, 1979.

Obstacles in the pathway of a flame may profoundly affect its rate of propagation. The flow generated in the fresh gas by the propagating flame creates a turbulent zone behind obstacles ahead of the flame. Measurements of flame propagation rates and pressures are presented to characterize this effect quantitatively.

Urake, E. M., "LNG Rollover--Update." Hydrocarbon Processing. 55:119-122, January, 1976.

The article considers LNG density, effects preceding rollover, rollover time prediction, heat storage, and discusses three documented cases of rollover.

Drake, E. M., Geist, J. M. and Smith, K. A., "Prevent LNG Rollover." Hydrocarbon Processing. 52:87-90, March 1973.

Studies were undertaken of basic mechanisms involved in LNG "rollover", to predict when they may occur and to evaluate effectiveness of possible preventive measures. Such measures include mixing during filling, limiting variations in LNG composition and lowering tank set point pressure. 
Drake, E. M., Jeje, A. A. and Reid, R. C., "Transient Boiling of Liquefied Cryogens on a Water Surface. I - Nitrogen, Methane, and Ethane." International Journal of Heat Mass Transfer. 18:1361-1368, 1975.

The results of an experimental study of the transient boiling rates of pure liquefied nitrogen, methane, and ethane in water are discussed. Nitrogen boiled with the lowest heat flux rate and the highest vapor superheat. For nitrogen, the heat flux rate was found to be proportional to the square root of the liquid head. The heat flux rate for ethane was the lowest and that for methane was intermediate.

Drake, E. M., Jeje, A. A. and Reid, R. C., "Transient Boiling of Liquefied Cryogens on a Water Surface. II - Light Hydrocarbon Mixtures." International Journal of Heat Mass Transfer. 18:1369-1375, 1975.

Light hydrocarbon mixtures similar to liquefied natural gas were boiled on a water surface. The rate of vaporization was measured and the heat fluxes were found to be much higher than that measured for pure liquid methane. Like methane, the rate of vaporization increased during the course of the experiment unless a continuous thick ice layer formed. No significant vapor superheat was noted.

Drake, E. M. and Reid, R. C., "How LNG Boils on Soils." Hydrocarbon Processing. 54 (5):191-194, Hay 1975 .

Implications of the paper are that: boil rates of LNG on compacted soils are influenced by soil type, moisture content and LNG composition; reduction in boiling rates can be obtained by sealing the dike surface; dikes of crushed rock or stone will have higher evaporization rates than compacted soil dikes; more studies are needed to assess insulating or sealing materials under LNG spill conditions and on LNG foaming behavior.

Drake, E. M. and Reid, R. C., "The Importation of Liquefied Natural Gas." Sci. Am. 236(4):22-29, 1977.

Arguments in favor and against large-scale importation of LNG are discussed, with the safety question receiving primary attention. on balance, ING appears to be a relatively safe and promising alternative energy source.

Drake, E. M. and Wesson, H. R., "Review of LNG Spill Vapor Dispersion and Fire Hazard Estimation and Control Methods." Proceedings of A.G.A. Transmission Conference, Las Vegas, iNV, May 1976.

This paper reviews techniques presently being used by the LNG industry for evaluating potential LNG vapor dispersion and fire hazards and will describe practical methods for reducing the severity of LNG spill accidents. 
Dreizler, U. "Gas as Source of Energy in Small and Medium-Sized Industry." (in German), Masch.-Markt. 85(5):66-69, 1979.

Natural gas and LPG can be economically used as a source of energy in industry. The necessary technical installations are described in some examples and rules and regulations are specified.

Duckham, H. E., "LNG Import Terminal Design Considerations." Cryogenics and Industrial Gases. pp. 41-48, September/October 1972.

This article describes the many processes and mechanical parameters involved in the design of an LNG import terminal. Included are discussions on facilities location, transfer lines, insulation, storage tanks, vapor handling systems, and LNG vaporizers.

Duffy, A. R., Gideon, D. N. and Putnam, A. A., Comparison of Dispersion From LNG Spills over Land and Water. Prepared by Battelle Columbus Laboratories for the American Gas Association, Project SI-3-7, September 4, 1974.

This study examines and compares the available data on dispersion from land and water spills, and explains similarities and differences in results on the basis of differences in experimental techniques and test conditions, and possible differences in pertinent phenomena.

Duffy, A. R., Gideon, D. N., Putnam, A. A. and Bearint, D. E., LNG Safety Program - Phase I - Potential LNG Spi11s. Report by Battelle Columbus Laboratories and University Engineers, Inc., to the American Gas Association, February 25, 1971.

The report presents data on known spills of LNG or other cryogens, a discussion and analysis of problem areas, and a discussion of consequences of spills including downwind dispersion, radiation from fires, and reactions with water. Conclusions are summarized and recommendations made for future research.

Dunn, W. A. and Tullier, P. M., Spill Risk Analysis Program Phase II Methodology Development and Demonstration. NTIS No. AD/785026, August 1974.

This report describes research and results in the development and demonstration of systematic methods of assessing the effectiveness of either proposed or recently implemented merchant marine safety regulations. The methods have been designed primarily to assist Coast Guard regulatory decision-makers in their selection of alternative means of reducing marine transportation casualties and spills of hazardous or polluting materials.

Durr, C. A. and Crawford, D. B., "LNG Terminal Design." Hydrocarbon Processing. November 1973.

This article discusses the special problems associated with design of an LNG terminal. Particular attention is given to the transfer line and the vapor handling and pressure control system. 
Durr, C. A., "Process Techniques and Hardware Uses Outlined for LNG Regasification." 0il and Gas Journal. May 13, 1974.

The following components of an LNG terminal are discussed by a process engineer from $M$. W. Kellog: LNG unloading, storage, vapor handling, sendout pumps, vaporizers, power generation, nitrogen system, and heat recovery.

Eckhoff, R. K. "Large-Scale Gas Explosion Experiments in Norway." From Discussion on Explosion Hazards at the 7 th International Colloquium on Gas Dynamics of Explosions and Reactive Systems, ed. H. Wagner, pp. 82-87, Max-Planck-Institute Fur Stromungsforschung, Gottingen, 1979.

As a consequence of discovery of oil and natural gas on the Norwegian continental shelf, the question of fire and explosion hazards associated with oil and gas activities on- and offshore has become an important issue in Norway. A research project is underway which is concerned with flame propagation and pressure development resulting from explosions in confined and semi-confined geometries, as encountered on offshore oil and gas platforms. Preliminary results indicate that for large vessels containing propane/air mixtures, the classical explosion venting type of volume scaling is invalid. A non-steady gas dynamic analysis accounting for shock waves and various complex mechanisms of flame acceleration must be used to achieve a realistic description of the pressure transients inside and outside the vessels.

Eckhoff, R. K., K. Fuhre, 0. Krest, C. M. Guirao, and J. H. S. Lee. Gas Explosions on Offshore Platforms - Flame Propagation and Pressure Development. Report CMI No. 790750-1, 1980.

Flame propagation and pressure development during semi-confined combustion of turbulent propane-air has been studied experimentally in a 50-m ${ }^{3}$ cylindrical test vessel with a $5-\mathrm{m}^{2}$ open vent to the atmosphere. Blast-wave decay characteristics have been determined for various modes of combustion, up to detonation. Experimental results are compared with theoretical predictions by alternative models.

Ecosystems, Inc., Expected Behavior of an LNG Release Under Specified Conditions. Report to Federal Power Commission, August 17, 1973.

The report comprised an assessment of hypothetical LNG spill situations in the Staten Island area. Results were calculated using methods of the Esso Research and Engineering Company. Three tasks described are analyses of a $100,000 \mathrm{~m}^{3}$ spill over water, analyses of evaporation and dispersion following an LNG tank roof failure, and a description of the New York Harbor climate. 
Edeskuty, F. J., Critical Review and Assessment of Problems in Hydrogen Energy Delivery Systems. Initial Report, Los Alamos Scientific Laboratory LA-74-PR Progress Report UC-41, August, 1978.

A preliminary risk assessment for the transport of gaseous hydrogen by pipeline and liquid by tank trucks is presented. Metal imbrittlement by liquid hydrogen is discussed and regulations are reviewed.

Edwards, J. G., "A Combustible Gas Detection System for an LNG Terminal." Analysis Instrumentation, Vo1. 17. Proc. 1979 Symposium on Measurement Technology for the 80's. Instr. Soc. Am., pp. 84-88, 1979.

For reasons of personnel safety and plant integrity, combustible gas detection systems are required in all LNG facilities. Practical guidelines are given for the reliable operation of such systems.

Edwards, R. M., "The Application of Sub-X Heat Exchanger for Vaporization of Liquid Natural Gas." American Society of Mechanical Engineers publication, 8 pp., September 1967.

The basic design and development of the Sub-X heat exchanger for vaporization of liquefied natural gas is presented in this paper. Detailed drawings and discussions are included.

Eichhoff, H. E. and Grethe, K., "A Flame Zone Model for Turbulent Hydrocarbon Diffusion Flames." Combustion and Flame. 35(2):267-275, August 1979.

The authors present a flame zone model which corrects the deficiency of two previous models (called the flame sheet and equilibrium models) by more correctly accounting for the intermediate reaction species. Comparison with experiment supported their model.

Eichler, T. V. and Napadensky, H. S, Accidental Vapor Phase Explosions on Transportation Routes Near Nuclear Power Plants. U.S. Nuclear Regulatory Commission, NUREG/CR-0075, 1977.

A review of vapor cloud explosion literature is used to develop a method to estimate TNT equivalency for accidental blasts as a tool for calculating exclusion distances for hazardous materials near nuclear plants.

Eidsvik, K. J. A Model for Heavy Gas Dispersion in the Atmosphere. Norsk Institutt for Luftforskning, ISBN 82-7247-113-2, 1979.

A simple model is developed for the dispersion of heavy and cold gas cloud. The theoretical solutions are justified with experimental data. The hazard of heavy gas clouds is predicted. 
Eidsvik, K. J. "A Model for Heavy Gas Dispersion in the Atmosphere." Atmospheric Environment. , 14:769-777.

The development of a cold and heavy gas cloud is described as it may be generated by a large spill of LNG. It is questionable, however, whether the new model represents an improvement over already existing models of this kind.

Eidsvik, K. J. "Heavy Gas Dispersion Model with Liquefied Release." Atmo. Environ. 15:1163-1174, 1981.

A model simulating LNG release, evaporation, and dispersion of the resulting heavy gas cloud is obtained by modification of Eidvik's (1980) heavy gas dispersion model.

Enger, T., "Explosive Boiling of Liquefied Gases on Water." Conference Proceedings on LNG Importation and Terminal Safety, Boston, MA, June 13-14, 1972.

Explosive boiling of a liquefied gas mixture such as LNG on ambient water can only be produced when the methane content is less than 40 mole percent. The potential hazard of having explosive boiling from an LNG spill is negligible during commercial transportation of LNG. In addition, energy estimates show that the potential damage from explosive boiling of a liquefied gas is minimal.

Enger, T. and Hartman, D. E., "Mechanics of the LNG-Water Interaction." Paper presented at the American Gas Association Distribution Conference, Atlanta, GA, ilay 8, 1972.

Shell Pipe Line Labs has conducted research since 1970 on rapid phase transformation which can occur when LNG is spilled onto water. "Explosive" LNG-water interaction results because of rapid phase transformation and violent expansion of a thin layer of superheated LNG at the interface between the LNG and water. It is stated that "explosions occur only when LNG is in a weathered state, i.e., when the methane content of LNG is less than 40 mole percent."

Enger, T. and Hartman, D. E., "Rapid Phase Transformation During LNG Spillage on Water." Paper presented at the Third International Conference and Exhibition on LNG, Washington, DC, September 24-28, 1972.

It is shown that "explosions" can only occur with "aged" LNG which contains less than 40 mole percent methane. The "explosive" interaction between a Iiquefied gas and water is caused by the rapid phase transformation and violent expansion of a thin layer of superheated liquefied gas at the liquefied gas-water interface. 
Enger, T., Hartman, D. E. and Seymour, E. V., "Explosive Boiling of Liquefied Hydrocarbon/Water Systems." Paper presented at the Cryogenic Engineering Conference, National Bureau of Standards, Boulder, C0, August 9-11, 1972.

The conditions which produce "explosions" when LNG is spilled on water at ambient temperature have been isolated and verified experimentally. It has been shown that "explosions" can only occur with "aged" LNG which less than 40 mole percent methane. Contact between water and LNG with more than 40 mole percent methane produces normal vaporization.

Enger, T., Hartman, D. E. and Seymour, E. V., "Explosive Boiling of Liquefied Hydrocarbon/Water Systems." Adv. Cryo. Eng. 18:32-41, 1973.

The mechanism of LNG/water interactions, and the conditions under which they can occur, are described. The explosive boiling, which has been observed, is explained as a result of superheating of the liquefied gas.

England, W. G., Teuscher, L. H., Hauser, L. E. and Freeman, B. E., "Atmospheric Dispersion of Liquefied Natural Gas Vapor Clouds Using Sigmet, a Three Dimensional Hydrodynamic Computer Mode1." Proceedings of the 1978 Heat Transfer and Fluid Mechanics Institute, Washington State University, Pullman, Washington, June 26-28, 1978.

The SIGMET dispersion model is presented in the form that it is applied to LNG vapor dispersion problems. Model results are presented for examples of plume behavior and to verify model predictions. Model numerical methods are also described.

Engshuber, M. "Unconventional Methods for the Storage of Natura1 Gas." (in German), Enerqietechnik. 30(9):353-358, 1980.

Three methods are discussed as alternatives to the storage of natuural gas in caverns: 1) storage of $L N G$, 2) cryogenic absorption of methane in LPG, and 3) storage as solid hydrate.

Ermak, D. L. and Bowman, B. R., "Average Dispersion of a Liquefied Natural Gas Vapor P1ume." UCID-17968-79-1, pp. 1-10, Lawrence Livermore Laboratory, 1979.

The theoretical predictions for the vapor spread from an LNG spill are compared with experimental data obtained in a China Lake test. Agreement is fair. prevailing winds are shown to have a significant influence but are hard to model. 
Ermak, D. L., Hogan W. J. and Koomman R. D. "Predicting the Hazards from Large Spills of Liquefied Gaseous Fuels." UCRL 86164, 1982.

A brief overview is presented of the LGF Spill Effects Program which was conducted by LLNL for DOE during recent years. Both computer model development and spill testing at China Lake, California are covered by the report.

Ermlich, K. "Generation and Use of Inert Gas on Board of LNG Tankships." (in German), Hansa. 112(18):1422-1423, 1975.

The quality necessary for inert gas and nitrogen produced on board of LNG-tankships is specified. Generator as well as mechanical and physical dehydration of the inert gas are described.

Escudier, M. P., "Aerodynamics of a Burning Turbulent Gas Jet in a Crossflow." Combustion Science and Technology. 4:293-301, 1972.

The study extends the entrainment theory for weak plumes by including into its framework the influences of radiative thermal-energy transfer, large density variations, and thermal-energy generation through chemical reaction. Thermal radiation is found to be of secondary importance to plume dynamics. Calculations show that a plume's motion is not significantly influenced by buoyancy forces until well downstream of the reaction zone.

Etzbach, V. et al. Cascading Refrigeration Cycles for Liquefying Low-Boiling Gaseous inixtures. U.S. Patent 3,970,441, assigned to: Linde A.G., 1976.

The invention involves some minor modification in the standard procedures for liquefying natural gas. Thereby, the overall complexity of the process is somewhat simplified.

Eubank, C. S., Rabinowitz, M. J. Gardiner W. C. and Zellner R. E. "ShockInitiated Ignition of Natural Gas-Air Mixtures." Proceedinas of the 18th International Symposium on Combustion, pp. 1767-1774, The Combustion Institute, 1981.

Experiments have shown that ignition induction times are reduced considerably if small amounts of higher alkanes are mixed in with methane. Since higher alkanes are naturally present in natural gas, this work verifies that it is easier to set off an explosion with natural gas than with pure methane.

Evaluatie van de Gevaren Verbonden aan Aanover, Overslag en Opslag van Vloeibaar Aardgas. TNO-Report, 1976.

A hazard assessment study of the supply and storage of LNG for the conditions applicable to the situation at the Dutch coast near the entrance of the river Maas has been carried out. 
Evaluation of LNG Vapor Control Methods. Report to the American Gas Association by Arthur D. Little, Inc., Cambridge, Massachusetts, October 1974.

It is shown that, for the high spill rates, the maximum downwind hazard zone is not significantly affected by shutdown of the leak in the 10-minute period specified in the NFPA Code. To be effective in reducing downwind hazards shutdown of the leak should be accomplished as soon as possible, preferably under 2 minutes.

Evlanov, S.F. "Concentration Limits of Flame Propagation of Mixtures of Natural Gas with Sulfurous Anhydride, Air and 0xygen." (in Russian), Tsvet. Met. 4:53-54, 1979.

It is shown that $\mathrm{SO}_{2}$ is a stronger flegmitizer of combustion, than inert gases and $\mathrm{CO}_{2}$. It is recommended that this finding be taken into account in estimating non-explosive regimes of operation of units using $\mathrm{SO}_{2}$, natural gas, $\mathrm{O}_{2}$ and air, and also in estimating categories of fire and explosion danger of these mixtures.

Fay, J. A., "Unusual Fire Hazard of LNG Tanker Spil1s." Combustion Science and Technology. 7:47-49, 1973.

This report gives theoretical expressions for the pool spread and evaporation rate of liquefied natural gas spilled on water, the gravitational spread, and the heating and downwind spread of the vapor cloud. It does not treat the diffusion or mixing of the vapor with air.

Fay, J. A. "Risks of LNG and LPG." Ann. Rev. Energy 5:89-105, 1980.

This paper reviews some of the more pertinant recent papers and studies on $L N G$ and $L P G$ safety and risk analysis.

Fay, J. A. and Lewis, D. H., Jr., "The Inflammability and Dispersion of LNG Vapor Clouds." Proceedings of the Fourth International Symposium on Transport of Hazardous Cargoes by Sea and Inland Waterway, Jacksonville, FL, October 26-30, 1975, NTIS No. AD/A023505, pp. 489-498, October 1975.

The paper considers the statistical properties of LNG vapor concentration, the mean vapor concentration in dispersing cloud and downwind distances for two flammability conditions.

Fay, J. A. and Lewis, D. H., "Unsteady Burning of Unconfined Fuel Vapor Clouds." 16th International Symposium on Combustion, 1976.

The problem of fireball hazards associated with LNG and LPG spills is investigated. A derivation of fireball maximum radius, height above surface and time required, are obtained by phenomenological, empirical and dimensional (with some physical and mathematical) analysis. Experimental corroboration is included. 
Fannelop, T. K. and Waldman, G. D., "The Dynamics of 0il Slicks - Or 'Creeping Crude'." AIAA Paper No. 71-14 presented at the AIAA 9th Aerospace Sciences Meeting, New York, New York, January 25-27, 1971.

The spread of an oil slick into calm water is considered from a theoretical viewpoint. The equations of motion are derived for the gravity-inertial and gravity-viscous flow regimes. For both two-dimensional and radial slicks, similarity solutions are obtained for the two flow regimes which give adequate agreement with available experimental data.

Farley, M., "The LNG Plant Design Engineer." LNG/Cryogenics. pp. 25-27, February/March 1973.

This article, through interviews with six individuals involved in LNG plant design activities, provides a brief overview of some of the problems they have had to cope with on various projects.

"Fast LNG-leak Detector Developed." 0il and Gas Journal. pp. 52, December 19, 1977.

A new device developed and patented by the Direction of Studies and New Techniques of Gaz de France is claimed to provide fast detection and location of leaks in large storage tanks. The location for the detector, at the bottom of the annular space between the walls and next to the internal tank, was determined following tests made on a reduced model tank.

Fauske, H., "The Role of Nucleation in Vapor Explosions." Transactions of the American Nuclear Society. 15:813-815, 1972.

The paper suggests a possible mechanism for vapor explosion and examines the validity of the mechanism in light of available experimental facts.

Fay, C., Desgroseillier, G., and Lewis, D., "Radiation from Burning Hydrocarbon Clouds." Combustion Science and Technology. 20, 1979.

This paper is a report of a series of experiments performed at M.I.T. Small scale fireballs were created in the laboratory and the time-dependent thermal emission was measured by a radiometer. Various correlations concerning fireball parameters (diameter, temperature, etc.) are presented.

Fay, J. A., Scale Effects in LNG Hazard Analysis and Testing. Progress Report for period $12 / 7 / 76$ to 8/21/77. ERDA Contract No. EE 77-S-02-4204.

The effect of LNG spill size on the physical parameters in hazard analysis has been investigated. Measurements of radiant heat envisions have been made. 
Fay, J. A. and Ranck D. "Scale Effects in Liquefied-Fuel-Gas Vapor Dispersion." DOE/EV/04204-5, Department of Energy, Washington D.C., 1981.

Dimensional analysis has been applied to vapor cloud dispersion phenomena with particular emphasis on LNG vapor clouds. A number of characteristic features of vapor cloud behavior could be correlated by this analysis.

Federal Power Commission (Bureau of Natural Gas). Construction and Operation of an LNG Import Terminal in Calcasieu Parish, PB 278071, September 1976.

An environmental impact statement for an LNG terminal in the Calcasieu Ship Channel in Louisiana.

Feirabend, C. E., "Design Considerations for LNG Production Facilities in Arctic Regions." 1978 Operating Section Preceedings, American Gas Association, Montrea1, Quebec, May 1978.

Operational and engineering design responses to extremes of temperature and windspeed in arctic regions are considered.

Feldbauer, G. F., Heig1, J. J. and McQueen, W. et al., Spills of LNG on Water Vaporization and Downwind Drift of Combustible Mixtures. Report No. EE61E-72, Esso Research and Engineering Company, May 24, 1972.

A total of seventeen LNG spill tests, ranging in size from about 250 to 2500 gallons, were carried out under a variety of weather conditions. The main thrust of the experimental work was aimed at measuring the parameters required to predict downwind concentrations. The aim of the experimental work was to measure the plume shape and other information which would permit the data on these variables to be extrapolated.

Felske, J. D. and Tien, C. L., "Calculation of the Emissivity of Luminous Flames." Combustion Science and Technology. 7:25-31, 1973.

A simple analytical basis for determining the total emissivity of luminous flames is developed. The analysis considers flames whose dominant emitting species are water vapor, carbon dioxide and soot particles. Calculations are made to illustrate the relative importance of gas and soot emission under typical flame conditions.

Feuerlein, P. "Safety Considerations for the Building of Vessels." (in German), Schweibtechn. Soudure. 7:135-142, 1978.

Large spherical storage vessels for gas and liquefied gas were normally damaged either by mode of operation (low temperature, periodical loads) or by external events (sinking, blast waves, earth tremor). Some of the resulting problems are discussed. Safety measurements and regulations are referred. 
Feuerlein, P. "Construction of Large Tanks." (in German), Chem. Rdsch. 34 $(51 / 42): 10,14,1981$.

The increasing volume of storage tanks for crude oil and liquefied gases leads to increasing risks. This requires extensive safety analysis and criteria and measurements for quality inspection and control. A method to assembly large tanks in a spiral construction is reported under these aspects.

Filstead, C. G., "The Design and Operation of LNG Ships with Regard to Safety." Shipping World and Shipbuilder. pp. 259-262, February 1972.

This article summarizes the safety features and operating procedures of LNG ships particularly the Methane Princess and Methane Progress.

Findlater, A. E. and Prew, L. R., "Operational Experience with LiNG Ships." LNG 5 - International Conference on Liquefied Natural Gas, 5th Proceedings, Session IV Paper 5, 16 pp., Duesseldorf, Germany, August 29-September 1, 1977.

Some of the experience gained during the initial years of operation of the shipping phase of the Shell Bruenei/Japan LNG scheme are presented in this paper. The operational planning required for the successful commissioning and operation of a fleet of gas carriers and the wide range of disciplines and expertise involved is also included in this paper.

Finsterwalder, K. "Cold Ductile Prestressed Concrete - a Safe and Economic Construction Material for LNG Tank Ships." (in German), Hansa. 114(3):2223-227, 1977.

The design of a $128,000-m^{3}$ LNG tank ship constructed of prestressed concrete is described. It is shown that a concrete tank ship would be more economic than a steel ship with respect to construction and transport costs. The design fulfills all prescriptions of Lloyd's Register, the US Coast Guard, and the IMCO.

Finsterwalder, K. "128 $000 \mathrm{~m}^{3}$ Tanker in Prestressed Concrete Structure for the Transportation of LNG." (in German), Schiff u. Hafen. 29(1):29-31, 1977.

Design and constructive details of a projected prestressed concrete LNG carrier are explained including methods of calculation, outer shell construction, integration and isolation of tanks.

Finsterwalder, K. "Floating Prestressed Concrete Construction for the Production and Storage of LNG." (in German), Schiff u. Hafen. 29(8):715-716, 1977.

The advantage of prestressed concrete as a material of offshoreconstruction is discussed. Projected pontons and semisubmersible platforms are described for production, storage and transfer of LNG. 
Finsterwalder, K. "COSMAR - Concrete Structures for Marine Production, Storage and Transportation of Hydrocarbons." (in German), Meerestechnik. 13(1):19-21, February 1982.

The aim of this international research program was to establish new fundamentals necessary for the design and operation of floating concrete structures for production, storage and transportation of liquid hydrocarbons. Extreme environmental conditions such as great water depths, artic climate, and the effects the cryogenic temperatures of the stored goods (up to approx. $-180^{\circ} \mathrm{C}$ ) have on the materials concrete and steel, and on the structure as a whole were examined. The choice of specific materials and the development of suitable concretes, structure types and calculation methods served to establish fundamentals necessary to design and construct concrete structures offering the same degree of safety and having the same working life as onshore structures.

The research program COSMAR was sponsored by the Commission of European Communities and Bundesministerium für Forschung und Technologie, and carried out by an international joint venture.

The budget for the project amounted to a total of DM 8 Mio.

Fischer, K., Geiger, W., Heudorfer, W. and Schnatz, G. Critical Appraisal of Mathematical Models of Explosive Gas Cloud Dispersion. (in English), Final Report, EUR 7034 of Battelle Institut, Frankfurt for the Commission of the European Communities, 1981.

One of the factors to be taken into account in designing nuclear power plants to resist external events is the conceivable pressure loading by a gas cloud explosion. This external pressure loading substantially depends on the maximum possible size, shape and drift width of the explosive part of the gas cloud and their variation in time. The aim of this study is to compare the existing mathematical models for the formation and dispersion of explosive gas clouds and to assess them in terms of accuracy of results, field of application and physical effects allowed for. The formation, spreading and dispersion of an explosive gas cloud can be divided into three phases: 1) release of liquefied gas, 2) spreading and evaporation of the liquefied gas, 3) spreading of the gas cloud and dispersion to beneath the lower flammability limit.

Flothmann, D., and Nikodem, H.J. "A Heavy-Gas Dispersion Model with Continuous Transition from Gravity Spreading to Tracer Diffusion." (in English), S. Hartwig (ed.), Heavy Gas and Risk Assessment, 89-102. Battelle-Institut e.V., Frankfurt am Main, Germany, 1980.

A dispersion model for dense gases is described. In difference to former parameter models, the transition between the gravity spreading phase and the tracer dispersion is treated as continuous. The model parameters were calculated by using van Ulden's freon experiments. The model was used up to now for risk and analysis of flammable gases. 
Fortson, R. M., Holmboe, E. L., Brown, F. B., Kirkland, J. T., Tullier, P. M. and Dayton, R. B., Maritime Accidental Spill Risk Analysis Phase I: Methodology Development and Planning. NTIS No. AD/761362, January 1973.

This report develops a methodological approach and task plan for assessing alternative methods of reducing the potential risk caused by the spill of hazardous cargo as the result of vessel collisions and groundings. In addition to developing the overall study approach, a very preliminary analysis of ship/barge accidents in U.S. territorial waters and port traffic was done to identify types of accidents to be examined in the next phase of the study effort.

Fourth International Conference on Liquefied Natural Gas. Papers, Place of llations, Algiers, Algeria, June 24-27, 1974.

This book is a collection of papers presented at the conference. The papers have been divided into 8 sessions according to their subject matter.

Fowles, G. R., "Vapor Phase Explosions: Elementary Detonations?" Science. 204:168-169, 1979.

A new theory is outlined which would explain a vapor explosion as an elementary detonation. It predicts the energy resulting from a superheated liquefied methane vapor explosion as $95 \mathrm{~J} / \mathrm{g}$.

Freeman, G. H., K. Potter and W. J. Walters. "Relative Roles of LNG and LPG in Today's and Tomorrow's Energy Market." Session I, Paper 7, Sixth International Conference on Liquefied Natural Gas, 1980.

Past, present, and predicted future world trade in LNG and LPG is compared and changes in the relative supply levels of both gases are considered. A significant increase in LPG supplies is forecast for the mid-1980s. Relative prices of ING and LPG to consumers will be influenced mainly by the supply and demand balance of those products.

Fritz, R. "Continuity of Supply of Natural Gas During Maintenance of Pipelines Using a Mobile LNG Installation." (in German), Gas Wärme Internat. 29(4):182$186,1980$.

A mobile LNG-unit is presented which is used as stand-by supply for natural gas by Thyssengas. Construction, technical data and experience are reported. 
Fuller, M. E. Site Considerations for LNG Facilities. LNG Terminals and Safety Symposium, pp. 324-339, in Applications of Cryogenic Technology 9. Flushing, New York, 1979.

The paper gives an overview of the multitude of federal and state regulations which must be met before an LNG terminal can be sited. More likely than not, a major siting process will become politicized, as shown in the example of the Point Conception terminal.

Fumarola, G., et a1. "Vapor Clouds Release and Explosion in Naphta Cracking Units." Third International Loss Prevention Symposium, 1980, 1/148-1/160.

Several disasters in naphta cracking units are considered and compared with particular reference to the dynamic vapor cloud release, diffusion, and explosion.

Garforth, A. and Pallis, C., "Luminar Burning Velocity of Stoichiometric Methane-Air; Pressure and Temperature Dependence." Combustion and Flame. 31:69-83, 1978.

The authors of this paper determine the flame velocity in a stoichiometric methane-air mixture (for initial various temperatures and pressure) experimentally and analytically, with resulting good agreement between the two.

Garland, F. and Atkinson, G., The Interaction of Liquid Hydrocarbon With Water. U.S. Coast Guard, Office of Research and Development, NTIS No. AD/753561, October 1971.

This is an investigation of the phenomena reported in a Bureau of Mines report which studied the hazards of LNG. During the investigation, LNG was dropped onto a variety of liquid samples. Explosions did not occur when pure water was used as the sample, but water contaminated with n-hexane or toluene gave an explosion every time. Peak explosion pressures are given for a variety of experimental conditions.

Gaydon, A. G. and Wolfhard, H. G., Flames - Their Structure, Radiation and Temperature. Chapman \& Hall Ltd., London, 1960.

The book includes information concerning premixed flames, flow patterns and shapes, burning velocity; propagation, diffusion, stability, carbon in flames, radiation, temperature, ionization, combustion processes of rocket fuels, and recent progress on some flame problems. 
Geiger, W. Status-Report on the Possible External Pressure Loadings on Nuclear Power Plants from Gas Explosions. (in German), Battelle Report BF-R.62.968-1, January 1977.

This report gives an overview of the standard of knowledge in the following topics: possibilities of release of a large amount of gas, formation of explosive vapor cloud, ignition and explosion process (deflagration as well as detonation), blast wave parameters in the surrounding air and structural dynamics and damage patterns. open questions are listened where more investigations are needed to design nuclear power plants against the impact of unconfined vapor cloud explosions.

Geiger, W. "Explosion Hazards of Transport Gases - Research Within the Reactor Safety Program of the Federal Republic of Germany." From Discussion on Explosion Hazards at the 7 th International Colloquium on Gas Dynamics of Explosions and Reactive Systems, ed. H. Wagner, pp. 46-59, Max-Planck-Institute Für Strömungforschung, Göttingen, 1979.

In West Germany every nuclear power plant has to be protected against external events such as aircraft crashes, earthquakes, and explosions. Explosions are considered to arise as unconfined vapor cloud events from accidental release of transported hydrocarbon gases. This paper describes a research program to be undertaken to develop information for use in refining Reactor Safety Guidelines. The research program is expected to cover three areas: 1) the mechanisms by which a quasi-detonation unconfined vapor cloud can take place, 2) the interactions between characteristic parameters of an incident pressure wave and structural response of nuclear power plant complex structures, and 3) pressure wave characteristics of a real gas cloud which detonated.

Geiger, W., and Synofzik, R. "Influence of Dispersion Behavior of Dense Explosive Gases on the Possible Strength of Explosion." (in English), S. Hartwig (ed.), Heavy Gas and Risk Assessment, 245-254, Battelle-Institut e.V., Frankfurt am Main, Germany, 1980.

To evaluate the effect of an unconfined vapor cloud explosion, one has to feed its given shape into the model. For reasons of simplification the cloud shape is usually assumed to be spherical or hemispherical. This paper takes into account that the cloud is often of pancake shape.

The resulting changes in flame propagation and in pressure generation in the case of an explosion are discussed. The predictions of the TNT equivalent model and the expanding piston model on one side are compared on a qualitative basis to the predictions of the pancake model on the other side. The comparison yields differences in the pressure pulse shape as well as in the peak overpressure. 
Grieger, W. and Synofzik, R. "Explosion of Flat Vapour Clouds: a Simple Model to Determine the Pressure Wave." (in German), Chem. Rdsch. 34(7):3,5-6, 1981.

To estimate the overpressure resulting from the accidental explosion of unconfined vapor clouds hemispherical models are commonly used. However, the vapor clouds formed after accidental releases of liquefied gas are often of pancake shape. A simple explosion model is proposed which accounts for the influence of the pancake shape on the range of serious overpressures, both for detonation and for deflagration. For both explosion modes the area over which the original explosion pressure is effective is obviously larger than predicted by the hemispherical model. On the other hand, because of the pressure relief behind the propagating wave front in the cloud by rarefaction waves from above, the decay of overpressure beyond the edge of the pancake-shaped cloud is more rapid than for a hemispherical cloud.

Greiger, W., Rischbieter, F. Stock, M. Synofzik, R. Moen, I.0. and Wiison, C.W. Detonation-1ike Explosion Modes. (in German), Interim Report for Gesellschaft für Reaktorsicherheit, Battelle-Institut e.V., Frankfurt am Main, February 1981.

A report is given of interim results of project 150411: detonationlike explosion modes. This project within the German Reaktor safety Program consists of six units:

1. Possible initiation of detonation-like explosion modes by partial confinement

2. Spontaneous explosion of segregated parts of the gas mixture

3. Flame front acceleration due to local explosions behind the front

4. Initiation of gas explosions due to radiation transport effects

5. Loading by the induced ground wave - propagation in the soil

6. Scientific coordination of the subprogram gas explosions with special consideration of the tasks entrusted to Battelle.

Geiger, W. "Experiments Concerning the Generation of Enhanced Overpressures in Gas Cloud Deflagrations" (in English) paper is presented at Euromach 139, Col10quium on Uncontrolled Blasts and Explosions in Industry, University College of Wales, Aberystwyth, Apri1 12-15, 1981.

Two research programs are currently under way in Germany, one dealing with the hazards from vapor cloud explosions as a consequence of accidents during transport and storage of liquefied hydrocarbons, the other dealing with the explosion hazard from process gas release in a future plant for using the high-temperature gas-cooled reactor for coal gasification.

Battelle-Institut in Frankfurt is engaged in both programs. In this paper a short overview is presented of its experimental investigations on mechanisms which could be responsible for the generation of enhanced overpressures in deflagrations. 
Geiger, W. "Ouantification of Hazards from Vapour Cloud Explosions-Research within the German Reactor Safety Program." (in Enqlish), Paper presented at the International Specialist Meeting on Fuel Air Explosion, Montreal, November 1981.

The objectives and the progress until now of the main tasks of the gas explosion research program within the German reactor safety program are briefly reviewed. The experimental tasks are directed mainly to assessing the possible mechanisms or situations for the initiation of detonation-like explosion modes (quasi-detonations, fast deflagrations) in a real-scale environment and on estimating, for different cases, the maximum conceivable pressure loading

functions. The theoretical tasks are concerned essentially with the response of nuclear power plant structures to the loads involved.

For illustration some examples of the work being carried out within the different tasks are discussed.

Geiger, W. "Present Understanding of the Explosion Properties of Flat Vapour Clouds." (in English), Paper presented at the 2nd Symposium on Heavy Gases and Risk Assessment, Frankfurt, May 25-26, 1982.

After the release of large amounts of liquefied hydrocarbons, large flammable clouds of pancake shape, i.e. of small height but of large extension in downwind and crosswind direction, may be formed. The pressure wave due to the unconfined explosion of a flat vapor cloud differs considerably from the pressure wave due to the unconfined explosion of a hemispherical cloud of the same amount of flammable mixture. In this paper an outline of the present knowledge of the explosion characteristics of flat vapor clouds is given.

Geiger, W., Synofzik, R. "A Simple Model for the Explosion of Pancake-Shaped Vapor Clouds." Third International Loss Prevention Symposium, 1980, 7/505-7/514.

A simple explosion model for pancake-shaped vapor clouds has been developed. It describes the blast wave over pressures for the case of detonation as well as for the case of deflagration.

General Accounting Office. "Need to Improve Regulatory Review Process for Liquefied Natural Gas Imports." ID-78-17, PB 283293, 1978.

It is shown how inadequacies and shortcomings in federal energy policy adversely affect the import of LNG. Recommendations are given for improving present U.S. conditions. The appendices describe relevant conditions in certain other countries (e.g., Japan) to be more favorable. 
Georgakis, C., Congalidis, J. and Williams, G. C., "Model for non-instantaneous LNG and Gasoline Spi11s." Fuel. 58:113-120, February 1979.

A predictive model for non-instantaneous spills is presented which is applied to holes in storage vessels for gasoline and LNG. Effects of spill size and shape and combustion are discussed and results are compared to those for instantaneous spills.

Geridoenmez, Oe. "Problems and their Practical Solution in Building Large Welded Cylindrical LGF-Pressure Vessels for Gastankers. Construction Peqardina Official Acceptance, Methods of Calculation, Duality Inspection and Keeping of Smal1 Tolerances. Part 1." (in German), Fachber. Huettenprax. Metallweiterver. 16(12):1060-1068, 1978.

The article describes the way of construction and building of large welded pressure vessels made of ALMg 4,5 Mn for liquefied gaseous fuel tankers. Especially problems and techniques of welding are discussed in the first part.

Geridoenmez, Oe. "Problems and their Practical Solution in Building Large Welded Cylindrical LGF-Pressure Vessels for Gas tankers. Construction Regarding Official Acceptance, Methods of Calculation, Duality Inspection and Keeping of Smal1 Tolerances. Part 2." (in German), Fachber Huettenprax. Metallweiterver. 17(2):115-119, 1979 .

The main field of the second part of the paper is the discussion of nondestructive methods and techniques for quality inspection and control, like techniques using $x$-rays, ultrasonics and water pressure.

Germanischer Lloyd "11th Colloquy on Shipbuilding - Germanischer Lloyd." (in German), Schiff u. Hafen. 29(4):385-392, 1977.

Summarized are topics and results of the shipbuilding colloguy in October 1975 on the field of construction and load criteria of liquefied gas tanks on ships.

Germeles, A. E., "A New Model for LNG Tank Rollover." Paper presented at the Cryogenics Engineering Conference, Kingston, Ontario, July 1975.

A dynamic model is presented which can give very accurate rollover predictions and is a potentially powerful tool in rollover prevention strategies. The excellent agreement between the predictions of the model and observations for the La Spezia rollover indicate that the model is valid. Uncertainties in the model transport coefficients indicate that further validation of the model would be desirable. The model has been computerized. 
Germeles, A. E., "Forced Plumes and lixing of Liquids in Tanks." Journal of Fluid Mechanics. 71:601-623, 1975.

A mathematical model for the mixing of two miscible liquids of different density is presented, from which the tank stratification can be computed.

Germeles, A. E., "A Model for LNG Tank Rollover." Advances of Cryogenic Enqineering. 21:326-336, 1977.

An attempt is made to explain the rollover phenomena which is occasionally observed in LNG storage tanks. Even though a mathematical model shows some qualitative resemblance of the rollover phenomenon, it is questionable whether it is based on correct assumptions.

Germeles, A. E. and Drake, E. M., "Gravity Spreading and Atmospheric Dispersion of LNG Vapor Clouds." Proceedings of the Fourth International Symposium on Transport of Hazardous Cargoes by Sea and Inland Waterway. Jacksonville, FL, October 26-30, 1975, NTIS No. AD/A023505, pp. 519-539, October 1975.

The paper presents methods for estimating the extent and location of flammable vapors as a function of spill and weather conditions, assuming that ignition does not occur. Models allow the width of the vapor cloud to be computed at the point of ignition for consequence analysis.

Geschwindt, S. "Dutch Drive for LNG Substitute." Chem. Age, p. 8, 1980.

Because of the Algerian postponement of an increased LNG production, the Netherlands plans to rely more on coal gasification. They consider the Shell-Koppers process as the most economical way for gasification.

Gibson, B. M. "World Market for LNG Trade--Present and Future." Adv. Cryo. Eng. 25:715-729, 1979.

The various sources of supply for natural gas are discussed. The largest are in the Soviet Union, Iran, and the U.S. The prospects for continued import needs are clearly favorable for Japan and Western Europe, and to a lesser degree, also for the United States.

Gibson, G. H., "Consider Safety, Reliability, Cost in Selecting Type of LNG Storage." 0il and Gas Journal. pp. 65-69, February 8, 1971.

Several types of ING storage are compared with respect to safety and cost. 
Gideon, D. N. and Putnam, A. A., "Dispersion Hazard from Spills of LNG on Land and on Water." Cryogenics. 17, January 1977.

This report analyzes the pertinent published data on dispersion of vapors from LNG spills on land and water. Correlation of these data is based on the commonly used relationships from dispersion theory. The report has emphasized peak concentration rather than average or 'maximum average' concentrations and for instantaneous spills. The peak concentrations of major interest to safety, are related to the peak vaporization rates.

Gideon, D. N., Putnam, A. A. and Duffy, A. R., Comparison of Dispersion from LNG Spills Over Land and Water. Report to the American Gas Association by Batte11e Columbus Laboratories, Project IS-3-7, A.G.A. Catalog No. M19877, September 4, 1974.

The report discusses dispersion variables, spill characteristics on water, a description of LNG programs, and provides comparisons of dispersion data.

Gideon, D. N., Putnam, A. A. and Duffy, A. R., "Safety Aspects of LNG Spil1s on Land." Advances in Cryogenic Engineering. 21:377-386. Paper presented at 1975 Cryogenic Engineering Conference held at Queen's University, Kingston, Ontario, July 22-25, 1975.

The paper provides information concerning experimental spills of LNG. Instrumentation and procedures, the dispersion hazard, the radiation hazard, and fire control and vapor suppression are discussed.

Giesbrecht, H. et al. "Analysis of the Potential Explosion Effects of Flammable Gases during Short Time Release into the Atmosphere." Proc., Symp. on Heavy Gas and Risk Assessment, pp. 207-225 (in German), 1979.

The flashing and deflagration phenomena resulting from an accidental bursting of pressurized containers filled with liquefied gases are experimentally investigated. Results are applicable to unconfined vapor cloud explosions. 
Giesbrecht, H., Hess, K., Leukel, W. and Maurer, B. "Analysis of the Potential Explosive Effect of Amounts of Combustible Gases Released into the Atmosphere. Part 1." (in German), Chem. Ing. Tech. 52(2):114-122, 1980.

Explosion hazard analysis of inflammable gas released spontaneously into the atmosphere. The processes of flash evaporation, atmospheric vapor cloud formation ignition and explosion after the bursting of vessels containing liquefied gas have been studied by model experiments with propylene heated up to $70^{\circ} \mathrm{C}$ and pressurized to $60 \mathrm{bar}$. The experiments have shown that a blast wave with considerable peak pressure in the vicinity of the vessel is produced already by flash expansion of the propylene. The experimentally determined decrease of peak pressure with growing distance could be scaled up to vessels of arbitrary size and different propylene temperatures. Scaling laws could be established as well for the calculation of peak pressure and positive pressure duration of the deflagration wave as functions of released mass and distance. The experiments have not revealed any evidence of a detonation process even when the cloud was ignited by an explosive charge.

Giesbrecht, H., Hemmer, G., Hess, K., Leukel, W. and Stoeckel, A. "Analysis of the Potential Explosive Effect of Amounts of Combustible Gases Released into the Atmosphere. Part 2. "Chem. Ing. Tech. 53(1):1-10, 1981.

Testing of models on the basis of cases of damage. A theoretical model set up to estimate the strength of undampened atmospheric gas cloud explosions occurring after bursting of vessels has been secured by thorough analysis of constructional damage caused by three explosions involving vessel contents of up to 30 tonnes of hydrocarbons. The maximum peak pressure of the pressure wave at the edge of the cloud was found to be ca. 0.3 bar. Diagrams are presented which facilitate estimation of peak pressure and time of action of the deflagration pressure wave as function of the distrance and the mass of gas released.

Gifford, F. A., Jr., "Use of Routine Meteorological Observations for Estimating Atmospheric Dispersion." Nuclear Safety. 2(4):47-51, June 1961.

The article considers vertical dispersion of a cloud or plume and gives estimates of the lateral spread as well as wind speed and direction.

Goldfeder, L. B., "Control Valves for LNG Facilities." Pipeline and Gas Journal. pp. 58-74, January 1972.

The types, applications and materials of construction of control valves for LNG are reviewed. 
Goodwin, R. D., The Thermophysical Properties of Methane, from 90 to $500 \mathrm{~K}$ at Pressures to 700 Bar. NBS Tech. Note 653, 1974.

An extensive tabulation of the thermophysical property data for methane is presented. The temperatures covered range from 90 to $500 \mathrm{~K}$ and the pressure up to 700 bars.

Gotaas, Y. "Aircraft leasurements in the Gas Cloud from the Blowout at an 0 il Platform in the North Sea." Journal of Air Pol1. Cont. Association. $30(7), 1980$.

A report is made on methane measurements for air concentrations and diffusion from a blowout at an oil platform. Estimates were made of the lower flammability point for the plume.

Green, K. A., Tiffin, D. L., Luks, K. D., and Kohn J. P., "Solubility of Hydrocarbons in LNG, NGL." Hydrocar. Process. 58(5):251-253, 1979.

Experiments are described to verify correlations for multicomponent solidliquid-vapor behavior of realistic natural gas systems. The resulting test data are in essential agreement with correlations derived earlier.

Greenwald, G. B. "LNG Carrier Safety: A Guide to the System of Federal Requlation." J. Marit. Law \& Commerce. 9:155-183, 1978.

A far-reaching and rather detailed discussion of the various federal regulations is presented which govern the transport of LNG across the seas. The Federal Power Commission and the U.S. Coast Guard are the two federal agencies primarily responsible for regulating such LNG trade.

Greer, J. S. Feasibility Study of Response Techniques for Discharqes of Hazardous Chemicals That Float on Water. DOT-CC-51870-A, 1976.

Potential response techniques for ameliorating the vapor hazards from discharges of hazardous chemicals onto water have been evaluated. Even though LNG is not specifically addressed, most methods discussed in the paper are applicable.

Greffier, R. "Technical and Safety Requlations for Storaqe and Installations of Liquefied Hydrocarbons." (in French), Gas d'aujourd'hui. p. 134, 1981.

The impact of new regulations (issued 1976 to 1980) on professional and public storage, installations, including gas stations for vehicle is discussed. 
Greunert, H. P. and M. Bookenhauer. "Studies of the Resistance of LNG Carriers to Collisions." Paper presented at the 6th International Conference on LNG, Session III, paper 6, 1980.

The study gives estimates for the limit of collision speeds beyond which the LNG containers aboard ship would incur rupture. Double-wall tankers are declared safe in collisions.

Griffis, K. A. and Smith, K. A., "Convection Patterns in Stratified LNG Tanks - Cells Due to Lateral Heating." Paper presented at the 3rd Conference on Natural Gas Research and Technology, Dallas, TX, March 6-8, 1974.

The paper treats the subject of layer formation due to a uniform lateral heat flux, such as exists at an LNG tank wall. Experimentally, a water sugar system has been used to model the methanehigher hydrocarbon system. Preliminary results indicate that convective layers will be relatively thin for cases which are germane to LNG storage.

Griffis, K. A., and Smith K. A. Numerical and Physical Experiments in DoubleDiffusive Convection: A Lateral Heat Flux Imposed on a Vertical Concentration Gradient. PB 80-205339, 1979.

The phenomena studied in this thesis provide an explanation for the occurrence of "rollover" in LNG storage tanks. This explanation is based on sound scientific principles and is verified by convincing experiments.

Gromholt, A. "Construction and Building of Large Spherical Tanks for the LNGTransport on Ships." (in German), Aluminium. 53(12):741-745, 1977.

Details are given on the construction problems in building spherical tanks of $720 \mathrm{t}$ mass out of $\mathrm{AlMg} 4,5 \mathrm{Mn}$. In the center of interest are questions of choice of material, problems of welding as well as control and acceptance.

Gugan, K., Unconfined Vapor Cloud Explosions. Gulf Publishing Company, Houston, Texas, 1979.

This report presents a comprehensive and critical study of incidents, experimental work and theory. Using current experience and knowledge, the study suggests possible solutions to the problems of prediction, prevention, and protection. 
Guise, A. B., "How to Fight Natural Gas Fires." Hydrocarbon Processing. 54:76-79, August 1975.

The following recommendations are made for coping with natural gas fires: 1) assume all fires to be impinging, 2) use potassium bicarbonate-base dry chemical, 3) use multipurpose dry chemical where water is not available, 4) use high velocity concentrated streams, and 5) use protective clothing and face shields.

Gullberg, R. W., "NWNG's Newport LNG Facility First User of CRYEX Purification." Pipeline and Gas J. 206(13):40-48, 1979.

A new concept for removing carbon dioxide from a gas stream is incorporated into Northwest Natural Gas Co.'s LNG peakshaving facility on Yaquina Bay, 114 miles southwest of Portland, Oregon.

Guthrie, J. K. and Gregory, E. J., "Design of Baseload Evaporators for LNG."

The design and operation of an open rack vaporizer and an indirect fired vaporizer are discussed.

Hadenhorst, H. G., Lorenzen, H. "Studies of the Storage of LNG in Salt Cavities." Fifth International Conference on LNG, 1977, Session II, paper 8.

The authors studied the thermodynamic behavior of the LNG/rock system as a function of time and the change in the rock mechanics resulting from the thermal influence of the LNG. Tests with liquid nitrogen were made to justify the theoretical studies.

Haddenhorst, H.G., Zünde1, F., Oellrich, L.R. and Schwier, K. "Storage of LNG in Salt Caverns." Erdöl und Kohle. 34:197-203, 1981.

This paper deals with a study of the technical and economic feasibility of the storage of LNG in salt caverns. The study was preceded by an experimental investigation during which a small cavern was filled with liquid nitrogen over a period of two days. The first task of the study was to confirm the experimental data obtained for temperature distribution in the surrounding rock and for rock mechanics by computation. This was followed by the development of a storage plant concept consisting of LNG salt caverns and above-ground facilities which formed part of an LNG receiving terminal. Thermodynamics and rock mechanics behavior of long-term storage operations were calculated. The study concluded with an economic comparison with an LNG terminal with above-ground storage tanks. 
Haines, G. H. and Thompson, J., "Offshore Gas Liquefaction Without Offshore LNG Plants. 0i1 \& Gas J. 78:87-91 February 18, 1980.

It is proposed to liquefy natural gas with liquid nitrogen stored aboard a tanker moored to an offshore drilling platform. At the shore-based terminal, the liquid nitrogen in turn is produced with some of the "cold" derived from vaporizing the LNG. It is claimed that such an operation is well within existing technology and is also economical.

Hale, D., "LNG Projects Develop Overseas, Only Regulations Develop in U.S." Pipeline and Gas Journal. pp. 17-21, June 1979.

The article provides an industry summary of LNG activities in 1978

and includes a list of foreign and U.S. LNG facilities.

Hale, D., "Peakshaving Capabilities Ready for 1979 - 1980 Winter Season." Pipeline and Gas J. 206(13):22-25, 1979.

U.S. peakshaving capabilities will be at a record high for the 1979-1980 winter seasons as underground gas storage capacity and withdrawal/sendout capacity reach new peaks and LNG peakshaving capacity reaches an all-time high; new peakshaving capacity is about 70 billion $\mathrm{ft}^{3} / \mathrm{day}$.

Hale, D., "Developments Proceed Slowly in World LNG Industry." Pipeline and Gas Journal, 121(3):17-19, 1980.

New regulations of the LNG industry are listed. New projects and potential supply sources, both in the U.S. and abroad, are described. LNG prices are shown to escalate. LNG accidents that occurred in 1979 are briefly discussed. The major LNG activity now appears to be in Europe, Japan, Southeast Asia, and Africa.

Ha1e, D. "Industry Peakshaving Capacity Greatest Ever for 1980-1981 Winter." Pipeline \& Gas J. 207(13):17-25, 1980.

An overview is given on the present storage capacity for various forms of gas storage, which includes storage in the form of LNG. The article contains also a brief discussion of significant new LNG developments, new LNG regulations for the past year.

Ha11, A. R., "Pool Burning." Oxidation and Combustion Reviews. 6:169-225, Elsevier Scientific Publishing Company, 1973.

This review of literature includes: influence on the burning characteristics; temperature distribution in the liquid and the phenomena of hot zone formation and boilover; prevailing concepts of heat transfer from the flame to the liquid; effect of water as a dispersed phase, and as a substrate, on burning. 
Ha11, D. J., Barrett, C. F. and Ralph, M. 0., Experiments on a Model of an Escape of Heavy Gas. LR 217 (AP), Harren Spring Laboratory. Department of Industry, Hertfordshire, United Kingdom, 1976.

The report describes model experiments on a release of a heavy explosive gas, propane or butane, into the atmosphere at ground level. Both long and short term released are considered and the validity of the model is discussed. A method of extrapolating the experimental results to full scale is provided.

Ha11, R. J., "CARS Spectra of Combustion Gases." Combustion and Flame. 35(1):47-60, May 1979 .

The author presents a theoretical basis for obtaining species concentration and temperatures in turbulent, sooty flames using Coherent-Anti-Stokes Ramen Spectroscopy (CARS). Comparisons of theory and experiment are presented.

Hall, S. F., A Simple Homogeneous Equilibrium Critical Discharge Model Applied to Multi-Component, Two Phase Systems. Safety and Reliability Directorate (U.K.), Report SRO R 127, May 4, 1978.

Two models of two phase critical discharge from reservoirs are presented which are applicable for spill calculations from breaches in storage tanks or piping.

Halverson, G., "Automatic Continuous LNG Level-Gauging and Temperature Measuring System." Proceedings of the lst Biennial Symposium on Cryogenic Instrumentation, Vol. 1, 1976.

This paper describes a system which is being used to make accurate measurements of the liquid level and temperature profile in LNG storage tanks.

Handman, S. E., "Pros and Cons of LNG Safety." Pipeline Industry. pp. 39-42, September, 1979.

This paper reviews types of existing LNG facilities, agencies which have jurisdiction over the facilities, and risks associated with LNG facilities versus risks associated with other human activities.

Haneke, M. "Special Steels for the Transport and Storage of Liquefied Gaseous Fuels." (in German), Abstract of a paper presented at the Hannover Messe 1976, Tech. Rdsch., Bern. 68(37):p.7, 1976.

For economic reasons storage and transportation of the technically important gases are performed in the liquid state at temperatures of -42.5 and $-165^{\circ} \mathrm{C}$. This requires special nickel steels which can be delivered in various forms. 
Hankel, C. C., LaFare, I. V. and Litzinger, L. F., "Purging LNG Tanks Into and Out of Service Considerations and Experience." Paper presented to the AGA Transmission Conference, Minneapolis, Minnesota, May 6-8, 1974.

This paper discusses detailed procedures used by Chicago Bridge

\& Iron for purging LNG tanks into and out of service.

Hankinson, R. W. and Thomson, G. W., "Calculate Liquid Densities Accurately." Hydrocarbon Processing. pp. 277-282, September, 1979.

Liquid density calculation methods are compared on 3000 compounds; results on 190 of these are presented. The Costald - Corresponding States Liquid Density method was found to be more accurate than the Yen-Woods or modified Rackett Equation (SDR) methods.

Hardee, H. C., Lee, D. 0. and Benedick, W. B., "Thermal Hazards from LNG Firebal1s." Combustion Sci. and Techn. 17:189-197, 1978.

LNG fireballs can pose serious burn hazards in their vicinity. Third degree burns from a very large $L N G$ fireball (several $10^{7} \mathrm{~kg}$ ) could occur out to several kilometers from its center.

Harris, N. C. "The Control of Vapor Emission from Liquefied Gas Spillages." Third International Loss Prevention Symposium, 1980, 15/1058-15/1067.

The paper discusses the physical mechanism which determines the extent of cloud formations and dispersion.

Harsha, P. T., LNG Safety Program Topical Report: Dispersion Modeling. Report RDA-TR-1100-003, by R\&D Associates for the American Gas Association, July 1976.

A variety of techniques exist for near-field LNG dispersion phenomena; Gaussian plume models are inappropriate; hydrostatic models are appropriate; three-dimensional numerical models have been demonstrated; a general LNG vapor dispersion model should incorporate sophisticated state-of-the-art turbulence models.

Hartwig, S., and Flothmann, D. "Open and Controversial Problems in the Development of Models for the Dispersion of Heavy-Gas." (in English), S. Hartwiq (ed.), Heavy Gas and Risk Assessment, 1-14, Battelle-Institut e.V., Frankfurt am Main, Germany, 1980.

In an overview, the main physical processes occurring during the release and dispersion of dense gases are described. Emphasis is placed on gaps in knowledge and controversial items. In particular the situation is discussed for gas storage under pressure at ambient temperature and for refrigerated gas storage without pressure. For all those areas the state-of-the-art of the model development and experimental validation of models have been considered. 
Hasegawa, K. and K. Sato. "The Experimental Study on the Thermal Radiation and the Blast Effect from Unconfined Vapor-Cloud Explosions." From Discussion on Explosion Hazards at the 7th International Colloquium on Gas Dynamics of Explosions and Reactive Systems, ed. H. Wagner, p. 70, Max-Planck-Institute Für Strömungsforschung, Göttingen, 1979.

The hazardous fratures of unconfined vapor-cloud explosions, its size, duration, thermal radiation, and blast effect have been studied on the basis of results obtained from semi-real scale experiments. The experiments were performed in the open air using samples of propane, pentane and octane. The maximum size of fireballs formed was empirically related to the mass of the samples. Fireball duration was found to depend on type of combustion and flame propagation velocity. The over-pressure due to the blast wave was related to flame propagation velocity. Conclusions could be applied to risk evaluation of accidents in chemical industries.

Haselden, G. G., "Developments in Gas Liquefaction and Separation. "Int. J. Refrig. 2 $(6): 207-210$, November, 1978.

Some of the most interesting papers presented to the Gas Liquefaction and Separation Commission of the IIR are reviewed. A novel LNG peak-load storage plant was described in which the excess cooling capacity available during most of the year is used to produce low cost liquid oxygen and nitrogen. On a larger scale, design studies were reported showing the advantages to be gained by cooling natural gas before admitting it to very long transmission pipelines. For duties above $100 \times 10^{9} \mathrm{~m}^{3} /$ year, piping LNG is recommended.

Haselden, G. G., "The Achievements and Potential of LNG for Energy Storage and Transport." Inst. Chem. Eng. Sym. 44:7-13, 1976.

The paper presents a brief general overview on present LNG technology, highlighting those features that make LNG transport economically attractive.

Haselden, G. G. "The Challenge of LNG in the 1980s." Mech. Eng. 103(3):46-52, 1981 .

An overall review is given on current developments in the field of LNG technology. The paper is based on presentations given at the 6th conference on LNG held in Kyoto, Japan, April 1980. It is expected that LNG trade will keep growing, since presently at least four times as much gas is still vented or flared as is liquefied and traded. 
Hashemi, H. T., Lott, J. L., Wesson, W., D. and Wesson, H. R., "Effect of Barometric Pressure Changes on Rate of Boiloff in a Storage Tank of Saturated Liquids." 1978 Operating Section Proceedings, American Gas Association, Montrea1, Quebec, May 1978.

An analytical model for prediction of boiloff variations due to atmospheric pressure changes in atmospheric storage tanks is presented. LNG examples are shown although the model can be applied to various other cryogenic gases.

Hashemi, H. T. and Wesson, H. R., "Cut LNG Storage Costs." Hydrocarbon Processing. pp. 117-120, August 1971.

Better, more precise designs can be made using a new mathematical model which more closely predicts actual boil-off rates. LNG losses and storage costs are reduced.

Hasselbacher, H. "Nitrogen Gas Turbines for LNG Regasification." Fifth International Conference on LNG, 1977, Session II, paper 12.

The paper describes the design of a standard nitrogen gas turbine for a plant with a LNG regasification rate of $210 \mathrm{t} / \mathrm{h}$. Two alternatives, a closed-cycle gas turbine and an open-cycle gas turbine, are also discussed.

Havens, J. A., A Description and Assessment of the SIGMET LNG Vapor Dispersion Model, U.S. Coast Guard Report, CG-M-3-79, 1979.

The mathematical model SIGMET, which has been developed to predict dispersion of LNG vapor clouds from large spills on water, is described in great detail. The particular features of the model are discussed and evaluated. Conclusions and recommendations for further improvement of the model are given.

Havens, J. A., Predictability of LNG Vapor Dispersion From Catastrophic Spills Onto Water: An Assessment. Report prepared by the University of Arkansas for the Cargo and Hazardous Materials Division, Office of Merchant Marine Safety, U.S. Coast Guard, April 1977.

The author has reviewed various mathematical models and the methodology described by SAI and believes that such techniques hold the most promise for accurate prediction of vapor dispersion from catastrophic spills on water. A program designed to evaluate the accuracy of the SAI model or other models should now be considered high priority.

Havens, J. A. "An Assessment of Predictability of LNG Vapor Dispersion from Catastrophic Spills on Water." J. Hazard. Mat. 3:267-278, 1980.

Seven different models for the dispersion of LNG vapors are evaluated. They give drastically different results. None of them can be considered satisfactory. 
Health and Safety Executive. Canvey, an Investigation of Potential Hazards from Operations in the Canvey IsTand/Thurrock Area. London: Her Majesty's Stationary office.

A two-part report: part 1 contains a summary by the Health and Safety Executive and part 2 contains the report of the investigating team. In the appendix, detailed information is given about the applied models.

Heat Transfer at the Air-Ground Interface With Special Reference to Airfield Pavements. Report Prepared by the Massachusetts Institute of Technology, Department of Civil and Sanitary Engineering, So il Engineering Division, Technical Report No. 63, January 1961.

The variables which affect the transfer of heat at the air-earth interface were studied as a part of an investigation to improve techniques for predicting subsurface temperatures. The investigation demonstrates that certain readily obtainable measurements may be utilized to predict the amounts of heat flow at the ground surface due to various atmospheric phenomena.

Hefflington, W. M., "Use the Right Heating Value." Hydrocarb. Process, $\underline{58}(6): 141-142,1979$.

When based on the heating value of methane, the heating value of natural gas is around 1,000 Btu/SCF. However, regasified LNG can have heating values up to $1,150 \mathrm{Btu} / S C F$. The article explains how to calculate the right heating value.

Hellmut, K. and Wilckens, H. "Technical Aspects of Floating Systems for the Production and Storage of LPG." Thyssen Tech. Ber. 9, (1):68-81, 1977.

Concept of a floating process and storage plant to use the associate offshore-gas in an economic way. Criteria for design, size, and description of technical process are given. Load conditions under heavy sea and the dynamic motions of the system are determined.

Henry, R. E., Gabor, J. D., Winsch, I. 0. and Spleha, E. A. et a1., "Large Scale Vapor Explosions." Argonne National Laboratory, Argonne, IL. Paper presented at the Fast Reactor Safety Meeting, Beverly Hills, CA, April 2-4, 1974.

Experimental results with Freon-22 and water show that the interface temperature homogeneous nucleation model accurately predicts the necessary temperature conditions for the onset of large scale vapor explosions. Test results for many different contact modes revealed that the magnitudes of explosions were highly dependent upon contact mode. 
Hertzberg, M., "The Theory of Free Ambient Fire. The Convectively Mixed Combustion of Fuel Reservoirs." Combustion and Flame. 21:195-209, 1973.

The theory of fuel-reservoir fires is extended and amplified into a quantitative formulation that includes all the significant physical processes: mass diffusion, heat conduction, convective mixing, convective heat transport, and radiative heat transport. The predictions are compared with the data for 3 fuels (gasoline, Iiquid hydrogen, and methanol), and the comparison gives reasonable agreement.

Hertzberg, M., Cashdollar, K., Litton, C. and Kansa, E., "The Diffusion Flame in Free Convection. Buoyancy-Induced Flows, Oscillations, Radiative Balance and Large-Scale Limiting Rates." Paper presented at the Central States Section, Combustion Institute Meeting on Fluid Mechanics of Combustion Processes, Cleveland, $\mathrm{OH}$, March 29-30, 1977.

Early studies of flame oscillations are reviewed and new data are presented for the fundamental infrared flicker frequencies of methanol pool flames and other diffusion flames. Measured frequencies decrease monotonically with increasing size, in good agreement with independent data obtained photographically and acoustically.

Hertzbert, M. et al. "The Spectral Radiance Growth, Flame Temperatures, and Flammability Behavior of Large-Scale, Snherical Combustion Waves." Proceedings of the 16th Symp. (Internat.) on Combustion, pp. 767-776, 1977.

Studies of fireballs in methane/air clouds have determined in quantitative terms the influence of nitrogen or halon additions on flame temperature and pressure rise for this type of combustion. The primary purpose of the study was the clarification of the influence of diluents and inhibitors on combustion behavior of methane.

Heskestad, G., Kung, H. C. and Todtenkopf, N. F., "Air Entrainment into Water Sprays and Spray Curtains." ASME Winter Annual Meeting, New York, New York, 1976.

Theoretically derived volumes of entrained air were found to agree with experimental values to within 17\%. While no explicit reference is made to ING, the results are sufficiently general to apply to the vapor stage of an LNG spill. 
Hess, K., Hoffmann, W., Stoecke, A. "Propagation Processes after the Bursting of Tanks Filled with Liquid Propane - Experiments and Mathematical Model." First International Loss Prevention Symposium, 1974, 227-234.

With geometrically similar tanks filled with liquid propane, tests were made to explain the bursting of the tanks under the pressure of the 1iquid and the development of explosive unconfined vapor-clouds. Ignition experiments show that the propagation processes after the bursting of the tanks can be described with a mathematical model for the nonsteady turbulent transfer of material. This mathematical model gives the reactive gas volume, the explosive energy, and the effect of the pressure upon the environment.

Hess, K., Leuckel, W., Stoecke, A. "Ausbildung Von Explosiblen Gaswolken Bei ijberdachentspannung Und Maßnahmen Zu Deren Vermeidung." (The Formation of Explosive Gas Clouds from Jet Releases and Measures to Avoid Them.) ChemieIng. Techn. 45:323-329, 1973.

The paper describes a mathematical model for the jet dispersion considering the difference of density between the gas and the environmental air. The solutions show that for a gas heavier than air, a larger amount of an inflammable mixture accumulates within the cloud at the top of the jet because of the gravity spreading. The different concentration profiles for such a cloud and the jet, as well as their influence on the course of a possible explosion, are discussed.

Higgins, K. and Baum, M., "Assessing LNG Tank Volume Calibrations." Dimensions/NBS 63(9):19, 1979.

Photogrammetric survey techniques are now used to determine the volume of LNG tanks. An NBS evaluation of such methods reveals that more accurate procedures for checking the photogrammetric methods are difficult to find.

Hikita, T. "A Film of Large Scale Field Experiments on Ethylene Hazards." From Discussion on Explosion Hazards at the 7 th International Colloquium on Gas Dynamics of Explosions and Reactive Systems, ed. H. Wagner, pp. 72-74, MaxPlanck-Institute Für Strömungsforschung, Göttingen, 1979.

Two large scale field experiments on ethylene hazards were conducted in 1969 and 1974 under sponsorship of Japanese Government with cooperation of industries, universities and national laboratories. An English-language motion picture was produced which demonstrated special test features such as dispersion of a liquid ethylene spill, fire control using a ary chemical foam, burning showing fire ball foundation, and explosion. The number of tests carried out were small because of difficulties involved in large scale tests. 
Hindle, W., Artic Islands LNG. Presented to the American Gas Association Transmission Conference, Montrea 1, Quebec, May 8-10, 1978.

Trans Canada has begun the study and design of an LNG project which would transport LNG from the high Arctic Islands to Quebec. The type of ship that would be used, an icebreaking LNG carier, is described.

Hinkley, E. D. "JPL Laser Measurement System for Methane." Proceedings of Current Research on Methane Detection and Measurement Sumposium, pp. 47-66, Environment Safety and Distribution Division, Gas Research Institute, Chicaao, Illinois, 1979.

The JPL Laser System is a single wavelength system similar to the ERT methane meter described above and operates on similar principles.

Hoehne, V. 0. and Luce, R. G., "The Effect of Velocity, Temperature, and Molecular Weight on Flammability Limits in Wind-Blown Jets of Hydrocarbon Gases." Proceedings, Division of Refining. API, 50:1057-1081, 1970.

Various diameter jets of methane, ethane, butane, and heptane gas were directed perpendicular to the wind stream in a wind tunnel. Measurements were made to define the flammable zone caused by the jet-wind interaction. The application of the test results to practical process plant vent spacing to minimize hazards during windy atmospheric conditions is illustrated.

Hoffmann, T. "Study of Nucleate Pool Boiling of some Liquefied Gases and their Binary Mixtures." (in German), Wärme u. Stoffübertrag. 11(3):189-193, 1978.

The work deals with experimental results about nucleate boiling of nitrogen, methane, ethane and nitrogen/methane, methane/ethane mixtures. Experiments were performed with pools on a copper-surface of $64 \cdot 10^{-4} \mathrm{~m}^{2}$ area. The data for the binary mixtures follow the equation of Happel and Stephan.

Hogan, W. J., "LLL Participation on LEF Safety Research." DOE/EV-0046, Department of Energy, Washington, D.C., Vo1. 2, pp. 481-492, 1979.

Lawrence Livermore Laboratory ( $L L L$ ) has the responsibility to develop analytical models to describe the effects of large LNG releases to the environment and to verify such models by performing spill tests. The paper gives a qualitative overview of the results that so far have been derived from the program. 
Hogan, W. J., Bowman, B. R. and Hase1man, L. C., Numerical Modeling of LNG Spi11 Phenomena. UCRL 82031, 1978.

The various existing models for LNG spills, vapor dispersion, and combustion effects are reviewed. The limitations of the models are discussed. The need for further improvements is emphasized.

Holman, 0. B., "LNG Peakshaving Plant Design Features and Operating Experiences." Paper presented to Seminar and Study Tour on LNG Peakshaving, Washington DC, March 5-9, 1979.

This paper reviews the design features and operating experiences of the Philadelphia Gas Works Richmond Peakshaving Plant. The plant uses a cascade liquefaction process, a prestressed concrete type design for storage and running film vaporizers.

Hotte1, H. C. and Sarofim, A. F., Radiative Transfer. Chapter 6, McGraw-Hi11 Book Company, 1967.

Chapter 6 deals with gas emissivities and absorptivities.

Hoult, D. P., "The Fire Hazard of LNG Spilled on Waters." Proceedings on LNG Importation and Terminal Safety. NTIS No. AD/754326, Boston, MA, June 13-14, 1972.

The paper considers the rate of evaporation of $L N G$ spilled on water, the negatively buoyant plume, heat transfer to the plume, the buoyant puff, and concludes that there is no single rule whereby the fire hazard of an LNG spill may be estimated.

Howard, J. L., and Andersen, P. G., "Barge-Mounted Gas Liquefaction and Storage Plant.". Chem. Eng. Progr. 75(10):76-81, 1979.

The design and operation of a floating LNG facility for liquefaction, storage and export of natural gas are described. This new plant was to be built in modules by shipyards in highly industrialized areas and to be towed to Iran for installation near Kangan.

Howard, J. L., Kvamsdal R. S. Naesheim K. "Building and Operating Experience of Spherical-Tank LNG Carriers." Marine Technol. 14:158-174, 1977.

The design, construction, and testing of large spherical-vessel LNG tankers is described. The conservative approach has resulted in ships of high integrity and safety. 
Howard, J. L. and Kuamsdal R. "LNG Ship Safety Enhanced by Research and Deve1opment." Proceedings of the Second Ship Technology and Research Symposium, San Francisco, California, May 25-27, 1977.

This report briefly discusses how research into the various aspects of LNG tank design and probability of occurrence of collisions involving LNG carriers have been used to enhance LNG ship safety. Safety analysis of the tanks include use of fault tree analysis, special materials, non-destructive testing and advanced structural stress analysis.

Howard, M. A., "Second Generating Peakshaving Plant Benefits from Experience." Pipeline and Gas Journal. November 1978.

Northern Natural Gas has two peakshaving plants, one built in 1975 and other in 1978. This article discusses the lessons learned at the first facility and the various design changes in the second facility that resulted.

Humbert-Basset, R. and Montet, A., "Dispersion dans 1'Atmosphere d'un Nuage Gazeux Forme par Epondage de G.N.L. sur le Sol." Paper presented at the Third International Conference on LNG, September 1972.

An experimental study conducted by GAZ de FRANCE at the test station of NANTES is described. To investigate the hazards occurring from spillage, measurements of evaporation rates of LNG on various soils were made. In addition, measurements were made of the extent that clouds generated from spillage in diked areas up to $200 \mathrm{~m}^{2}$. A mathematical model was utilized in the extensive study of the hazards problem.

Hunt, L. "Computer Analysis Reveals Cold Facts of LNG Storage." Process Engineering, p. 137, November 1979.

A computer program is briefly described which determines the thermal stresses existing in ING storage vessels and their supporting structure.

Huskens, L. and Rick, H. "Liquefied Gaseous Fuels-Air Mixer." (in German), Gas Waerme Int. 30(12):609-615, 1981.

The mixer is used to generate combustible gases of adjustable calorific value and density out of liquefied gaseous fuels expecially propane or butane but also methane. Technical concepts and components are discussed. 
Huther, M., N'Guyen Ket and Noyon, H. "Motion of Liquids on Ships - New Developments." (in French), Bu11. Tech. elu Bur. Veritas. 62(9):324-332, 1980.

On the first journeys of large gas tankers an alarming and unforeseen phenomenon was observed due to the motion of liquids in tanks filled more than 95\%. This article describes some investigations of international cooperations on this problem, disucsses the results, and suggests some additional investigations for the assessment of load conditions.

Huther, M., Benoit, F., and Lega1, Y. "Calculation of Stresses for Fatigue Application for Membrane Tanks of LNG-Tankers." (in French), Bu11. Tech. e1u Bur. Veritas. $63(5): 228-236,1981$.

Fatique and crack propagation play an important role in calculating the system of tanks for LNG-transportation. The article discusses a method based on latest standard of knowledge which is used by Bureau Veritas too. The lifetime of a part of membrane tank in the system 'Gaz Transport' is given as an example.

Hynes, J. P., J. Dah1gren, M. A. Aguilar, Oceanborne Transportation of Liquefied Natural Gas, Petroleum, and Methanol Fuels. EPRI-EA-1256, 1979.

The report presents an overview of the economic, technical, and environmental aspects of oceanborne transportation of LNG and petroleum liquids. Methanol has been considered as an alternative to $L N G$.

Ing., Dr., H. R. Hansen. "Safety and Reliability of Marine Gas Liquefaction and Storage Units." Presented at Gastech 78 LNG/LPG Conference, Monte-Car1o, Monaco, November 7-10, 1978.

This paper discusses very generally some safety related aspects of Marine LNG facilities. Much of the discussion is related to segregation of process equipment and storage areas on a floatable marine facility.

Ishchenko, A. Ya, N. V. Novikov, "Mechanical Properties of Soviet and American Al-Mg Alloy Plates and Welds for LNG Systems." Adv. Cryo. Eng., 24:491-509, 1978.

Two AI-Mg alloys (one of U.S., one of USSR manufacture), widely used for LNG applications, have been tested in a Russian laboratory. Results showed them to be very similar and to be well-suited for cryogenic use. 
Isting, Ch.; Thier, B. "Process- and Safetytechnological Design of Pidework Systems in Chemical Plants." (in German), Chem. Ing. Techn. 49(7):528-535, 1977.

This article describes the technical problems in pipework systems with transient and oscillating flow and thermal extension. Calculational methods and technical measures are discussed. The dosing of liquefied gaseous fuels is given as an example.

Jackson, R. H. F., "Custody Transfer Systems for LNG Ships: Tank Survey Techniques and Sounding Tables." NBSIR 79-1751, 1979.

A precise photogrammetric method is described which allows determining the exact volume of large LNG storage containers. Sounding tables are generated from the photogrammetric survey so that the LNG volume in a vessel can be determined from simple height measurements.

Jamison, L. R., "United States Codes and Regulations Affecting the Marine Aspects of LNG Movements." 1978 Operating Section Proceedings, American Gas Association, Montrea 1, Quebec, May 1978.

This paper presents a collection of regulations which influence marine movement of LNG. Agencies regulating this transport are the U.S. Coast Guard, Intergovernmental Marine Consultative Organization, and the Republic of Liberia Bureau of Marine Affairs.

Janzon, W. and Baumgardt, H. "Steels for Storage and Transportation of Liquefied Gaseous Fuels at Temperatures down to $-55 \mathrm{Cel}$." (in German). Thyssen Tech. Ber. 12(1):24-29, 1980.

Development of low carbon steels for low temperatures on the basis of $0.10 \% \mathrm{C}, 0.25 \% \mathrm{Si}, 1.50 \% \mathrm{Mn}, 0.040 \% \mathrm{Al}$ and according to the sheet thickness $0.030 \% \mathrm{Nb}$. The paper gives data of strength and toughness of thick plates and wide flat steel used at low temperatures down to $-55^{\circ} \mathrm{C}$.

"Japanese Market to Keep Top LNG Role." 011 \& Gas J. 78:22-23, Ju1y 21, 1980.

A forecast is made for the development of world LNG trade during the $1980 \mathrm{~s}$ and 1990s. A growth rate of $12 \%$ per year is predicted. The main consumers for LNG will be Japan, followed by the USA and Western Europe. 
The Japan Gas Association, A Study of Dispersion of Evaporated Gas and Ignition of LNG Pool Resulted From Continuous Spillage of LNG Conducted During 1975.

Apri1 1976.

LNG spill tests were conducted for continuous releases to determine the characteristics of evaporation, dispersion, and ignition of pool fires. Tests were concerned mainly with the vapor cloud dispersion and the resultant cloud dimensions and character.

Jaquette, D. L., Possibilities and Probabilities in Assessment of the Hazards of the Importation of Liquefied Natural Gas. Rand Corporation. Study P-5411, AD/A019353, 1975.

Currently prevailing assessment of the safety hazards of LNG spills is criticized. The unknowns of such spills are listed and the need for more definitive information is stressed.

Javelle, B. and Raynaud, J., "Structural Problems in Methane Carriers." Shipping World and Shipbuilder. pp. 831-833, September 1975.

The authors briefly discuss stress calculations for LNG ships. They include fatigue, lamellar teaming, crack propagation, and liquid motions.

Jeje, A. A. and Reid, R. C., "Boiling of Liquefied Hydrocarbons on Water." Paper presented at the Third Conference on Natural Gas Research and Technology, Dallas, TX, sponsored by the American Gas Association, March 1974.

The cryogens studied were liquid nitrogen, methane, ethane, and several typical LNG compositions. In general, boiling fluxes increased slightly as the initial water temperature was lowered and as more cryogen was spilled. For LNG mixtures, significant foaming resulted and it is also suspected that ice is rapidly formed and remelted by eddy circulation in the upper layer of water.

Jeje, A. A. and Reid, R. C., Transient Pool Boiling of Cryogenic Liquids on Water.

Boiling rates of $L N G$ and $L P G$ on water are determined as a function of water temperature and liquefied gas composition.

Jenrich, J. "Price, Policy Cast Cloud on U.S. Imports of LNG." $0 i 1$ \& Gas J. 78:17-21, Ju1y 21, 1980.

The present uncertainty about future LNG imports is discussed from various viewpoints. The outlook lies somewhere between the extremes of vigorous growth and complete phaseout. The U.S. government presently does not favor LNG imports, primarily because of recent large price hikes by the main exporters. 
Jensen, D. E. and Jones, G. A., "Reaction Rate Coefficients for Flame Calculations." Combustion and Flame. 34:1-34, 1978.

Current functional forms for chemical reaction notes and corresponding uncertainty factors are presented.

Jensen, D. E., Spalding, D. B., Tatche11, D. G. and Wilson, A. S., "Computation of Structures of Flames with Recirculating Flow and Radial Pressure Gradients." Combustion and Flame. 34(3):300-326, April 1979.

The authors present a technique for modeling steady-state, axis symmetric, highly-turbulent chemically reacting flow from a rocket engine. This technique has many features relevent to LNG pool fire modeling.

Johnson, D. W. and Welker J. R. Develooment of an Improved LNG Plant Failure Rate Data Base, Final Report. GRI-80/0093 prepared for the Gas Research Institute by the Applied Technology Corporation, September 1981.

Failure rate data on subsystems and components at LNG baseload and satellite plants was collected by sending questionnaires to plant operation. Responses were combined to broaden the failure rate data base for major LNG plant equipment. Results generally agree with data collected in an entire survey (see Welker and Scharr, 1979).

Jung, W. "Process Technology of the Evaporation and Conditioning Installations in the LNG-Plant Nievenheim." (in German), Gas u. Wasserfach-Gas/Erdaas. 118(8): $334-341,1977$.

The LNG installation is used in times of peak consumption of gas. The liquefied and hence quite pure natural gas has to be conditioned when removed from the storage. The gas feeded into the pipeline system is natural gas with an admixture of air. The technical problems of storage (weathering problem) and reliquefaction are described in the article.

Kama1, M. M. and A. Kha1i1. "Explosion Hazards of LNG and LPG Carriers During Transport." Adv. Cryo. Eng. 25:757-762, 1979.

An analytical method is briefly described for computing the pressure rise resulting from an LNG vapor cloud deflagration. The detonation limits are included in the treatise. 
Kame1, M. M. "Explosion Hazards in the Suez Canal-An Overview." From Discussion on Explosion Hazards at the 7 th International Colloquim on Gas Dynamics of Explosions and Reactive Systems, ed. H. Wagner, pp. 34-39, Max-Planck-Institute Für Strömungsforschung, Göttingen, 1979.

This paper is a concise exposition of the explosion danger that the densely populated Suez Canal zone is subjected to due to the passage of supertankers and liquefied natural and petroleum gas (LNG and LPG) carriers. Accidental causes of explosions are enumerated, different scenarios leading to the detonation of explosive fuel-air clouds resulting from liquefied gaseous fuel spills are discussed and, finally, possible avenues of research in this field are outlined.

Kardaun, G. "How LNG Fits in Dutch Gas P1anning." Session I, Paper 1, Sixth International Conference on LNG, 1980.

The need for international cooperation in the whole LNG delivery system from well-head to user is discussed. The technical aspects of this program are stressed from plant start-up to personnel training.

Kato, D., "U1tra Low-Temperature LNG Compressors." Fifth Internationa1 Conference on LNG, Session II, paper 10, Institute of Gas Technology, 1977.

Special compressors for recompression of LNG boil-offs in storage facilities are described.

Katz, D. L., "LNG-Water Explosions." NTIS No. AD/775005, 1973.

The "limit of superheat" is identified as the cause of LNG-water explosions. However, theoretical support for this argumentation is mainly speculative.

Katz, D. L., "Superheat-Limit Explosions." Chemical Engineering Progress. 68:68-69, May 1972.

The rapidity of this superheat-limit event as compared to nucleated bubble growth in a partially superheated liquid provides an explanation for vapor explosions discussed in the literature.

Katz, D. L. and Sliepcevich, C. M., "LNG/Water Explosions: Cause and Effect." Hydrocarbon Processing. 50:240-244, November 1971; a1so NTIS No. AD/775005.

The paper discusses the limit of superheat, the methane-water system, LNG mixtures, massive LNG spills, and considers other systems such as Iiquid methane poured into pure pentane in the absence of water. 
Katz, D. L. and West, H. H., "LNG Shipping and Storage." Paper Presented to the Engineering Foundation Conference on Risk/Benefit Methodology and Application, Asilomar, California, September 21-26, 1975.

This article gives an overview of the history and development of the LNG industry with emphasis on storage and shipping. Potential hazards associated with LNG are discussed briefly.

Kau, E. "New BG-Chemie Explosion Protection Rules and Gas Industry Related Examples from the Examples List." (in German), Gas u. Wasserfach-Gas/Erdqas $\underline{118}(6): 217-219,1977$.

Ignition temperature for gas-air mixtures are defined and zones of explosion danger are determined for densifying and control installations. Protection standards for high-pressure gas are discussed.

Kaustinen, 0. M., "Polar Gas Project." Presented to the American Gas Association Transmission Conference, Montrea 1, Quebec, May 8-10, 1978.

Some of the alternative methods of moving natural gas from Canada's Arctic Islands are discussed.

Kee, R. J. and Miller, J. A., "A Split-Operator, Finite Difference Solution for Axisymmetric, Laminar-Jet Diffusion Flames." AIAA Journal. 16(2), February, 1978.

An economical numerical solution of a vertical diffusion flame is presented. The complete chemical kinetics of the problem are included. Discussions of possible numerical treatment of the thermo-hydrodynamics and the "stiff" chemical kinetics are presented. "Majorant" splitting (as opposed to ADI methods) and the Gear-Hindmarsh "stiff" equation methods are utilized in the paper.

Kee, R. J., The Computational Nature of Combustion Modeling, Sandia Laboratories, SAND78-8245, A7buquerque, New Mexico, JuTy 1978.

The report presents a fundamental approach to computations for combustion systems. Specific problems and numerical algorithms are presented. 
Keeny, R. L., Kulkarni, R. B. and Nair, K., "Assessing the Risk of an LNG Termina1." Technology Review. pp. 65-71, October 1978.

The report presents a description of LNG risk analysis methods for an import terminal using as its example the risk study prepared for the proposed Elaspsed Natural Gas Co. Matagordo Bay Terminal.

Keens, D., "Technology of LNG Plants Still Undergoing a Steady Evolution." 0il and Gas Journal 78:84-89, Apri1 7, 1980.

In order to improve the profitability of LNG operations, various new engineering development schemes are discussed. These include areas in gas pre-treatment, cryogenic heat exchangers, refrigerant compression, compressor drives, offshore loading, and energy recovery in revaporization. Some of the schemes are already being applied to new LNG projects.

Kelley, C. S., Radiative Transfer Between Flame Burning Zone and Unburned Fuel. EATR-4555, Edgewood Arsena 1, Maryland, NTIS No. AD/732405, October, $\overline{1971 .}$

An assessment of the complex role of radiative heat transfer in the interaction of fuel and flame is presented. The thermo-physical properties of the fuel are included in the analysis.

Kelsey, R. A., F. G. Nelson, "Mechanical Properties of US/USSR Al-Mg Plate and Welds for LNG Applications." Adv. Cryo. Eng., 24:505-518, 1978.

The two Al-Mg alloys tested were found to be quite similar and showed favorable properties for low temperature (LNG) applications.

Kempen, H. W. J., "Natural Gas as Vehicle Fuel." Gas 93:8-13 Netherlands, (in Dutch), January 1973.

Topics include comparison with other fuels, storage tank requirements, tank filling, and safety. Also described is the plan by four companies, along with government assistance, to install a small test installation to liquefy natural gas and to convert some 400 vehicles to LNG operation.

King, W. S., On the Fluid Mechanics and Heat Transfer of Liquefied Natural Gas Spilis. RAND Corp., P5396, 1975.

A new mathematical model for the interaction between LNG and water is proposed. However, no details are supplied on the analytical and numerical details for practical use of the model.

Kiveylo, J. "Evaluation of the Effects of Detonation in a Spherical Bomb." From Discussion on Explosion Hazards at the 7 th International Colloquium on Gas Dynamics of Explosions and Reactive Systems, ed. H. Wagner, pp. 100-110, Max-Planck-Institute Für Strömungsforschung, Göttingen, 1979. 
Presented here is an analysis of the time-dependent pressures and impulse loadings on the walls of the hemispherical dome of a nuclear reactor pressure vessel arising from a centrally ignited hydrogen-oxygen detonation. Investigated in this context are the effects of richness of the detonable gas mixture as well as those due to the inclusion of water vapor. In the analysis the gas mixture was treated as a perfect gas, and the partial differential equations governing the gasdynamic flow were integrated using a finite-difference technique set in Lagrangian coordinates and incorporating the smoothing action of artificial viscosity. The most interesting results pertain to the ringing of pressure pulses at the walls. Their frequency is quite uniform, and their pressure peaks, at levels significantly higher than that of combustion at constant volume, decay at a negligible rate.

Kletz, T. A., "Consider Vapor Cloud Dangers When You Build a Plant." HydroCarb. Proc. 10:205-212, 1979.

A catalog of 15 items is presented which should be considered when building a facility in which vapor cloud explosions could occur (such as in an LNG plant).

Kneebone, A. and Prew, L. R., "Shipboard Jettison Tests of LNG Onto the Sea." Paper presented at the Fourth International Conference on LNG, Session 5, Paper 5, 1974.

The first part of the paper describes the procedures and results of a series of jettison tests carried out on board ship and discusses the operational safety aspects of such discharges. The second part is concerned with the environmental hazards associated with the release of large quantities of LNG to the sea in terms of the extent of vapor cloud formed; its characteristics and rate of dispersal.

Kodaira, N. "Energy Problems and Measures Taken to Promote Wider Use of LNG in Japan." Session I, Paper 3, Sixth International Conference on Liquefied Natura 1 Gas, 1980.

This report takes up the current problems of LNG - one of Japan's major primary energy sources - and the measures being considered in order to deal with them. State subsidies are under consideration to encourage wider LNG use by industry.

Kogarko, S. M., "Detonation of Methane-Air Mixtures and the Detonation Limits of Hydrocarbon-Air Mixtures in a Large Diameter Pipe." Soviet Physics. 3 , 1958.

A review is made of the Russian literature on methane-air detonation. The author describes his work using tubes with diameters up to 0.305 meter and lengths to 12.2 meters. Gas mixtures were initiated with 50/50 amatol explosive charges. The author concludes that the limits and the possibility of a detonation vary with the diameter. 
Kolodner, H. J. "A Practical Approach to Vapor Cloud Protection." Second International Loss Prevention Symposium, 1977, 333-337.

Some researchers have dwelt on early detection, isolation of leaks, remotely activated valves and other means of cloud prevention. Others have concentrated on cloud dispersion, better constructions of buildings or other means of secondary protection. This paper details these two approaches to the vapor cloud problem and gives suggestions as to the advantages and disadvantages of each. Recent study results and risk and system analysis techniques will be discussed.

Kozlowski, B. "Methane Roof Layers." (in Polish), Przegl Gorn. 31(3):95-98, 1975.

Explosions caused by gas concentrations behind supports suggest classification of layers and advanced safety measures, which are diagrammatically illustrated.

Knystentos, R., Lee, J. H., Moen, I. and Wagner, H. G. G., "Direct Initiation of Spherical Detonation by a Hot Turbulent Gas Jet," Proc. 17th Symp. on Combustion, The Combustion Institute, pp. 1235-1245, 1979.

It has been shown experimentally that transition from deflagration to spherical detonation is possible if large-scale eddies, superimposed by fine-scale turbulence, are present in burning vapor clouds. Since tests were conducted only with $\mathrm{C}_{2} \mathrm{H}_{2} / \mathrm{O}_{2}$ mixtures, the question of detonations in LNG vapor clouds remains unresolved.

Koopman, R. P., Kamppinen L. M., Multhaul L. G., Bingham G. E. and Frank D. N. "A Review of the 1978 China Lake Liquefied Natural Gas Dispersion Experiments and Instrumentation: The Laurence Livermore Laboratory Effort." Proceedings of Current Research on Methane Detection and Measurement Symposium, pp. 121-160, Environment Safety and Distribution Division, Gas Research Institute, Chicago, Illinois, 1979.

This paper describes the sampling configuration, types of equipment, and data recording system used to detect the dispersion of the LNG. The gas detection instruments included grab sample system by $L L L$, a forced-flow heat capacity sensor by shell, flow sensor by ThermoSystems Inc., Infrared gas analyzer built by Anarad Inc., rapid response infrared sensor developed by DOE, and MSA gas sensor. The results of the tests are presented and the various instruments compared as to measurement accuracy and sensitivity. 
Koopman, R. P. "Coyote Series- $-40 \mathrm{~m}^{3}$ Liquefied Natural Gas Dispersion, RPT and Vapor Burn Test." UCID-19211, Lawrence Livermore National Laboratory 1982.

The 1981 LNG spill tests at China Lake, California are very briefly described. They investigated rapid phase transitions in spills of LNG with various compositions and burning of LNG vapor clouds. A full account of the tests will be given later in a more detailed report.

Kot, C. A. et al. "Hazards to Nuclear Power Plants from Large LNG Spills on Water." NUREG/CR-2490, Nuclear Regulatory Commission, Washington D.C., 1981.

The highly unlikely accident of an LNG tanker spilling its contents in the vicinity of a nuclear power plant is analyzed. Serious damage to the plant could occur only from nearby blast-wave effects.

Kramer, J. "Natural Gas Production on the Basis of LNG and Methanol for Offshore-Applications." (in German), Erdoel-Erdgas-Z. 96(3):81-84, 1980.

Process plants on groundbased steel platforms are used to exploit deposits of natural gas and gases associated with crude oil. Either LNG or methanol can be produced in such a plant. The technical installations for the alternatives are discussed.

Kramer, J. "Offshore Liquefaction Platform." (in Enalish), Hansa. 115(20):1725, 1978.

The components necessary to liquefy and store LNG/LPG at an offshore platform are described. After a short comment on cleaning and liquefying, different platform systems are discussed: 1) for 60 to 80-m water depth, a pontoon of about 30,000 tons on four cylindrical legs, lifted hydraulically $30 \mathrm{~m}$ above sea level; 2) for 60 to 180-m water depth, it is planned to place the iack up of the pontoon on a frame work substructure of sufficient height.

Kraus, H. Techniques of an LNG Chain. AED-CONF 78-155-038 (in German) 1978. The paper describes briefly LNG production (liquefaction), transportation, storage, re-evaporation, and distribution to the end-user.

Krey, G. and D. Weber. "How to Improve the Economy of LNG Terminals." Session II, Paper 7, Sixth International Conference on Liquefied Natural Gas, 1980.

Using the cold energy in an LNG terminal with a closed-cycle gas turbine for electricity generation and LNG vaporization means a potential worldwide saving of $4.2 \times 10^{6} \mathrm{~kg}$ of $\mathrm{LNG} /$ day, referred to 1985 . 
Kuh1, A. L., H. J. Carpenter, and F. R. Gilmore. "Perspectives on Research on LNG Vapor Cloud Dispersion." From Discussion on Explosion Hazards at the 7 th International Colloquium on Gas Dynamics of Explosions and Reactive Systems, ed. H. Wagner, pp. 90-99, Max-Planck-Institute Für Strömungsforschung, Göttingen, 1979.

In this paper, key physical mechanisms affecting cloud dispersion are discussed and a research approach for predicting dispersion of vapor clouds from large LNG spills is suggested.

Lancaster, John F., "What Causes Equipment to Fail?" Hydrocarbon Processing. pp. 74-76, January 1975.

This article deals with four main causes of service failure in process equipment. They are: fatigue, general corrosion, stress corrosion cracking and manufacturing defects. Comments and suggestions for reducing each type of failure are included.

Lannoy, A. and Gobert, T. "Evaluation of Hazards from Industrial Activities near Nuclear Power Plants - Deterministic and Probabalistic Studies." (in English), Nuclear Engineering and Design. 57:207-214, 1980.

This paper presents the methodology developed by Electricité de France to evaluate the consequences of accidents affecting:

- Industrial facilities: refineries, chemical and petrochemical plants, storage areas, pipelines of gaseous, liquid and liquefied materials.

- Transportation routes (roads, railways, inland waterways) used to carry dangerous substances (solid explosives, liquid, gaseous or liquefied hydrocarbons).

Probabilistic methods have been developed by analysis of actual accident statistics (e.g. risks induced by transportation routes) and realistic and representative accident scenarios have been set up. The paper gives an overview of the methods and the main assumptions used to deal with:

- Formation of a fluid jet at a breach.

- Evaporation and possible formation of a liquid layer.

- Atmospheric dispersion and drift of a gaseous cloud.

- Heat radiation from fire.

- Unconfined explosion of a gaseous cloud.

Laoussine, H. A., "LNG Grows as World Energy Source." Hydrocarb. Process, $59(4): 130-133,1980$.

It is claimed that proven natural gas reserves are about $2.2 \times 10^{12} \mathrm{ft}^{3}$ and constitute (next to coal) the world's most abundant energy source. Estimated reserves are in the order of $10^{13} \mathrm{ft}^{3}$, which is equivalent to 2,000 billion barrels of oil. Algeria is the biggest exporter of LNG. Presently, about $11 \%$ of the natural gas production in the world is still flared or vented. 
Lauer, K.-H. "Experiences in Detecting Gas in Liquefied Gaseous Fuels - Air Distribution Networks." (in German), Gas U. Wasserfach-Gas/Erdqas 121(7):308$312,1980$.

A report is given about 'Gaz de France' tests to detect leaks in five underground heavy gas pipeworks using the vacuum-method. The advantage of this method is discussed in comparison to other methods for leak detection.

Laurendeau, N.M. "Thermal Ignition of Methane/Air Mixtures by Hot Surfaces: A Critical Examination." Combust. \& Flame 46:29-49, 1982.

Theoretical and experimental work relating to ignition of flammable gas/air mixtures is reviewed. Attempts are made to correlate experimental results published in the literature. A general, satisfactory theoretical treatment of the involved ignition phenomena is not available yet.

Laurendeau, N. M. and Carson, R. N. Comb. \& Flame, 46:213-218, 1982.

It has been verified by laboratory experiments that the ignition temperature of methane-air mixtures decreases as the size of the hot igniting metal surface is increased.

Lautkaski, R., Fieandt, J. "Risk Assessment of the Transportation of Hazardous Liquefied Gases in Bulk." Third International Loss Prevention Symposium, $1980,14 / 1052-14 / 1057$.

Risk assessment of the transportation of hazardous liquefied gases in Finland has been performed. The gases are: chlorine, sulphur dioxide, ammonia and liquefied petroleum gas. The actual transportation modes (rail, road, and ship transport) have been covered.

Lawrence, G. H., "Comments of the American Gas Association on Delegation of Functions by the Secretary of Energy to the Administrator of the ERA and FERC." American Gas Association, November 15, 1978.

The American Gas Association requests revision of the delegation due to confusing and inconsistent language, a failure to correct jurisdictional overlaps, and the increasing cost of regulations.

Lawrence, G. H. "Role of Liquefied Natural Gas in a Worldwide Gas Energy Option." Session I, Paper 6, Sixth International Conference on Liquefied Natural Gas, 1980.

A concentrated effort is expended to utilize natural and supplemental gas energy in a variety of ways to offset the precipitiously high use of oil. World supply/demand imbalances for gas energy can be alleviated only through accelerated development of LNG as a dependable and effective worldwide natural gas energy transportation system. 
Ledbetter, H. M. "Anomalous Low-Temperature Elastic Constant Behavior in Fe-13 Cr-19 Mn." Meta11. Trans. 11A:543-544, 1980.

A new Soviet steel has been investigated for its behavior at low temperatures so that its fracture mechanics parameters could be established. It was found to be well-suited for LNG applications.

Lee, J. H. S. and I. O. Moen. "The Mechanism of Transition from Deflagration to Detonation in Vapor Cloud Explosions." Progr. Energy Combust. Sci. $\underline{6}: 359-389$, 1980.

An extensive review is given on the role of turbulence in the transition from deflagration to detonation. It is shown to be possible that the transition proceeds only part of the way, resulting in blast waves which are not as strong as detonation waves but which are still substantially above the pressure level of simple deflagration waves.

Lee, R. H. C. and Happel, J., "Thermal Radiation and Methane Gas," I\&EC Fundamentals. 3:167-176, May 1964.

The infrared absorption of methane in three wavelength regions (2.37, 3.31 , and 7.65 microns) has been determined at various temperatures and optical depths. The semi-empirical expressions for the bank absorption so obtained are used to calculate the total and band emissivities of methane from 0.01 to $2.0 \mathrm{ft}$-atm. and from $500^{\circ}$ to $3750^{\circ} R$.

Lee, W. A. and M. Weinstein. "Computer Modeling of Massive LiVG Spills from Storage Tanks at Point Conception, Oxnard and Los Angeles Harbor, California." ASME Century Two Engineering Technology Conference, Cryogenic Processing Equipment Section, pp. 83-99, 1980.

The distance for an LNG vapor cloud to reach the lower flammability limit has been computed for a massive spill of two million barrels of LNG. Two different computational methods were utilized and applied to the three candidate sites for LNG terminals on the California coast.

Leeper, J. E. "Mercury - LNG's Probiem." Hydrocarbon Process. 59:237-240, November 1980.

Mercury is present in trace amounts in certain natural gas wells. Upon gas liquefaction this mercury can cause corrosion in the heat exchangers of mixed refrigerant LNG plants. A method is proposed for removing the mercury from the raw gas.

Lees, F. P., "Some Data on the Failure Modes of Instruments in the Chemical Plant Environment." Chem. Engineer. 277:418-421, September 1973.

Failure mode data are given based on a previously presented survey of failure rate data for 9500 instruments in chemical works. 
Lehrer, P. "Brandversuche Mit Flüssigem Erdgas an Modell-Behältern." (Experimental Investigation of LiNG Fires on Storage-Tank Models) Gas Wasserfach, Gas Erdgas, 114:340-344, Ju1y 1973.

Leakage of LNG storage tank can cause fire and explosion hazards. With the purpose of getting insight into the mechanics of such hazards an experimental study on LNG tank of $4.5 \mathrm{~m}$ dia. has been carried out by the Technical works of the city of stuttgart, $W$. Germany. It has been ascertained that LNG tanks do not present greater fire hazards than other fuel tanks of similar dimensions. Indeed poor ignition behavior and the short distance from the tanl: up to which an ignition can occur have to be considered as an advantage. Inert powder was found to be the most efficient LNG fire extinguisher.

Lehrer, P. "New LPG Plant for the Peak Shaving at the TWS." (in German), GWFGas/Erdgas, 123:62-67, 1982.

A report is given about design and building of two spherical LPG tanks of $4000 \mathrm{~m}^{3}$ volume for the municipal "Technical Works stuttgart" (TWS).

In the center of interest are measures of safety technology because of the close vicinity to dwelling-houses and traffic roads.

Lehto, D. L. and Larson, R. A., Long Range Propagation of Spherical Shockwaves From Explosions in Air. NOLTR 69-88, NTIS No. AD/698121, U.S. Naval Ordinance Laboratory, White Oak, Maryland, July 22, 1969.

Hydrocode calculations for spherical shock propagation using the artificial-viscosity method are carried out to 0.2 psi overpressure for a nuclear explosion and for a TNT explosion. An ideal-gas integration from the literature is used to extend the results to $1.6 \times 10^{-4}$ psi. Below 1.0 psi, 1 kiloton nuclear is equivalent to 0.7 kilotons of TNT.

Leonard, D. A., and Caputo, E., Technical Report: Remote Sensing of LNG Spill Vapor Dispersion Using Raman LIDAR. UCRL-13984, Computer Genetics Corp., Wakefield, MA, 1979.

The feasibility of using a Raman LIDAR scheme for the measurement of LNG vapor concentration has been demonstrated. The report describes the test apparatus and discusses the quality of the obtained results.

Lester, T. W. and Wittig, S. S. K., "Soot Nucleation Kinetics in Pre-mixed Methane Combustion." Presented at the 16th International Symposium on Combustion, 1976.

This paper is an investigation of the early chemical kinetics of soot formation in fuel rich methane flames. 
Lev, Y. "A Novel Method for Controlling LNG Pool Fires." Fire Technology. 1981.

It has been demonstrated that LNG pool fires can be controlled successfully with cellular glass scrap (Foamglass), floating on the pool. Supposedly, this approach is more efficient than the use of high expansion foam.

Lev, Y., "The Use of Foam for LNG Fire Fighting." Fire Technology, 17(2):17-2^, February 1981.

Experiments have domonstrated that high expansion foam can effectively control an LNG pool fire if it is applied profusely and continuously. However, for very large LNG spills such foam protection methods might be impractical because of the huge quantities of foam required.

Levine, A. D., Theoretical Models of LNG Dispersion Studies (Phase III - LNG Safety Program), Part I: Modeling of LNG Spills. AGA Project IS-129-1, Technical Report TLN-1, October 17, 1975.

A series of theoretical models relating to the growth and evaporation of cryogenic pools is reviewed, and new ones added in order to allow for complete empirical correlation. Agreement with all experimental results is quite good although the scaling law is somewhat questionable. Continuous spills are modeled using harmonic function analysis with adequate results.

Levine, A. D., Theoretical Models for LNG Dispersion Studies. Report on A.G.A Project IS-129-1, 1975.

Progress reports survey basic relations of detonation phenomena used to emphasize the importance of kinetics and induction time for the initiation process. Current knowledge of explosives in open air gas mixtures suggest that induction time may be very important in correlating experiments with theory.

Levy, M.M., "The Cove Point LNG Terminal: Its First Year of Operation." Paper presented to Seminar and Study Tour on LNG Peakshaving, Washington DC, March 5-9, 1979.

The design and operating experience of the Cove Point LNG terminal is reviewed. 
Lewis, D. H., The Dispersion and Ignitability of LiNG Vapor Clouds. il.S. Thesis, Massachusetts Institute of Technology, Cambridge, liassachusetts, June 1974.

The flammability of vapor clouds resulting from instantaneous spills of $L N G$ is determined quantitatively using statistical methods. A new physical theory on the vapor dispersion process is presented and compared to available experimental data. Numerical predictions of distance to various flammability limits are presented graphically.

Leyer, J. C. "Unconfined Hydrocarbon Air Mixture Explosion Studies Performed in France by CEA-EDF-GDF and the University." From Discussion on Explosion Hazards at the 7 th International Colloquium on Gas Dynamics of Explosions and Reactive Systems, et. H. Wagner, pp. 40-45, Max-Planck-Institute Für Strömungforschung, Göttingen, 1979.

This paper summarizes vapor cloud theoretical and experimental studies initiated in France in 1976 aimed at protection of nuclear power plants located in regions where large quantities of hydrocarbons are transported or stored. Research on two different topics had been undertaken at the time of this presentation: 1) blast effects produced by detonation of ethylene, acetylene, and propane-air mixtures and 2) acceleration of various fuel and air mixtures in the deflagration made. Future work includes investigation of maximum flame velocity to be expected by interaction with obstacles and partical confinements displayed on the flame path.

Liesen, K. "Natural Gas in Western Europe." (in French), Gas Wasser Abwasser. $\underline{58}(2): 103-108,1978$.

This article describes the supply of Western Europe with natural gas and its advantage as a source of energy. The discussion of resources and future development includes the delivery of LNG from Algeria and the project of an LNG plant in Wilhelmshaven.

Lind, C. D., Explosion Hazards Associated With Spills of Large Quantities of Hazardous Materials - Phase I. U.S. Coast Guard Report CG-D-30-75. NTIS No. AD/A001242. October 1974.

This report documents the results of a program to guantify the explosion hazards associated with spills of material such as LNG, $L P G$, or ethylene. The results are: a phenomenological description of a spill; an examination of the detonation properties of methane; a qualitative theory of non-ideal explosions; a plan for Phase II of the study. 
Lind, C. D. and Whitson, J. C., Explosive Hazards Associated with Spills of Large Quantities of Hazardous Materials. Phase II. U.S. Coast Guard Report CG-D-85-77. NTIS No. AD/A047585, 1977.

Tests have been conducted to investigate the burning behavior of ING type materials. No detonations have been observed in any of these tests.

Lind, C. D. and Strehlow, R. A., "Unconfined Vapor Cloud Explosion Study." NTIS No. AD/A023505, presented at the Fourth International Symposium on iransport of Hazardous Cargoes by Sea and Inland Waterways, Jacksonville, FL, October 26-30, 1975.

Five-meter radius hemispherical bag tests of ignition of $10 \%$ methane/ propane-air mixture were conducted. Results indicated that ignition of fuels in this amount does not produce a detonation or damaging pressure waves.

Lind, C. D. and Whitson, J. C., "China Lake Spill Tests." Report L, Liquefied Gaseous Fuels Safety and Environmental Control Assessment Program: A Status Report. D0E/EV-0036, Department of Energy, Washington, DC, 1979.

The 1978 LNG spill tests at China Lake are briefly described. No data analysis is included.

Lind, C. D. and J. C. Whitson. "Update of Dispersion, Fire, and Explosion Testing at China Lake." LNG Terminals and Safety Symposium, pp. 340-345, in Applications of Cryogenic Technology 9. Scholium International, Flushing, New York, 1979.

Overall results from combustion/detonation tests of various cryogenic fuels are given which were contained as vapors in plastic hemispheres. LNG spill tests on water ponds are also described briefly.

Lindblom, U. LNG in Rock: A New Storage Option. STU Report 75-4514, 1978.

It is argued that storage of natural gas in underground caverns is safer and more economical than storage in conventional LNG surface tanks. This claim is backed up by computer analysis and various types of tests and laboratory experiments.

Liquid Natural Gas, Characteristics and Burning Behavior. Conch Methane Services, Ltd., Villers House, Strand/London, W.C. 2, England.

A synopsis of a comprehensive engineering report prepared for Conch Methane Services Ltd., based on large-scale field tests conducted near Lake Charles, Louisiana, plus laboratory data from the Bureau of Mines and available information in the literature. Field tests measured the levels of radiation by use of thermopiles; and extinguishment trials, using various extinguishment media, were conducted in conjunction with burning tests. 
L:chfield, A. B. "LNG Terminal for Storage and Regasification." Chem. Eng. rogr. $77(1): 83-88,1981$.

The design and operation of the new LNG terminal at Cove Point, MD is described. Safety considerations are included. When in full operation, the facility is capable of regasifying LNG at the rate of $28,000,000 \mathrm{~m}^{3} / \mathrm{d}$.

LING Safety Program - Interim Final Report. (Draft) R\&D Associates Report RDA-TR-1100-006 to the American Gas Association, September 30, 1976.

This program represents a comprehensive LNG safety study and includes the following tasks: LNG spread and boiloff rates, subscale land experiments performed in a wind tunnel, dispersion modeling, radiation and detonation studies, and a field test program definition which represents a major focal point of all other tasks. Emphasis is placed on scaling, instrumentation, and data analysis methodologies.

LNG Safety Program - Interim Report on Phase II Work. A.G.A. Project IS-3-1, Report to the American Gas Association by Battelle Columbus Laboratories, July $1,1974$.

Models for dispersion and radiation were developed, which fit data for 80-ft spills and will predict the hazard for spills into dikes up to 400 to $500 \mathrm{ft}$ dia. Experiments verified reduction of dispersion hazards by insulated dike floors and high dikes. Predictions are given of downwind distances of travel of flammable vapors and radiation intensities on targets near fires on soil, and in low dikes up to 500 ft in dia.

LiNG Terminal Risk Assessment Study for Los Angeles. Report by Science Applicatiors, Inc., for Western LiNG Terminal Company, December 22, 1975.

Science Applications, Inc., concludes on the basis of this study that LNG risks to populated areas near the Los Angeles Harbor site are extremely low. The physical characteristics of LNG, the design of the facility and tankship and the planned operating rules account for the low risk values.

LiNG Wind Tunnel Simulation and Instrumentation Assessments. Report RDA-TR105700-003, Draft by R\&D Associates for the U.S. Energy Research and Development Administration, Apri1 1977.

Information is presented on LNG flame radiation, test site criteria, wind tunnel modeling, and test instrumentation.

Lootvect, R. and P. Jean. Fastening Arrangement for Sealing Barrier in Insulating Wall of Insulated Compartment Built into a Ship's Hul1. U.S. Patent 3,990,382, assigned to: Gaz Transport, 1976.

A detailed design is described on how two fluid-tight layers and two heatinsulating layers are arranged around LNG storage vessels aboard LNG tankers. 
Love, T. J., Hood, J. D., Shahrokhi, F. and Tsai, Y. W., "A Method for the Prediction of Radiative Heat Transfer From Flames." ASME Publication 67-HT-47 presented at the ASME-AIChE Heat Transfer Conference and Exhibit, Seattle, WA, August 6-9, 1967.

This paper presents a method, based on the transport equation, to predict the radiative heat flux from methanol and acetone flames of arbitrary size and geometry. Predicted and measured values of tile radiative flux were compared for several larger flames and found to be in good agreement for free-burning flames of acetone and methanol.

Luks, K. D., and Kohn J. P. "LNG Liquid-Liquid Immiscibility." Hydrocarb. Process. 60:257-259, 1981.

Multicomponent LNG systems can under certain pressure/temperature conditions form a second liquid phase, which may be different in density and composition. For the proper design of LNG processing equipment the potential existence of such a second phase should be taken into account.

Luks, K. D. and Kohn J. P. "Avoid Freeze-Up in LNG/LPG lork." Hydrocarb. Process. 60:135-138, 1981.

The thermodynamics of multicomponent hydrocarbon mixtures, as they may be found in commerical LNG and LPG, is developed. Examples are given for the pressure/temperature loci at which crystallization of the various solutes may proceed. This determines the conditions for potential fouling (by solid formation) of process equipment used in $L N G / L P G$ work.

Lützke, K. "Untersuchungen über das Verhalten von Flüssiggas beim Ausströmen ins Freie." (Investigation on the Behavior of LPG Escaping into Open Air.) Erdöl Kohle-Erdgas-Petrochem.ver mit Brennst.-Chem. 24:165-172, lärz, 1971, 231-238, Apri1 1971, (2 papers).

The two-part paper presents results of an experimental investigation on the behavior of releases from gaseous and liquefied propane and butane. Escaping volume and the velocity and the direction of the wind were taken into account. The measured ignition distances on the releases from liquefied propane and butane as function of escaping volume and wind velocity were used to devlop an empirical formula for estimating the maximum ignition distance. 
Maab, E. R. "Combined Gas/Steam Turbine for the PropuTsion of a LNG Tank Ship." (in German), Hansa. 113(22): 1980-1983, 1976.

The design of a propulsion system using only boiling off and transported gas as fuel supply for a $125,000-m^{3}$ LNG tank ship is given. By modification of an existing gas turbine (omitting a heat exchanger and installation of a steam circulation), an economic solution becomes possible.

Mackay, D. and Matsugu, R. S., "Evaporation Rates of Liquid Hydrocarbon Spills on Land and Water." The Canadian Journal of Chemical Engineering. j]:434-6.39, August 1973 .

Experiments on the evaporation of cumene, water and gasoline are described and the evaporation mass transfer coefficient correlated with the windspeed, liquid pool size and the vapor phase Schmidt Number. Comparison of the correlation with flat plate mass transfer correlations shows satisfactory agreement and suggests that turbulent transfer occurs, the rate being enhanced by liquid surface roughness.

liaezawa, M., Experiments on Fire Hazards of Liquefied Flammable Gases. Osaka Gas Company, Ltd., May 1973.

Part I discusses the fire properties of liquefied flammable gases. Part II presents the results of an experiment in fire extinguishing. Part III is concerned with a dispersion experiment. Briefly, the flame temperature of each liquefied gas is 700 to $800^{\circ} \mathrm{C}$ compared to gasoline at $1100^{\circ} \mathrm{C}$. LNG burning rates are much larger than gasoline. Radiation energy is also larger than gasoline.

Magnussen, B. F. and Huertager, "Mathematical Modeling of Turbulent Combustion with Special Emphasis on Soot Formation and Combustion." Presented at the 16th International Symposium on Combustion, pp. 719-729, 1976.

This paper presents a mathematical model of turbulent diffusion and/or premixed flames. Methods for thermal radiation and soot formation predictions are also presented. Soot formation is analyzed as a two-step process (nucleation site formation and soot particle formation). Thermal radiation is evaluated using a two-flux equation. 
Mlaher, J. B. and Van Gelder, L. R. "Rollover and Thermal Overfill in Flat Bottom LNG Tanks." Pipeline and Gas Journal. 199:46-48, September 1972.

Conclusions are that high venting incidents involve thermal overfill; surface layer phenomena occurs in flat bottom LNG tanks filled through bottom with a liquid of saturation pressure greater than pressure capability of the tank; bottom filled tanks should provide venting over entire fill time consistent with degree of thermal overfill; if top layer is continually agitated during filling, thermal overfill will not occur.

Marchaj, T. J. System for Storing Liquefied Gas. U.S. Patent 4,110,995, assigned to: Preload Technology, Inc., 1978.

A design for LNG storage tanks is proposed which minimizes the contact of the relatively warm gases below the dome of the storage tank with the LNG surface. This helps to reduce undesirable gas vaporization.

Marcus, H. S. et a1. Alternative Liquefied Gas Carqoes: Manaqement Strateoies and Design Philosophies, MA-RD-940-78062, 1978.

The feasibility of providing single-cargo liquefied gas carriers with the capability for transporting alternative liquefied gas cargoes is investigated on a broad technical and economic basis. In particular, the added capability of LNG carriers for transporting LPG appears to be quite inproblematic and would only increase the original construction costs by about $3 \%$ to $5 \%$.

ilarkstein, G. H., "Scaling of Radiative Characteristics of Turbulent Diffusion Fiames." Paper presented at the 16th International Symposium on Combustion, 1977.

It is shown that radiative properties of gaseous-fuel turbulent diffusion flames can be scaled successfully over a fairly wide range of fuel flow rates. In addition, radiometric scans were found to provide quantitative information on flame length and diameters and their scaling properties. The work was part of a program to develop a generally applicable model of fire radiation.

Marsha11, M. R. "Gaseous and Dust Explosion Venting: Determination of Explosion Relief Requirements." Third International Loss Prevention Symposium, $1980,16 / 1210-16 / 1229$.

The paper gives a brief description of the processes which take place during a vented explosion. From this description the required characteristics of an explosion relief vent are derived. The influence on the explosion pressure generated of parameters other than those pertaining to the explosion vent is also discussed, e.g., properties of the fuel-air mixture ignited. 
Martin, K., "Utilization of Cold of Liquefied Natural Gas." Erdoel-Erdgas Z, 95: (6):200-206, June 1979.

Various possible processes for utilizing the cold from LNG are described. In addition to supplying the power for the LNG terminal itself, some processes can export and sell surplus energy.

Martinsen, W. E., S. P. Muhlenkamp, J. 01son, "Disperse LNG Vapors With Water." Hydrocarbon Processing. 56 $(7): 261-266$, July 1977.

This paper discusses the potential for enhancing LNG vapor cloud dispersion by water sprays into the cloud. Experiments showed increased mixing due mainly to mechanical turbulence induced by the watery sprays and a resultant decrease in the distance a vapor cloud spreads before reaching the lower flammability limit.

Martinsen, W. E. and W. D. Cavin. "LPG Land Transportation and Storage Safety." DOE/EV/06020-T, Department of Energy, Washington D.C., 1981.

Accident statistics for LPG land transportation within the U.S.A. are evaluated. They show that the fatality rates are guite low, namely about 6 per year.

Masliyah, J. H. and Steward, F. R., "Radiative Heat Transfer From a Turbulent Diffusion Buoyant Flame With Mixing Controlled Combustion." Combustion and Flame. 13:613-625, 1969.

A mathematical model of a turbulent buoyant diffusion flame is postulated. The radiative interchange between the flame and a plane surrounding its base is determined. From this radiative distribution, it is possible to determine the radiative heat flux to the liquid fuel which is vaporizing to feed the flame. A graphical solution is presented which yields the rate of burning of a liquid fuel of given physical properties in a fixed diameter fuel source.

Mathiesen, T. C., Flatseth, H. H., Solberg, D. M. and Tueit, O. J., "Risk Manacement in Marine Transportation of LNG," 1979.

Measures are being described for dealing systematically with LNG hazards as they might occur in marine transportation. The measures are largely based on reliability engineering results. 
Matsui, H. and Lee, H., "On the Measure of the Relative Detonation Hazards of Gaseous Fuel-0xygen and Air Mixtures," Proc. 17th Symp. on Combustion, The Combustion Institute, pp. 1269-1280, 1979.

The critical energies for direct initiation of spherical detononations for eight gaseous fuels have been measured. These fuels include pure methane and pure higher alkenes, which are the main constituents of LNG. The measured values extend over about six orders of magnitude.

Haurer, B., Hess, K., Giesbrecht, H., Leuckel, W. "Modeling of Vapor Cloud Dispersion and Deflagration after Bursting of Tanks Filled with Liquefied Gas." Second International Loss Prevention Symposium, 1977, 305-319.

The processes of flash evaporation, atmospheric vapor cloud formation, ignition, and explosion after the bursting of liquefied gas vessels have been studied by model experiments with propylene.

May, W. G. and i.lcQueen, W., "Radiation From Large LNG Fires." Combustion Science and Technology. 7(2):51-56, 1973.

Radiation from flames of burning LNG were measured in a burning pool contained in a trench. Eurning rates over the range of 13,500 to $40,000 \mathrm{BBL} / D$ of $L N G$ were studied. Measured flux varied from 60 to $480 \mathrm{Btu} / \mathrm{hr} / \mathrm{ft} \mathrm{f}^{2}$ at ground level and 300 to 600 feet from the flame center and from elevated points. An inverse square law of radiation versus distance held fairly well.

May, W. G., McQueen, W. and Whipp, R. H., "Dispersion of LNG Spills." Hydrocarbon Processing. 52:105-109, May 1973.

The paper discusses data analysis of plume shape and plume dispersion characteristics. Correlations show that dispersion of LNG vapors can be predicted from observed facts and controlled conditions.

May, W. G., McQueen, W. and Whipp, R. H., "Spills of LiVG on Water." Paper presented at the American Gas Association Distribution Conference, Washington, DC, May 14, 1973.

The conclusions reached cover: effect of variables on flow rate; inequality of downwind flow rate and evaporation rate; effect of density on plume shape; dependence of plume density on air humidity; effect of plume heating; weather effects; predictions of downwind plume travel. 
May, W. G., McQueen, W. and Whipp, R. H., "Spills of LNG on Hater." Proc. Div. of Refining, API, pp. 626-653, 1973.

The vapor dispersion from large LNG spills on water was experimentally determined. The tests, carried out by Exxon, were intended to verify and extend results obtained earlier in the Bureau of Mines and Gaz de France tests.

May, W. G., and Perumal, P. V. K., The Spreading and Evaporation of LNG on Water. ASME paper 74 - WA/PID-15, 1974.

The paper proposes a semi-empirical relationship for estimating the total evaporation from a LNG spill on water. Correlations are based on LNG spread rate, maximum pool diameter and evaporation rate per unit area.

McCarthy, D., A Comparison of inathematical Models for the Prediction of LNG Densities. NBSIR 77-867, National Bureau of Standards, October 1977.

Four mathematical models of the equation of state for LNG like mixtures are compared using experimental data optimized for each model. The objective of predicting LNG densities to within $\pm 0.1 \%$ could not be assessed due to discrepacies in the input data. Model listings are included.

McHenry, H. I., et a1., "Low-Temperature Fracture Properties of USSR Aluminum-6\% Magnesium Alloy." Adv. Cryo. Eng., 24:519-528, 1978.

The fatigue crack growth rates and the fracture toughness of the Russian alloy AMg6 were determined at cryogenic temperatures. The results indicate that the alloy should be very useful in LNG applications.

MciNaughton, D. J. and Berkowitz, C. M., "Overview of U.S. Research Activities in the Dispersion of Dense Gases." Symposium Schwere Gase (Heavy Gas), Battelle-Institute, Frankfurt, F6 R, September 3-4, 1979.

This paper presents an overview of U.S. research in heavy gases particularly LNG. Topics include mathematical modeling, experiments, and facility controls available to decrease gas release or increase gas cloud dilution. Recommendations on further research are included. 
McQuaid, J. Dispersion of Heavier-than-Air Gases in the Atmosphere: Review of Research and Progress Report on HSE Activities. Health and Safety Laboraiories, Technical Paper 8, ISBN $0717600297,1979$.

The Chemical Defence Establishment (Porton Down) has executed a program of trials on sudden releases of heavier-than-air gases. The recent report presents the justification for the form of the trials chosen and describes the way in which account was taken of existing information on the behavior of dense gas clouds. The program of trials and the conclusions that can immediately be drawn from them are summarized and the need for further work is reviewed.

Meckelburg, E. "Use of Nickel Steels in Cryogenics." (in German), Schiff u. Hafen. $30(10): 926-929,1978$.

An overview is given on the practical use of $9 \% \mathrm{Ni}$ steels, austentic stainless steels, 36\% Ni-FE-alloy and 5-6\% Ni-Mo-steels in building storage tanks for liquefied gaseous fuel tankers. The material parameters due to strength, fatigue, thermal expansion, fire protection and weldability are described. German and U.S.-notations for materials are compared.

Heinen, E., "LiNG Storage in Prestressed Concrete Safety Walls - 1." 0 il and Tas Journal. May 14, 1979.

The concrete safety wall incorporated in the design of the Maasvlakte LNG plant in the Netherlands is described. The properties of steel and concrete at cryogenic temperatures are reviewed.

Meinen, E., "LNG Enclosure Design - 2." $0 i 1$ and Gas Journal. May 21, 1979.

The design, testing and construction steps for the retaining wall and the tank foundation of the Maasvlakte LNG plant are outlined. Analytical procedures and test results are described.

Mellor, G. L. and Yamada, T., "A Hierarchy of Turbulence Closure Models for Planetary Boundary Layers." Journal of the Atmospheric Sciences.

pp. 1791-1806, October 1974.

Turbulence models centered on hypotheses by Rotta and Kolmogoroff are complex. In the present paper, we consider systematic simplifications based on the observation that parameters governing the degree of anisotropy are small. Discussion is focused on density stratified flow due to temperature. 
Meroney, R. N., iNeff, D. E. and Cermak, J. E., "Wind Tunnel Modeling of LNG Spi11s." 1978 Operating Section Proceedings, American Gas Association, Montrea1, Quebec, May 1978.

The author's report scales of spill conditions that may be successfully simulated in Colorado State University wind tunnels. Simulations of 1974 AGA LNG land spill experiments and uses of wind tunnels in experimental design are also discussed.

Meyer-Detring, D., Berger, E., Butt, H. G., Finsterwalder, K. and Petersen, K. "Utilization of Marginal Gas Deposits with Significant NGL-Content by Natural Gas Liquefaction and Offshore Tanker Loading." (in German), Erdöl-Erdgas Zeitschrift. 97,314-320, 1981.

Offshore natural gas production by liquefaction on floating or fixed structures, followed by offshore loading and tanker transport, can be an economic alternative to conventional methods. The paper describes development and design of a natural gas liquefaction plant for the utilization of marginal gas deposits with significant NGLcontent.

LNG plant, drilling and production facilities, accommodation, intermediate storage tanks for LNG and natural gasoline and the LNG/NGL loading system are located on two fixed platforms connected by a steel bridge.

The design is related to a specific marginal North sea field in 50-m water depth, but principal design characteristics can be modified to suit different gas compositions or different geographical areas.

Meyer, H. "The $125800 \mathrm{~m}^{3}$ LNG/LPG Tank Ship of HDW - Desian and Construction Problems and Their Solution." (in German), Hansa. 113 (18):1481-1485, 1976.

The most important problems arising during the construction of spherical tanks of the Moss-Rosenberg Type with diameters of $36.5 \mathrm{~m}$ and the experiences made are discussed from the viewpoint of the shipyard's project management.

Miller, B., "Possibilities in Hydrate Storage of ivatural Gas." Gas Age. 97:37-40, May 1942 .

The formation of methane and LNG hydrates was reviewed. Data concerning hydrate storage, properties and decomposition pressures were discussed. Refrigeration and heat requirements for hydrate storage and regeneration were also presented. 
Miller, H. "Transfer Installation for LNG with Safety Shut-off Valve." (in German), Chemie-Techn. $7(1): 23-24,1978$.

The paper describes an electrohydraulic system for a rapid disconnection in the LNG transfer line in the case of destruction by strong movements of the ship in rough sea during discharge. Both ends of the line are connected via shut-off valves.

Miller, R. C. and Hiza, M. J., "Experimental Molar Volumes for Some LNG-Related Saturated Liquid llixtures." Fluid Phase Equilibria. 2:49-57, 1978.

Saturated (orthobaric) liquid molar volumes are reported for some methane-rich mixtures containing ethane, propane, isobutane, normal butane and nitrogen at temperatures between 100 and $115 \mathrm{~K}$. These lata were obtained with a gas-expansion system calibrated against pure methane orthobaric liquid molar volumes. Comparisons are shown between the experimental molar volumes and the results of some recent calculational methods.

MITRE Corp., A Summary of Accidents Related to Non-Nuclear Energy. EPA 600/9-77-012, PB-271506, 1977.

This report is an executive summary of a more extensive EPA study on accidents, in non-nuclear energy. LNG accidents are covered rather briefly, since only a few accidents have occurred in this category.

Miyahara, S. "Power Generation from Cryogenic Energy." Section II, Paper 8, Sixth International Conference on Liquefied Natural Gas, 1980.

The effective utilization of LNG cold becomes important in Japan because of the large amounts of LNG to be imported in the future. The technical problems to commercialize the various porjects in the use of LNG cold are reviewed.

Modak, A. T., "Thermal Radiation From Pool Fires." Paper presented at Western States Section, The Combustion Institute Meeting, La Jolla, CA, October 18-20, 1976 .

This analysis computes: radiative energy fluxes to surfaces located external to the fire in any arbitrary orientation; variations of radiative heat flux along the fuel surface; total radiative heat transfer from flames to fuel surface; forward radiative heat transfer from fire to virgin fuel bed external to the fire; angular distribution of radiative flux emitted by the pool fire; total radiative power output of the fire. 
Hoen, I. 0. and J. H. S. Lee. "Research on Vapor Cloud Explosions and telated Phenomena in Canada." From Discussion on Explosion Hazards at the 7 th International Colloquium on Gas Dynamics of Explosions and Reactive Systems, ed. H. Wagner, pp. 25-33, Max-Planck-Institute Für Strömungsforschung, Göttingen, 1979.

In Canada, there is increasing interest in the field of vapor cloud explosions and related phenomena, and various government and industrial bodies are engaged in conducting studies for safety aspects of regulations. Atomic Energy of Canada, Ltd. is involved in a 5-year investigation into the combustion properties of hydrogen-air-steam under confinement conditions particularly regarding pressure transient. At MCGill University, research is focused on the influence of turbulence, obstacles, mixture inhomogeneities and confinement on combustion processes in vapor clouds. At the University of Calgary, the fire-spread characteristics through nonhomogeneities formed under the combined effect of diffusion and buoyancy are being studied.

Moen, I.0. et a1. "Pressure Develonment Due to Turbulent Flame Propagation in Large Scale Methane/Air Explosions." Combustion \& Flame 47:31-52.

The results of large-scale methane/air explosion tests performed at Raufoss, Norway are described and discussed. Due to obstacles in the path of the flame, surprisingly large overpressures were generated. High flame speed acceleration due to intense turbulent mixing is held responsible for these overpressures.

More1, J. P. "Control of Tiahtness (Leak Tests) of Containers for Liquefied Gas." (in French), Gaz d'aujourd'hui. p. 492, 1976.

The procedures to ensure the tightness of containers for liquefied gas during marine transport are described (use of tracer substances).

Mori, H., Y. Miyata, iN. Akagawa, Y. Sato, "Technical Improvements in LIJG Vaporizers for Receiving Terminals in Japan." Presented at LNG 6 - International Conference on LNG, Kyoto, Japan, Apri1 7-10, 1980.

This paper considers the following areas related to Open Rack Vaporizers (ORV) and Submerged Combustion Vaporizers (SCV):

- Fundamental Heat Transfer Phenomena

- Improvements (ORV) or Developments (SCV)

- Operation and Maintenance

- Corrosion Protection and Durability

This paper provides background information on these two types of vaporizers and points out areas relating to release prevention. 
Morkramer, F. "Modern Installations for Industrial Gas Works." (in German), Gas Aktue11. 13:25-43, 1977.

An overview is given on technical possibilities and installations for storage, handling and supply of liquefied gaseous fuels, like natural gas. Technical data, constructive details and practical examples are added.

i?ontoya-Lirola, C., "Manufacture of Gels, Especially Liquid Fuels, and Their Subsequent Reversible Liquefaction." Chem. Abstrac. 76:27001g, Span. 362, 146 (to Gelsa S. A.), 1970.

LNG could be gelled by generating a mixture of 20 percent water containing $2.5 \%$ of a vegetable albuminoid, saponin or viscous resinous gum with $80 \%$ LNG.

Morrow, T. B., Bass R. L. and Lock J. A. "An LPG Pipeline Break Flow Mode1." Paper presented at the "Pipeline Supervisory and Control Systems Workshop, ASME Petroleum Div., 1982.

The influence of the spacing of pipeline isolation valves and of the shutdown reaction time are investigated regarding the flammable cloud which could result from a break in a liquefied propane pipeline. The analytical results are based on various models of two-phase flow and vaporization.

Morton, B. R., "Modeling Fire Plumes." Paper presented at the Tenth International Symposium on Combustion, Cambridge, UK, August 17-21, 1964.

Theoretical treatments for turbulent diffusion flames and for the strongly heated regions of fire plumes in a still environment may be based on those developed for weakly buoyant plumes. A discussion is given of some of the modifications that are needed, and the effects of large variations in density on the plume dynamics are aspects of heat transfer by radiation are presented separately.

Morton, I. P. and Roman 0. S. "Film Flow Effects in LNG." Cryogenics. 20: $463-466,1980$.

A vigorous surface film flow can occur at the internal walls of an LNG container above the liquid level. This is explained as a surface tension driven phenomenon, induced by temperature gradients in the walls. The effect can contribute to the stratification of LNG under conditions of long-term storage. 
Mousset, P., LeDiraison, J. and Foltier, C. "Experiments Relating to LNG Fires: Radiation Measurements and Extinguishing Techniques." (in French), Congrés Association Technique de L'industrie du Gaz, pp. 1-24, 1975.

The paper reports on Gaz de France's work on the question of safety in plants involving the use of liquefied natural gas. Described are preventive measures for averting accidental LNG spilling and the emergency intervention techniques for preventing LNG ignition or for getting the fire under control and protecting the surrounding plant. These measures were developed on the basis of experiments on largearea fires.

Mousset, P. et al. "Experiments on LNG Fires: Radiation Measurements and Techniques of Extinction." (in French), Gaz d'aujourd-hui, p. 389, 1975.

Results of 15 years of experiments are given, chemical foams showed up unfit. Good results were achieved with physical foams expanding 250 to 1000 times (air emulsified in water containing a tenside).

Mueller, K. "Peakshaving with Groningen-Natural Gas." (in German), Linde Ber. Techn. Wiss. 39:31-35, 1976.

This report shows calculational methods for the design of LNG storage tanks used for peakshaving. Additional problems occur with natural gas from Groningen. Its boiling point is shifted about $90^{\circ} \mathrm{K}$ to lower mperature according to its relatively high nitrogen content. The solution to this problem is discussed with the examples of the liquefaction plants of NEDERLANDSE GASUNIE and DISTRIGAZ in Belgium.

Mullen, F. et a1., Thermal Radiation and Overpressures from Instantaneous LNG Release into the Atmosphere - Phase II. TRW Systems Group Report No. 08072-9, to A.G.A., A.G.A. Catalog ìlo. H60015, May 1969.

This report considers the fluid mechanics and thermochemistry of thermal radiation; boil-off, LNG vapor/air mixture dispersion experiments, and blast of overpressure; dike design; and a discussion of the flame program and vapor cloud studies. 
Miiller, H.-W. Dispersion and Ignition of Hydrocarbon Vapour Clouds. Status Report (in German), Deutsche Gesellschaft für Mineralölwissenschaft und Kohlechemie e.V. (DGMK)- Project 248, 1981.

This DGMK-Research Report describes the actual knowledge about dispersion and ignition of hydrocarbon vapor clouds.

The time depending concentration contours - i.e., the boundary of upper resp. lower flammability limits of the ignitable cloud have been described by more than 20 dispersion models. Which of these different models gives the best description of reality cannot definitely be stated, because presently comperative calculations have only been executed for a selection of partly obsolete dispersion models. Results deviate the order of magnitude of $1: 33$. Where as model calculations for stratified atmospheric cloud spreading (flue gas flumes) are giving satisfactory results, the conditions of propagation, mixing and interchange for heavy gas clouds are more complex and mathematical treatment is much more difficult.

The kinetics of ignition of gas mixtures are very complex. Therefore, model descriptions existing at present are only qualitative and comparative statements. After ignition one has to distinguish between deflagrations (flame velocity smaller than velocity of sound) and detonations (flame velocity higher than velocity of sound). Magnitude and effects of the pressure wave, which propagate ahead of the flame front, differ correspondingly. According to the present knowledge it has to be assumed that unconfined hydrocarbon clouds do not detonate but deflagrate under the normal conditions of a weak ignition. Only a part of the cloud volume takes part in the reaction; this portion being 10-30\% of the total cloud volume, depending on the mode of release.

According to various authors' statements the efficiency of $1 \mathrm{~kg}$ hydrocarbon-air-mixture within the ignition limits corresponds to 1 kg TNT.

Hulthauf, L. G., Frank, A. M. and Koopman, R. P., Remote Measurement of LNG Vapor Dispersion Using LIDAR. UCID-17968-79-1, pp. 15-22 Lawrence Livermore Laboratory, 1979.

This is essentially an abbreviated version of Lawrence Livermore Laboratory report UCID-18237.

Multhauf, L. G., Frank, A. M. and Koopman, R. P., Remote Sensing for Diagnosing Vapor Dispersion in Spills of Liquid Energy Fuels. UCID-18237, Lawrence Livermore Laboratory, 1979.

A laser ranging (LIDAR) technique is described for measurement of gas concentrations in vapor clouds emanating from LNG spills. Results of a feasibility test at China take are discussed. 
Munson, R. and Clifton, R. A., "Natural Gas Storage with Zeolites."

PB Report iNo. 203892. U.S. National Technical Information Service, 1971.

Zeolites were used as an adsorbent for methane. For instance, Calcium $A$ zeolite would retain up to 5 weight percent methane at $72^{\circ} \mathrm{F}$ and $200 \mathrm{psia}$. The potential of zeolites for vehicular natural gas storage was discussed.

Murata, T. and Nakanishi, E., "How Osaka Gas Uses the Cold from LNG." Pipeline and Gas Journal 121(3):23-38, 1980.

Osaka gas will effectively use the cold available in LNG for power recovery, ammonia synthesis, desalination, air separation, food freezing and storage, cryogenic crushing and related operations. Regasification at Osaka will amount to about 6.3 million tons LNG annually.

Murgai, M. P., "Radiative Transfer Effects in Natural Convection Above Fires." Journal of Fluid Mechanics. 12(3):441-448, ilarch 1962.

This paper describes the results of examining the influence of radiative heat transfer on turbulent natural convection above fires in an atmosphere of constant potential temperature, under both the 'opaque' and 'transparent' approximations. It turns out that on the basis of the overall approximations introduced in this investigation, the former case reduces to that of no radiative transfer.

Murgai, M. P. and Emmons, H. W., "Natural Convection Above Fires." Journal of Fluid Mechanics. 8:611-624, 1960.

The turbulent natural convection above fires in a dry calm atmosphere with a constant lapse rate has been the subject of several recent investigations. The present paper presents solution curves from which the natural convection may be computed over a fire of arbitrary size in an atmosphere with arbitrary lapse-rate variation.

Murray, F. W., Atmospheric Dispersion of Vaporized Liquefied ilatural Gas. Rand Corp. Rpt. P5360, AD/A010940, 1975.

A sophisticated mathematical model for the dispersion of LNG clouds is proposed. However, no details on the equations and on their numerical treatment are given. 
Murray, F. W., Jaquette, D. L. and King, W. S. Hazards Associated with the Importation of Liquefied Natural Gas. Rand Corp., NTIS No. AD/A037928, June 1970.

Four previous reports by Rand Corporation are summarized and updated in this most recent publication, which discloses probable cause of accidental spills of LNG, the hazards surrounding these spills, and methods of estimating the probabilities of major accidents. In assessing the risks associated with LNG transport and processing, it is concluded that not enough evidence has been collected to comment on the safety of $L N G$ or the ability to extrapolate from past experience.

Miuscari, C. C., The Evolution of Liquid Natural Gas on Water. M. S. Thesis, MIT, 1974.

Governing equations are given for the simultaneous spread and evaporation (burning) of an LNG spill on water. Equation solutions determine the 1) maximum radial extent of the spil1, 2) time duration of complete dissipation of spill volume, 3) graphics of spill volume versus time, evaporation rate versus time and spill thickness versus distance (from origin of spill).

Muska, V. A. Liquefaction of a Vapor Utilizing Refrigeration of LiVG. U.S. Patent 3,962,881, assigned to: Airco, Inc., 1976.

The cold contained in LNG is utilized to condense another gas, such as $\mathrm{CO}_{2}$. The methods and equipment used for this purpose are the object of the patent claim.

Nakagawa, A., "Japanese LNG Receiving Terminal is Reliable." 0 il and Gas Journal. pp. 174-182, January 28, 1980.

The design, operation, and maintenance characteristics of the Sodegaura Terminal are described. The computer control system and the preventive maintenance operations are outlined.

Nakanishi, E. and Reid, R. C., "Liquid Natural Gas-Water Reactions." Chemical Engineering Progress. 67:36-41, December 1971.

This paper cites previous studies and discusses both quantitative and qualitative experimental results. Consideration is given to water on cryogens, underwater release of cryogens, cryogens on ice, cryogen spills on water and on coated liquids. Finally, a tentative hypothesis is presented for the explosion phenomena. 
National Fire Protection Association. Standard for the Production, Storage, and Handling of Liquefied Natural Gas. NFPA No. 59A - 1979. National Fire Codes, Vol. 5, 1980.

An especially established committee on LNG has formulated a standard for the production, storage, and handling of LNG. This code is primarily intended for the day-to-day operation of LNG facilities. Only general rules for fighting LNG fires are given.

ileary, R. M., "Safety in LNG Semi-Trailer Design." Paper presented to the AGA Transmission Conference, Las Vegas, Nevada, May 3, 1976.

Included in this paper is a description of LNG semi-trailers and the various DOT regulations regarding them. Also included is a discussion of and a picture of an LNG trailer that was exposed to a fire as a result of an accident.

Nelson, W., "A New Theory to Explain Physical Explosions." Combustion. 44, May 1973.

This paper summarizes some known facts about explosions, with emphasis on physical explosions, describes a new explosion mechanism, and suggests current and future applications of the new theory to prevent smelt-water explosions in kraft chemical recovery furnaces.

ilelson, W. L., "What is Cost of Cryogenic Gas Processing Plants?" $0 i 1$ and Gas Journal 77:96-97, June 18, 1979.

The costs of various cryogenic gas processing plants are compared. It is found that LNG baseload and LNG peak-sharing plants are the most expensive when based on Equal capacity.

Neugebauer, A. Wilckens, H. and Backhaus, H. "Floating LPG Production and Storage System - The Missing Link in the Chain Necessary for the Use of Natural Gas." (in German), Hansa. 113 (11) 971-974, 1976.

The components of a floating liquefaction plant are described. Process technique (compression, processing, separation, and fractionating), problems of ship technology (anchorage, staff rooms, gas storage, transfer system), and the economy with respect to different gas prizes are discussed.

Newel1, R. G., "Station Coordination Critical in LNG Pipeline Efficiency." 0i1 and Gas J. 77(18):239-244, 1979.

Pumping and cooling stations along an LNG pipeline must be designed for unattended operation and must use only LNG as the source of energy. Technology for such pipeline operation is proven. The paper presents guidelines for the overall design of an LNG pipeline. 
ilicholls, J. A., Sichel, M., Gabrijel, Z., Oza, R. D. and Vandermolen, R., "Detonability of Unconfined Natural Gas-Air Clouds," Proc. 17th Symp. on Combustion, The Combustion Institute, pp. 1223-1234, 1978.

It is experimentally and analytically investigated under what conditions a methane/oxygen mixture with various amounts of nitrogen diluent can be detonated. The results confirm the presently held opinion that natural gas clouds mixed with air will almost never detonate. However, there is not yet absolute certainty about this conclusion.

Nielson, H. J. and Tao, L. N., "The Fire Plume Above a Large Free-Burning Fire." Paper presented at the Tenth International Symposium on Combustion, Cambridge, U.K., August 17-21, 1964.

A model which describes the variation with altitude of the composition, temperature, and velocity of the gases within a plume above a large free-burning fire is presented. This model is an extension of previous analysis of buoyant plumes which includes the effects of combustion, composition variation, and radiation losses from the hot gases.

Niepenberg, H. P., Oppenberg, R. and Rick, F. "The Use of Liquefied Gaseous Fuels in Industrial Plants - Part I, II." (in German), Part I: Industriefeuerung. 13:74-78, 1978; Part II: Industriefeuerung. 14:16-19, 1979

The most important rules and regulations are reported which are relevant for industrial plants using liquefied gaseous fuels. Various technical needs and concepts are discussed regarding storage tanks, pipes and connections, valves and fuel engineering.

Nierman, A. J., "Transportation of Natural Gas as a Hydrate." U.S. Patent $3,975,167$ (to Chevron Research Co.), U.S. Patent Office, 1976.

Transportation of LNG hydrate by submarine was described. This procedure required supplementary refrigeration, a hold or void in which natural gas can be hydrated, and a membrane pervious to gas and water within the hold. Provisions were suggested for in situ removal of hydrate heat of formation.

Wikodem, H. J., D. Flothmann, W. Geiger, B. Oberbacher, G. Schnatz, and W. Schneider. Risk Assessment Study for the Harbor of Gothenburg. Prepared for the Swedish Energy Commission by the Battelle-Institute e.v. Frankfurt BF-R-63.371-1, 1978.

An assessment was made of the risk to the general public which arises from transport, storage and refining of crude oil and petroleum products. A large contribution to the overall risk, in particular cases with large numbers of fatalities per event, results from LPG operations. 
Wikodem, H. J., Flothmann, D., Geiger, W., Schnatz, G. and Schneider, W., "Risk Assessment Study for an Assumed LNG Terminal in the Lysekil Area." prepared for the Swedish Energy Commission by the Battelle-Institute E.V. Frankfurt BR-R-31.109-1, 1978.

This report presents a risk assessment for a proposed LNG terminal and distribution system in Sweden using state-of-the-art dispersion and gravity/spread models. Risks included direct contact with LNG, suffocation, radiation and pressure wave destruction.

Nikodem, H. J. "Risk Analysis for Storage and Transport of LNG." (in English), S. Hartwig (ed.), Heavy Gas and Risk Assessment, 177-184, Battelle-Institut e.V., Frankfurt am Main, Germany, 1980.

The paper describes the most important results and the applied models used in a risk analysis of a Swedish LNG-terminal. Both types of risks, the risk of the society and the individual risk are estimated. A strong influence of topography to the risk is apparent.

Nuclear Regulatory Commission, "Safety Evaluation by the Office of Nuclear Reactor Regulation Regarding the Proximity of Cove Point LNG Facility: Baltimore Gas and Electric Company Calvery Cliffs iNuclear Power Plant Units Nos. 1 and 2." Docket ilos. 50-317 and 50-318, March 13, 1978.

An analysis is described which shows the effects of various hypothetical LNG accidents at Cove Point on the Calvert Cliffs Power Plant. Results indicated that no new operating restrictions or other limitations needed to be placed on the plant to assure normal operations.

Odishariya, G. E., et al., "Technical and Economic Aspects of Integrating LNG Pipelines and Cryogenic Electric Power Transmission Lines." In: Problems of ilodern Cryogenics. NASA TT-F-16, 841, 1976.

It is proposed to use coaxial pipelines for the simultaneous transmission of electric power and of LNG over long distances (Siberia to European USSR). The electric power would be carried by superconducting metals (along the inner channels), cooled by liquid helium, which is derived from the LNG. The latter is carried through an outer channel of the concentric piping.

Office of Technology Assessment, Transportation of Liquefied Natural Gas. Congress of United States, Washington, DC.

A review of LNG transportation technology provided as support for Congress on Future Energy Legislation. The LNG import system is criticized; public concerns are summarized; and laws, permit requirements and pending legislation are examined. 
Office of Technology Assessment. Alternative Energy Futures; Part I. LNG Imports. OTA-E-110, 1980.

The economic and energy implications of future LNG imports into the U.S. are evaluated for the next two decades. It is expected that these imports will have doubled by 1995.

"Offshore LNG Terminal Deemed Feasible." Marine Equipment News. pp. 6-7, Spring 1977.

This article discusses the potential of offshore receiving terminals and describes several generic types that could be used. There are currently no offshore terminals in operation or construction, however, due to onshore siting difficulties they are being given serious attention.

Ohsaka, K. et al., Membrane Structure in a Liquefied Gas Storage Tank. U.S. Patent 4,149,652, 1979 .

An improved structural design for LNG storage tanks is described. It minimizes thermal strains and practically eliminates potential sources of leaks that were present in earlier designs. Required labor for installing the new tanks is also greatly reduced.

Oiern, P. J. and K. H. Osmundsvaag. Vessel Comprising a Hull for Transporting

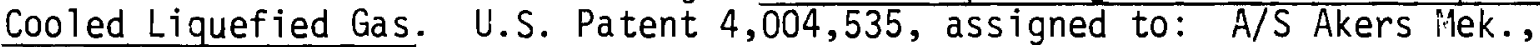
1977.

New design features for LNG tankers are proposed which allow better utilization of the maximum permissible dead weight of the ship. It is implied that oil and LNG are transported by the same vessel.

Okamoto, T. et al. Tank Supporting Structure for Ships. U.S. Patent 4,000,711, assigned to: Hitachi Ltd., 1977.

Repetitive loading and unloading LNG causes temperature cycles in the storage vessel, which then causes fatigue to the tank and its support members. The invention proposes ways to minimize the stresses in the support structure by providing chocks around the tanks which engage corresponding chocks tied to the ship's hull.

Okumura, T. "Recommended Practice for LNG Inground Storage." Session II, Paper 10, Sixth International Conference on Liquefied Natural Gas, 1980.

This is the first technical and safety standard manual for LNG concrete and membrane type inground storage tanks. It contains results from freezing and seismic tests, as well as field safety surveys of LNG terminals throughout the world. 
O'Neal, W. C. 500-m $\mathrm{m}^{3}$ Spill Test Facility for Liquefied Gaseous Fuels. Lawrence UCID-19154, Livermore National Laboratory, 1981.

Preliminary plans are outlined for a large LGF test facility at Frenchman Flats, Nevada. The anticipated tests would include spilling on land and water, evaporation, dispersion, burning and explosion of the various types of fuels.

Ong, H. L. "Current Status of California LNG Regulations." LNG Terminals and jafety Symposium, pp. 281-286, in Applications of Cryogenic Technology 9,

Scholium International, Flushing, New York, 1979.

The main aspects of the proposed safety standards for LNG facilities in California are briefly discussed. According to the Liquefied Natural Gas Terminal Act of 1977, the California Public Utilities Commission has the exclusive power to issue building permits for LNG terminals.

Ooms, G., Mathieu, A. D., Zelis, F. "The Plume Path of Vent Gases Heavier than Air." First International Loss Prevention Symposium, 1974, 211-219.

The plume path theory developed at Koninlijke/Shell-Laboratorium, Amsterdam (KSLA) for predicting the dispersion of stack gases having a density equal to or lower than that of the surrounding air was checked on its validity for gases heavier than air.

Opschoor, G., "Investigations into the Spreading and Evaporation of LNG Spilled on Hater." Cryogenics. 17:629-633, 1977.

Analytical expressions for the spreading of LNG spills on open and confined areas of water have been derived. They agree with known available experimental data.

Opschoor, G. "The Spreading and Evaporation of LNG- and Burning LNG-Spills on Water." $\mathrm{J}$. of Hazardous Materials, 3:249-266, 1980.

This paper contains the results of a theoretical investigation into the evaporation and spilling of $L N G$ and the burning of LNG on open water and on a confined water surface.

Opschoor, G. "Investigations into the Evaporation of Liquefied Gases Spreading on Land." Cryogenics. 21:281-286, 1981.

Based on a semiempirical model, the evaporation of spilled liquefied gases from $d r y$ and wet land is predicted. Also, described analytically is the spreading of a spill on a flat surface. 
Oran, E. S., Boris J. 0., Young T., Flanigan M., Burks T., and Picone $M$. "Numerical Simulations of Detonations in Hydrogen-Air and Methane-Air Mixtures." Proc. 18th Symp. (Internat.) on Combustion, pp. 1641-1649, 1981.

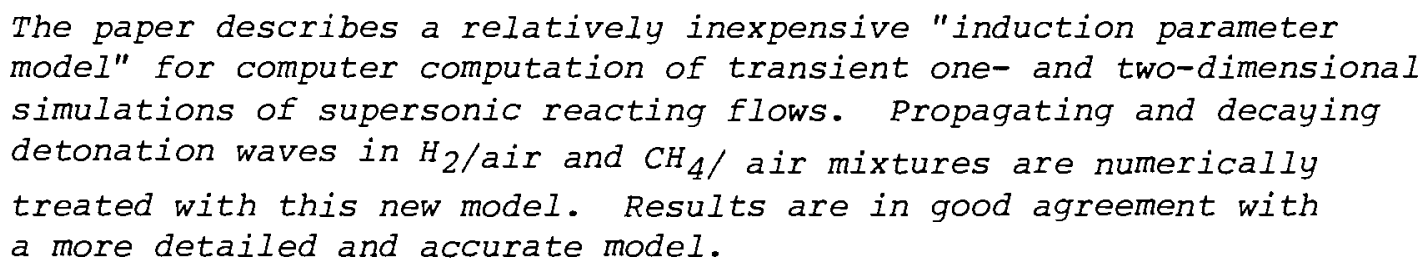

Ordin, Paul M., Bibliography on Liquefied Natural Gas (LNG) Safety. IASA Technical Hemorandum, IVASA TM X-73408, Apri1 1976.

This bibliography contains citations concerned with the safety of LNG and liquid methane. The raw data for this report was a computer printout based on a keyword search strategy of descriptions in the cryogenic safety data bank dealing with LNG.

O'Rourke, P.J. and F. Bracco, "Two Scaling Transformations for the Numerical Computation of iultidimensional Unsteady Laminar Flames." Journal of Computational Physics. 3(2), ilovember 1979.

The authors of this paper address the problem of flame propagation in a multi-dimensional system. Problems involving sonic propagation and small flame thickness are solved by means of a transformation. An actual simulation of combustion of methane in a chemical bomb are presented.

Osipov, S.N. "Correlation Analys is of the Effect of the Molecular Structure of a Fuel on the Lower Limits of Explosiveness of Vapor-Gas-Air Mixtures." (in Russian), Khim. Prom. 1:23-26, 1976.

The existence of a very strong correlation between the lower limit of explosiveness of a vapor-gas-air mixture and the composition of hydrocarbon compounds is demonstrated. For all homologous series a correlation with a correlation ratio of 0.98 and arrms deviation of 0.035 is established. For most known derivatives of hydrocarbons a correlation with a correlation ratio of 0.83 is established. The governing parameters are the number of carbon and hydrogen atoms in the molecule, the presence of higher bonds between the carbon atoms, and the number of radicals in the compound. 
Otterman, B., "Analysis of Large LNG Spi11s on Water - Part 1: Liquid Spread and Evaporation." Cryogenics. 15(8):445-460, August 1975.

The first part of this two-part review considers the theoretical and experimental results obtained on liquid spread and evaporation of large LNG spills on water. Both instantaneous spills, in which the spill time is much smaller than the time for complete vaporization, and continuous spills are considered. Also, applications of the correlations are discussed.

Sverly, J. R. and Overholsen, K. A., "Calculation of Minimum Ignition Energy and Time Dependent Luminar Flame Profiles." Combustion and Flame. 31:60-83, 1978.

The authors simplify the calculational method of spalding by use of a transformation of variable. The authors employ this technique to calculate ignition energy and flame propagation.

Oyez Intelligence Report. An Analysis of the Canvey Report. ISBN 0851204651 , 1980.

An independent study was carried out on the Canvey Report (1.5.38). Several criticisms of their conclusions were made in the report. Including the use of a Gaussian model for dispersion of $L N G$.

Oyez Intelligence Report. The Bulk Storage and Handling of Flammable Gases and Liquids. ISBN $0851204597,1980$.

This report includes papers presented at a recent oyez conference dealing with bulk storage and handling of flammable gases and liquids.

Oyez Intelligence Report. The Carriage of Hazardous Goods Overland. ISBN $085120399 x, 1980$.

The conference was concerned with increased hazards due to increased shipment of hazardous goods. Discussions were presented on the economic factors as well as the technological aspects of designing equipment for use in shipping these goods.

Panofsky, H. A., "The Atmospheric Boundary Layer Below 150 Meters." Annual Review of Fluid Mechanics. 6:147-177, 1974.

The article considers profiles and fluxes over homogeneous terrain (surface layers, extension to the tower layer) and profiles over changing terrain (wind profiles, temperature characteristics, energy budgets, horizontal velocity components, temperature and humidity spectra, cospectra, and boundary layer models). 
Pantin, C. "Exploration and Desian for Underground Storaqe of Liquefied Pressurized Gas." (in French), Gaz d'aujourd-hui p. 317, 1981.

Storage of LPG in cavities mined in salt or rock is compared with respect to different user demands (salt cavities being easily enlarged, rock cavities can hardly be modified). The construction of additional rock cavities can influence the level of the groundwater table, thus the hydrostatic pressure can be changed and result in LPG losses in cavities which were tight before.

Pantin, C. "Underground Storage of Liquefied Pressurized Gas in Mined Cavities." (in French), Gaz d'aujourd'hui. p. 293, 1981.

Techniques for the underground storage of liquefied propane and butane in rocks are discussed, especially problems arising from the fact that sufficient hydrostatic pressure of the groundwater must be available taking into account that groundwater is flowing into the cavity from the bottom.

Papp, J. F., Lazzara C. P., and Biordi J. C. Effects of CF2Brz on Composition, Net Reaction Rates, and Rate Coefficients. Report RI-8551, Bureau of Mines, 1981 .

Chemical flame inhibitors act by interfering with the normal chemical reaction paths of flame propagation. By using molecular beam mass spectrometry, this report tries to find the characteristic molecular actions of Halon 1202, when compared with the more commonly used Halon 1301.

Pappas, J. A. and D. M. Solberg. Unconfined Vapor Cloud Explosions: A Prestudy. Veritas Report No. 79-0615, 1979.

A thorough review of the current knowledge on vapor cloud explosions is given. Special emphasis is placed on problems of understanding phenomena caused by non-ideal features of vapor clouds. Suggestions for further research are presented.

Parent, J. D., "The Storage of Natural Gas as Hydrate." Institute of Gas Technology Bulletin iNo. 1. 1948.

A very thorough review of the technical literature was presented. This included phase diagrams, heats of reaction, equilibrium ratios, cooling requirements, and operating pressures. 
Parker, R. 0., "Calculating Thermal Radiation Hazards in Large Fires." Fire Technology. 10(2):147-152, 1974.

The author has developed, and discusses here, a method for assessing the thermal radiation hazards to objects from fires. A comparison of the calculations to an actual fire experience seems to indicate that the method is reasonably accurate, though somewhat conservative.

Parker, R. 0., "Study of Downwind Vapor Travel From LNG Spills." Paper presented at the American Gas Association Distribution Conference, May 1970.

The problem can be treated as a heat transfer calculation at the earth-liquid interface yielding the input; a second heat transfer problem if there is no wind, or if there is wind, an atmospheric dispersion problem. The conclusion is that it is very unlikely that vapor concentrations of more than $1 / 2$ the lower flammable limit will exist 600 or more feet downwind of the lee dike.

Parker, R. 0. and Spata, J. K., "Downwind Travel of Vapor From Large Pools of Cryogenic Liquids." Paper presented at LNG-1 Conference, Chicago, IL, 1968.

A method is developed for calculating vapor concentrations downwind of large pools of cryogenic liquids. Vapor concentrations at any downwind position is found as a function of time, wind speed, and wind structure. Lateral and vertical dispersion coefficients are determined using meteorological observations. Practical applications include hazard studies and air pollution estimates.

Parnarouskis, M. C., C. D. Lind, P.K. Raj and J. H. Cece. Vapor Cloud Explosion Study, Paper 12, Session III, 6th International Conference on LNG, 1980.

A major multifaceted test program has been conducted in an attempt to quantify the potential hazards resulting from the accidental spill of liquefied, flammable gases. Data has been collected on pool formation, vapor concentration, flame radiation, and detonability of LNG, LPG, and gasoline.

Parrish, W. R., Arvidson, J. M. and LaBrecque, J. F., "Evaluation of LING Sampling Measurement Systems for Custody Transfer." 1978 Operating Section Proceedings, American Gas Association, Montreal, Quebec, May 1978.

A method for sampling moving LNG streams for composition and heating value is described. The main component of the technique and the main source of error is a gas chromatograph. 
Parrish, W. R., Arvidson, J. M. and LaBrecque, J. F., "System is Accurate, Precise for LNG Sampling." Hydrocarbon Processing. April 1978.

A three component system including a sampling probe, vaporizer, and gas analyzer is described which can be used to monitor heating value from moving streams of LNG. Detection error is derived mainly from error in the gas analyzer.

Parrish, W. R., Brennen, J. A. and Siegwarth, J. D., "LNG Custody Transfer Research at the National Bureau of Standards." 1978 Operating Section Proceedings, American Gas Association, Montreal, Quebec, May 1978.

This paper presents a summary of research on determining the thermophysical properties of LNG components, on flowmeters, and on LNG sampling and composition measurements.

Pasman, H. S., Groethuizen, Th. M., DeGooijer, H. "Design of Pressure Relief Vents." First International Loss Prevention Symposium, 1974, 185-189.

A numerical method for the calculation of the vent opening area required to relieve explosive pressure is given.

Parry J. and Grain C. "Solid State Dectors for Methane and Organic Vapors." Proceedings of Current Research on Methane Detection and Measurement Symposium, pp. 199-219, Environment Safety and Distribution Division, Gas Research Institute, Chicago, Illinois.

Solid-state devices have been used for the detection of organic vapors and gas. These devices are based upon a change in the electrical characteristics of an inorganic semiconductor material. This paper gives a brief description of the operating mechanisms, experimental results and advantages and limitations of these devices.

Patankar, S. V. and Spalding, D. B., Heat and Mass Transfer in Boundary Layers. International Textbook Company, Ltd., 2nd edition, London, U.K., 1970.

The authors of this text describe a computational technique for solving the time dependent conservation equations (mass, momentum, energy and species) needed to describe flame propagation in onedimensional planar, cylindrical or spherical geometry.

Peebles, M. W. H. "WorId LNG Trade: Current Status and Prospects for Growth." Session I, Paper 8, Sixth International Conference on Liquefied Natural Gas, 1980.

This paper reviews the progress that the international LNG industry has achieved to date. Discussion is concentrated on the prospects for growth in LNG supplies in the United States, Western Europe, and Japan through to 1990 . 
Pelloux-Gervais, P. and Sermanet, G., "Liquid Natural Gas Service Station for Vehicles." Paper No. A3.13 presented at the 14 th International Congress of Refrigeration, Moscow, (in French), September 20-29, 1975.

L'Air Liquide's completely automated LNG service station for fueling vehicles quickly and safely is described.

Pelto, P. J., Baker, E. G. and Ha11, R. J., "Assessment of LNG Release Prevention and Contro1." DOE-EV 0046, Department of Energy, Washington, D.C., Vo1. 2, pp. 471-480, 1979.

The early results of a program of finding ways to minimize the frequency of occurrence and the size of a potential LNG release are described. Three systems are discussed: release prevention, release detection, and release control.

Pergament, H. S. and Fishburne, E. S., "Influence of Buoyancy on Turbulent Hydrogen/Air Diffusion Flames." Paper presented at the Central States Section Combustion Institute Meeting on Fluid Mechanics of Combustion Processes, Cleveland, $\mathrm{OH}$, March 29-30, 1977.

The results show that: flame properties scale with nondimensional distance for Froude numbers ( $F r$ ) greater than about $10^{6}$; buoyancy affects temperature decay rates downstream of the location of maximum temperature (after all the $\mathrm{H}_{2}$ has burned); the predicted influence of $F r$ on buoyant flame lengths is consistent with the available data.

Petsinger, R. E. and Vance, R. W., LNG Terminals and Safety Symposium Applications of Cryogenic Technology Volume 9, 1979.

The proceedings of the LNG Terminals and Safety Symposium held October 12-13, 1978, in San Diego, CA, are provided. Session topics include: LNG Export Terminals, LNG Import Terminals, and LNG Research and Safety.

Petrash, D. A., Barber, J. R., Chambellan, R., and Englund, D. R., "Gelled Liquid liethane." NASA Spec. Pub1. NASA SP-5103, Se1. Techno1. Gas Ind. pp. 86-88, 1975 .

Results of work toward use of LNG as fuel for supersonic aircraft was reported. The problem of "boiloff" due to decrease of pressure with altitude was eliminated by preparing LNG gels with water or methanol. ING-methanol gel was recommended due to the total heat of combustion. 
Pfoertner, H., "Ignition Behavior of Natural-Gas/Air Mixtures in Free Clouds." Gas-Wasserfach, Gas/Erdas. 120(1):19-24, 1979 (in German). (For transiation see Lawrence Livermore Laboratory UCRL-TRANS-11478.)

Based on combustion analysis it is concluded that only deflagrations and no detonations would occur when a natural-gas/air cloud is ignited. This conclusion is backed up by a series of tests.

Pförtner, H. "Gas Cloud Explosions and Resulting Blast Effects." (in Enqlish), Nuclear Engin. Design. 41:59-67, 1977.

The design of nuclear power plant structures to resist blast effects due to chemical explosions requires the determination of load-time functions of possible blast waves.

Results of experimental investigations are discussed in detail, which show that in a free cloud with deflagrative ignition (flame, heated wire, sparks) the occurrence of a gas detonation can practically be excluded. Apparently, free gas clouds can only be induced to detonate by a sufficiently strong detonative initiation. Independently of the initiating event in the practice of damage analysis, it has become customary to describe the consequences of an explosion by means of the so-called TNT equivalent. Therefore, it is attempted to specify this equivalent for hydrocarbons by means of energetic considerations including the propagation functions for the case of spherically symmetric detonations. Analogous to the safety distance required in the handling and storage of high explosives, a mass-distance relation of the form $R=k(L)^{1 / 3}$ could be considered where $L$ is the mass of spontaneously released hydrocarbon and $k$ varies only with the structural shape of the blast loaded buildings.

Phillips, H. "Research on Vapor Cloud Explosions in the U.K." From Discussion on Explosion Hazards at the 7th International Colloquium on Gas Dynamics of Explosions and Reactive Systems, ed. H. Wagner. pp. 69-70, Max-Planck-Institute Für Strömungsforschung, Göttingen, 1979.

The UK attitude to research into vapor cloud explosions is inspired by their experience at Flixborough and the desire to prevent further disastrous explosions. To this end the Health and Safety Executive continuously reviews current knowledge and engage in developing procedures that will identify plants that are subject to risk and to advise legislators how to avoid the risk. The data they draw on is derived largely from the accumulated experience of accidents in chemical plant in UK and elsewhere.

Philipson, L. L. "The Reliability of LNG Systems." Energy Sources 5:13-29, 1980.

A qualitative evaluation of the reliability of the entire LNG supply chain has been provided. Even though the reliability has been high so far, a certain degree of redundancy in the LNG systems is recommended. 
Picciotti, M., "Why an LPG 0lefins Plant?" Hydrocarb. Process, 59(4):223-228, 1930.

In order to ensure a steady supply of olefins, the possibility of cracking LPGs and/or naphtha in existing ethylene plants has been considered. Some modifications in the chemical plans would be required, however, to make such processes economical.

Picknett, R. G. "Field Experiments on the Behaviour of Dense Clouds." Report PTN/TL 1154/78/1, Chemical Defense Establishment, Porton Down, Wilts., Contract report to the Health and Safety Executive, Sheffield, 1978.

This report gives information about the field experiments on the behavior of dense clouds, which were performed on request from the Health and Safety Executive. The report contains a review of the results, a discussion of the observed behavior of the dense clouds, and a theoretical model of aispersion. The distinctive features of dense gas dispersion are presented and predictions are made concerning larger scale releases of dense gas.

Pierrat, J. "Ultrasonic Fl ow Measurement for Liquefied Gases." (in German), Gas U. Wasserfach-Gas/Erdgas 118(8):342-344, 1977.

The measuring method is based on the effect that the sound velocity in $a$ flowing medium differs with the direction. A flow meter is described which uses this method to measure the volume of a liquid in the range $2-30 \mathrm{~m}^{3} /$ hour with $+1.5 \%$ accuracy.

Pipkin, 0. A. and Sliepcevich, C. M., "Effect of Wind on Buoyant Diffusion Flames." Industrial and Engineering Chemistry Fundamentals. 3:147-154, 1964.

Buoyant diffusion flames of natural gas were observed in wind tunnel experiments to determine the extent of bending by wind. A flame drag coefficient, $C_{f}$, is introduced in the flame momentum balance. A single straight-line correlation of In $C_{f}(R e)$ versus In $R e$ is obtained after extracting the influence of flame angle of tilt and applying an empirical correction to account for increasing flame roughness at larger diameters.

Ploum and Arnold, J. W., "The Brunei Liquefied Natural Gas Plant." LNG 5 International Conference on Liquefied Natural Gas, Duesseldorf, Germany, August 29-September 1, 1977.

This paper reviews and highlights some of the design concepts and operating experiences gained particularly from the liquefaction plant at Brunei. 
Pluta, P. J. and Williams, R. G. "U.S. Coast Guard LNG Requlations." Applications of Cryogenic Technology. 9:293-323, 1979.

An overview is given of the coast Guard marine safety functions as they pertain to the transportation of LNG across the seas and in port facilities. The implementation of international (IMCO) codes by the coast Guard is discussed in detail.

Pluta, P. J. and R. G. Williams. "U.S. Coast Guard LNG Regulations." pp. 243-323, in Applications of Cryogenic Technology 9, Scholium International, Flushing, New York, 1979.

U.S. Coast Guard's efforts consist mainly in implementing codes developed by the Intergovernmental Maritime Consultive Organization (IMCO). These codes relate primarily to cargo containment and safety systems of LNG tankers. LNG terminals are regulated in the U.S. by the Coast Guard and also by DOE and the Materials Transportation Board of DOT.

Poittier, M. and Dussaud, M. "Meteoroloqical Problems During the Supervision of Storages in Salt Caverns." (in French), Gaz d'aujourd'hui. D. 392, 1975.

Methods to calculate the free volume of gas caverns under different pressure and temperature conditions with a certitude up to $6-8 \%$ are described.

Pol1, J. "Versuche zur Verdampfung von ausgelaufenem Flüssiggas." (Experiments on Livg Vaporization from Pools.) Gas- und Wasserfach 116, 263-265, 1975.

Practical devices and experimental procedures are described. The results are discussed and presented in graphical and tabular form. The tests showed that the spontaneous evaporation of LNG is by orders of magnitude smaller than mentioned previously.

Porricelli, J. D., Keith, V. E. and Paramore, B., Recommended Qualifications of Liquefied Natural Gas Cargo Personnel, Volumes I, II and III. NTIS No. AD/A026109, AD/A026110, Apri] 1976.

The report presents recommendations, based on task analysis, concerning training and other qualification requirements appropriate for personnel of liquefied natural gas (LNG) ships and barges.

The study was a pilot effort to demonstrate a method of determining qualifications for new technology ship occupations when there are few or no operating examples to study. 
Porter, G. and Higgins, K., "Liquefied ilatural Gas: An Energy Alternative." Dimensions/NBS 63(9):14-18, 1979.

Presently, there are no internationally agreed-upon standards for measuring the quantity and quality of LNG contained in a tanker. The ultimate goal of the NBS LNG thermophysical properties program is, therefore, to reduce the total uncertainty in LNG measurements from the current estimates of from $5 \%$ to $7 \%$ to a much more tolerable $1 \%$ potential error per shipment.

Porteous, W. M. and Blander, M., "Limits of Superheat and Explosive Boiling of Light Hydrocarbons, Ha locarbons, and Hydrocarbon Mixtures." AIChE Journal. 21:560-566, May 1975.

Thirteen light hydrocarbons and 4 light halocarbons were tested to determine their limits of superheat at one atmosphere pressure using a superheating column. Even with some variation in temperature to which a compound could be superheated before boiling explosively, the reduced limits $T_{L} / T_{C}$ were always close to 0.88 . Super heat limits of binary hydrocarbon systems and tertiary mixtures were close to mole fraction averages of the limits of the pure compounds.

Porteous, W. M. and Reid, R. C., "Light Hydrocarbon Vapor Explosions." Chemical Engineering Progress. 73:83-89, May 1976.

This article includes information relating to spills on water of propane, propylene, isobutane, binary mixtures containing ethane, pure alkanes and pure alkenes. Some explosive compositions and ranges for hydrocarbon spills are also given. Previous studies are cited and factors affecting violence of explosions are discussed.

Poten \& Partners, Inc. Liquefied Gas Ship Safety, Analysis of the Record. 1964-1979, Poten \& Partners, Inc., New York, 1980.

The analysis reveals that the safety record for LNG tankers has been superior. Of the total of 7 incidents only one resulted in a minor LNG spill. No fire ensued.

Poten \& Partners, Inc. "Liquefied Gas Ship Safety." Analysis of the Record 1964-1981. New York, 1982.

The latest edition of the yearly report on marine transportation of liquefied gases confirms again the exemplary safety record of this industry. As in earlier years, there were no cargo spills. Five potentially serious incidents during 1981 did not involve the cargo. 
Pozzolini, P.-F et al. "Welded Profiles Made of Low Temperature Steels." (in French), Bu11. Techn. Bur. Veritas. 60(10):255-258, 1978.

For the transportation of LPG $\left(-50^{\circ} \mathrm{C}\right)$ and LNG $\left(-163^{\circ} \mathrm{C}\right)$ on sea, special problems of material load behavior of tank walls are important. A report is given of low temperature special steels and the welding of profiles.

Pozzolini, F. "Cryogenic Steels in Ship-Building." (in French), Bull. Tech. du Bur. Veritas. 63(2):55-61, 1981.

A report is given of the material parameters of various special steels used in building ships for the transportation of LNG. Different alternatives are discussed with respect to the economical effect, like the use of a carbon-mangan-steel with $0.5 \%$ nickel.

Prew, L. R. "LNG Ship Cargo Systems--Some Design and Operating Considerations." Trans. I. Mar. Eng. 88:92-107, 1976.

Safety aspects of the shipping phase of the Shell Brunai/Japan LNG scheme are discussed. Practical operating experience is presented and suggestions for further improving tanker designs and operations are made.

Price, J. P. et al. Environmental Impacts of Energy Transportation: Liquefied Natura1 Gas. EPRI-EA-2039, Section 4, Electric Power Research Institute, 1981.

A wide ranging summary has been given on potential environmental problems of LNG transport and storage. Since the paper is concise and rather brief, it can serve as an introduction to the subject matter.

Priestley, C. H. B. and Taylor, R. J., "On the Assessment of Surface Heat Flux and Evaporation Using Large-Scale Parameters." Monthly Weather Review. 100(2):81-92, February 1972 .

Data from a number of saturated land sites and open water sites in the absence of advection suggest a widely applicable formula for the relationship between sensible and latent heat fluxes.

Putnam, A. A., "A Model Study of Wind-Blown Free-Burning Fires." Paper presented at the 10th Symposium on Combustion, The Combustion Institute, 1965.

Specifically, the dimensionless flame height varied with the negative 1/4-power of the Froude number based on cross-wind velocity and undisturbed flame height, above a Froude number of 0.2. The horizontal extension of the flame, on the other hand, increased rapidly with increasing cross wind at first, and then less rapidly with the 1/6-power of the Froude number. 
Putnam, A. A., "Area Fire Considered as a Perimeter-Line Fire." Combustion and Flame. 7:306-307, 1963.

The hypothesis that line fires and area fires are basically related was tested by examining available data on sources in a line and in a hexagonal pattern. A mathematical analysis is given to justify the hypothesis.

Putnam, A. A. and Grinberg, I. i., "Axial Temperature Variation in a Turbulent, Buoyancy-Controlled, Diffusion Fiame." Combustion and Flame. $9(4): 419-420$, 1965.

An analytical expression was formulated which correlated the temperature profile of a turbulent diffusion, buoyancy-controlled flame to fuel properties and flow conditions. The expression is valid in the region after combustion is completed, and is valid at higher temperature levels than previously used correlations which are accommodated as a limiting case.

Putnam, A. A. and Speich, C. F., "A Model Study of the Interaction of Multiple Turbulent Diffusion Flames." Paper presented at the 9th International Symposium on Combustion, 1963.

This research program has shown that a valid model for studies of mass fires can be produced using multiple jets of gaseous fuels. The basic requirement is that the fuel jets produce turbulent diffusion flames which are buoyancy controlled. A specific operating range where this requirement is met was found for this model.

Radiative Transfer in Fiultidimensional Systems of Non-Gray Molecular Gases Effects on Combustion. Columbia University. A.G.A. Project on LNG Fire Study. (See LNG 1976 Annual Report).

An analytical technique has been developed to treat band radiation from non-gray molecular gases. The technique has been simplified so that the frequency integrations can be performed with simple quadrature formulae. The simplified technique is being applied to multidimensional radiative transfer problems as well as problems involving combustion.

Raj, P. K., "A Criterion for Classifying Accidental Liquid Spills into Instantaneous and Continuous Types." Comb. Sci. \& Techn. 19:251-254, 1979.

A dimensionless critical time is suggested, which could serve to divide LNG spills into "instantaneous" and "continuous" types. 
Raj, P. and Atallah, S., "Thermal Radiation from LNG Spill Fires." Advances in Cryogenic Engineering.

The authors of this paper present results of experimental measurements made in LNG fires which were 6,20 and $80 \mathrm{ft}$ in diameter. Correlations are given for the wind induced plane tilt angle and length to diameter ratio of the flame. Also measured are the radiative absorption coefficient, radiative flux at a distance from the plume and the fraction of energy which leaves the fire as thermal radiation.

Raj, P. and Emmons, H. W., "Burning of a Large Flammable Vapor Cloud." Paper presented at the Central States Section, Combustion Institute ileeting, San Antonio, Texas, April 21-22, 1975.

A theoretical analysis is presented to estimate the ground level width of a two-dimensional turbulent flame as a function of time for the burning of a large combustible vapor cloud in the atmosphere for a given turbulent flame speed. The base width of the flame is assumed to be controlled by the rate at which the vapor is fed into the combustion zone and the air entrainment rate.

Raj, P. and Kalelkar, A. S., Assessment Models in Support of the Hazard Assessment Handbook. A report by Arthur D. Little, Inc., to the Department of Transportation, U.S. Coast Guard, Report ilumbers CG-D-65-74. NTIS No. AD/776617, January 1974.

Analytical models are derived to describe the hazards caused by the accidental release of chemicals into the atmosphere or spills onto water. The models encompass a variety of physical phenomena that can occur such as dispersion of vapor in the atmosphere, dispersion of liquid in water, spreading on water, burning of a liquid pool, etc. Analyses include the modeling of the phenomenon and solution to equations.

Raj, P. and Kalelkar, A. S., "Fire Hazard Presented by a Spreading, Burning Pool of Liquefied Natural Gas on Water." Paper presented at the Western States Section, Combustion Institute Meeting, 1973.

A time-growth rate for an LNG spill on water is obtained and the fire duration, determined by complete evaporation time, is established. An effective flame height is established and the radiation field about the flame calculated. Based on thermal radiation flux and fire duration, safe separation distances from the LNG pool fire for people and combustible materials (wood) are determined. 
Raj, P. K. "Models for Cryogenic Liquid Spill Behavior on Land and Water." J of Hazardous Materials $\underline{5}: 11-130,1981$.

Evaluation of the potential hazards rising from the accident spills of cryogenic liquids on land and water requires calculation of their spread extent and rate of vaporization. Expression for the radius of spread, evaporation rate and volume of liquid remaining at any time are developed. Types of spills modeled include instantaneous and continuous types. Spills on land are modeled with first order decreasing heat transfer rate with time and spills on water are analyzed based on constant heat flux.

Kairsde11, J. V., Jr. and Hinds, W. T., "Concentration Fluctuations and Peakto-ilean Concentration Ratios in Plumes From a Ground-Level Continuous Point Source." Atmospheric Environment. ㄴ:483-495, 1971.

Diffusion data were collected by 63 incremental samplers during four short duration, continuous releases of $85 \mathrm{Kr}$. Cumulative frequency distributions and the intensity of short-term concentrations are shown to be a function of the relative crosswind position within the mean plume. Peak-to-mean concentration ratios are shown as a function of relative crosswind position within the plume and the ratio of the durations of the mean and peak.

Rasbach, D. J., Rogowski, A. W. and Stark, G. W. V., "Properties of Fires of Liquids." Fuel. 35:94-107, 1956.

Alcohol, petrol, benzole and kerosene fires, burning freely in a vessel of $30 \mathrm{~cm}$ dia, have been studied. Measurements were made on the temperature, rate of burning and change in composition of the liquid, and on the dimensions, upward velocity, temperature and emissivity of the flames. It was estimated that with hydrocarbon liquid fires, heat transfer to the surface was mainly by radiation, but for the alcohol fire mainly by conduction.

Rausch, A. A. and Levine, A. D., "Rapid Phase Transformations Caused by Thermodynamic Instability in Cryogens." Cryogenics. 13:224-229, Apri1 1973.

Thermodynamic metastability and incipient stability are used to explain the cause of rapid phase transformations. When liquid cryogen comes into sudden contact with a warmer host liquid, it is heated and forms a thin layer of metastable, superheated liquid at the interface. A heat transfer and thermodynamic model is used to predict the host liquid temperature that will cause a shockwave for a given cryogen. 
Raynor, G. S., llichae1, P., Brown, R. M. and SethuRaman, S., "A Research Program on Atmospheric Diffusion from an Oceanic Site." BllL 18924 presented at the Symposium on Atmospheric Diffusion and Air Pollution, Santa Barbara, CA, September 9-13, 1974.

Analyses of meteorological data collected in this program show that wind profiles measured on the beach are representative of those over the ocean during onshore flows. Data obtained from tracer releases show that diffusion over the sea differs appreciably from that over land at the same time and is largely determined by the air-water temperature difference.

Raynor, G. S., litichael, P., Brown, R. M. and SethuRaman, S., Studies of Atmospheric Diffusion From a ilear-Shore Oceanic Site. BNL 18997, Brookhaven National Laboratory, June 1974.

Preliminary results show that diffusion is governed primarily by water and air temperature differences. With colder water, low-level air is very stable and diffusion minimal but water warmer than the air induces vigorous diffusion.

Raynor, G. S., R. M. Brown and S. SethuRaman. 1978. "A Comparison of Diffusion from a Small Island and an Undisturbed Ocean Site." Journal of Applied Meteorology. 17(2).

Comparison of oil fog plumes from a small island $(\sim 800 \mathrm{~m} \times$ $175 \mathrm{~m})$ with a plume from a ship showed increased widths ( 1.5 to 4 times) and decreased centerline concentrations (1/2) with those from the boat's plume.

Reid, R. C., "Possible Mechanism for Pressurized-Liquid Tank Explosions or BLEVE's." Science. 203:1263-1265, 1979.

The hypothesis is made that rapid depressurization of hot saturated liquids may result in an explosion. Such a situation could arise, e.g., if a tank filled with liquefied propane would be engulfed in a fire due to some accident.

Reid, R. C., "Superheated Liquids." American Scientist. 64(2):146-156, March Apri1 1976.

The article cites numerous studies concerning superheated liquids and indicates that significant evidence suggests that superheated liquids are a trigger leading to the extensive arrangementation that may well set off large vapor explosions. 
Reid, R. C. et al., Flameless Vapor Explosions. American Gas Association, Catalog ilo. l.120177, 1977.

Flameless vapor explosions are discussed for a wide variety of substances, including LNG. Theoretical explanations are based on the superheat limit temperature.

Reid, R. C. and Smith, K. A., "Behavior of LPG on Water." Hydrocarbon Processing. pp. 117-121, April 1978.

Boiling of LPG is described as initially but very briefly violent followed by quilt evaporation. Boiling rates are not sensitive to changes in composition.

Reid, R. C. and Smith, K. A., Boil-Off Rate of Liquid Nitrogen and Liquid Hethane on Insulated Concrete. Interim Report from MIT LiNG Research Center to A.G.A., December 1975.

Experiments were conducted to measure the boil-off rate of both liquid nitrogen and liquid methane on insulation concrete. Results are fragmentary but do allow approximations of the rate of vapor generation that could result from spills of cryogens on typical insulating concretes.

Reid, R. C. and Wang, R., "The Boiling Rates of LNG on Typical Dike Floor llaterials. Cryogenics. 13(3):401-404, 1973.

The insulating qualities for various types of floor materials for LNG dike storage compounds have been determined in LiVG boiling tests. Their numerical values are tabulated.

Reid, R. C., L. M. Shanes and P. S. Virk. LNG Gels: Structure, Rheology, and Production Energy Requirements. GRI-77/0012, Gas Research Institute, 1979.

Twice as much energy was required for the production of gelled LNG over normal LNG. Additional tests are suggested to reduce the high energy costs.

Reid, R. C., L. S. Wilkens and P. S. Virk. "Liquefied Natural Gas Gels," Cryogenics 20:567-570, 1980.

Laboratory methods are described to gell LNG with water or methanol. Even though static yield stress of the LNG can be increased easily, the flow viscosity is much less affected. Safety benefits are not yet discernible, especially if the cost of gelling is taken into account. 
Reid, R. C. Boiling of LNG on Typical LNG Dike Floor Materials. GRI-79/ 0026. Prepared for Gas Research Institute by LNG Research Center, Massaciusetts Institute of Technology, Cambridge, Massachusetts, 1980.
Boiling rates of LNG and Iiquid methane were measured for various substrates which are or could be used as dike floor materials. These rates were cor- related with theoretical heat transfer models to allow interpolation and extrapolation. Two very effective insulations were identified: Grace zonolite insulating concrete and corrugated metal plates. The former has very low density, is quite strong, and has a low thermal conductivity. The latter is inexpensive, easily placed into position and leads to quite low boiling rates. Also shown was the fact that $L N G$ vaporizing on a solid surface is in vapor-liquid equilibrium and, therefore, standard thermo- dynamic correlations may be used to estimate the composition of the evolved cloud.

Reid, R. C., Smith, K.A. and Virk P. S. LNG Storage: Safety Analysis. Gas Research Institute Report 79/0045, January 1980.

A brief progress report is given on four LNG safety research projects at MIT. They involve rapid phase transition and rollover phenomena, spreading characteristics of $L N G$ on water, and $L N G$ boiloff response to pressure variations.

Reid, R. C., Smith K. A. and Virk P. S. LNG Storage: Safety Analysis Annual Report for January-December 1980. Gas Research Institute Report 80/0032, February 1981.

This progress report for 1980 discusses the LNG safety projects conducted at MIT. The three areas discussed include: 1) theoretical models of heat and mass transfer between layers of different density; 2) transient response of boil-off rate to changes in ambient pressure in LNG tanks; and 3) an experimental setup to measure simultaneous boiling and spreading of $L N G$ from a tank spill.

Reisler, R. E., Ethridge, N. H., LeFevre, D. P. and Giglio-Tos, L., Air Blast Measurements From the Detonation of an Explosive Gas Contained in a Hemispherical Balloon (Operation Distant Plain, Event 2a). BaTlistic Research. Laboratories, BRL MR 2108, AD/73216, U.S. Army Aberdeen Research and Development Center, Aberdeen Proving Ground, Maryland, July 1971.

Air blast was measured from the detonation of a mixture of oxygen and propane equivalent to 20 tons of TNT in a hemispherical balloon anchored to the ground surface. Comparisons made of overpressure waveshape and impulse as a function of shock overpressure show an equivalent yield of 20 tons or larger and a dynamic pressure impulse about 60 percent larger than for a corresponding 20 ton TNT charge. 
Reker, F. "Transportation and Storage of LNG on Sea." (in German), Aluminium. $\underline{53}(2): 120-126,1977$.

An overview is given of the worldwide use of aluminum in LNG-ship building. The development of the material, improvements in welding techniques and the construction of cubic and spherical tanks are reported.

Rhoads, R. E. and Johnson, J. F., "Risk in Transporting Haterials for Various Energy Industries." Nuclear Safety. 19(2):135-149, March-Apri1 1978.

A risk assessment model is presented to assess the comparative safety of various energy systems in relation to other natural or man-related risks. Examples from assessments using the analysis technique are also presented along with future assessment plans. This paper encourages risk sensitivity studies and risk comparisons to provide a basis for decisions.

Ricou, F. P. and Spalding, D. B., "Measurements of Entrainment by Axisymmetrical Turbulent Jets." Journal of Fluid Mechanics. 11:21-32, 1961.

Measurements have allowed the deduction of an entrainment law relating mass flow rate, jet momentum, axial distance, and air density. When the injected gas burns in the jet the entrainment rate is up to $30 \%$ lower than when it does not.

Riedl, R. G., "Consumers' Gas LNG Satellite Firms Ottawa Valley Gas Supply." Pipeline \& Gas J. 206(13):30-36, 1979.

New LNG peakshaving satellite plant, supplied from Montreal LNG peakshaving/ liguefaction plant, is ideally located in middle of service area and has proven itself in both emergenices and for peakshaving service.

Rigard, J. and Vadot, L., "Evaluate LNG's Storage Hazards." Hydrocarb. Process. pp. 267-268, Ju1y 1979.

It is shown that experimental water modeling, based on Neyrtrec's water analog technique, can be a useful aid to planning protection of LNG tankage. 
Rischbieter, F. "Extended Analys is of Gas Explosion Accidents with Special Consideration of Deflagrative Events." (in English), Paper No. J 10/7 presented at SMIRT 6; Paris, August 1981.

In the first part of this paper, a comparison is made of the reaction of a window-pane, which is one of the most common objects in damage analysis, to pressure-time histories typical for a detonation and a deflagration. In the second part, some aspects of the damage pattern of the accident at the Nypro plant at Flixborough, UK, are reviewed. It has been concluded that the most probable model for the Flixborough accident is a forced deflagration with a flame speed in the near subsonic range.

Rivard, W. C., Farmer, 0. A. and Butler, T. D., RICE: A Computer Program for Multicomponent Chemically Reactive Flows at All Speeds. LA-5812, March 1975.

Is computer code capable of solving the thermal-hydrodynamics of chemically reactive flows is presented. A strong point of the code is that it is not limited by sonic propagation constraints.

Rohrer, F. "New Explosimeter 'Gasotrans." (in German, French), Techn. Mitt. PTT. $55(2): 71-84,1977$.

With the introduction of natural gas in Switzerland the danger of gas accumulation in underground cable systems has increased considerably. As a result, the telephone regions have had to be supplied with a new explosimeter, whose technical data and operating principle are described. Attention is drawn to some points that should be observed when using the instrument in the field.

Rosak, J., Skarka, J. "Methods for Estimation of the Effects of Accidental Releases of Liquefied Gases." Third International Loss Prevention Symposium, $1980,15 / 1173-15 / 1182$.

The paper deals with the method for estimating the effects of accidental release of inflammable substances. The estimation is based on two models. The first one is the statistical model for the dispersion of exhalations, the second one is for an abrupt release of large amounts of the substance kept under pressure in an equipment.

Rosenberg, S. D. and Vander Wal1, E. M., "Gelled Cryogenic Liquids and Method of Making Same." U.S. Patent 4,011,730 (to Aerojet-General Corp.), 1977.

LNG or methane hydrates were prepared by introducing finely divided solid water or methanol into the cryogenic liquid. Less than 2 weight percent decreased the solubility of nitrogen in LNG to nearly zero at $-280^{\circ} \mathrm{F}$. 
Rudnicki, M. I. et a1. Study of Gelled LIVG. DOE/EV/02057-T2, 1980, Department of Energy, Washington, D. C.

Characteristics of gelled LNG have been determined in an experimental program. Static yield stress is increased significantly, but apparent viscosity only slightly. Boil-off rates are reduced.

Rudnicki, M. I. et a1. Study of Gelled LNG. TIC-11452, U.S. Department of Energy, Washington D.C., 1981.

This report gives a final account on attempts by a research team at Aerojet to gel LNG by water.

Russ, R. M., Detection of Atmospheric Methane Using a 2-Wavelength $H_{e}{ }^{N}$ Laser System. Masters Thesis, Mass. Institute of Tech., June 1978.

The report describes the design of a system to reliably measure concentrations of methane in air of 0.1 to $100 \%$ which may arise in LNG spill tests. Discussions of design requirements, alternatives, and model and laboratory test results are presented.

Santman, L. D., "The Department of Transportation's Role in LNG Safety Regulations." 1978 Operating Section Proceedings, American Gas Association, Montrea1, Quebec, ilay 1978.

DOT authority over LNG safety is derived from the ports and waterways safety ACt of 1972 and the natural gas pipeline safety Act of 1968. Proposed regulatory action on HR. 11622 is discussed.

Sapko, M. J. et al. Quenching Methane-Air Ignitions with Water Sprays. U.S. Bureau of Mines Report RI-8315, 1977.

Experiments at the Bureau of Mines have shown that it is possible to prevent methane/air mixtures from igniting by dispersing a fine water spray within the vapor cloud. It appears that such a method could be applicable for controlling LNG vapor clouds.

Sarkes, L. A., Iribe, P. C. and Smith, R. B., "LING: Current Status Confirms Its Technical Maturity." Pipeline and Gas Journal. November 1978.

The history and current developments in the LNG industry are summarized. Some of the safety concerns and safety related research are discussed. 
Sarsten, J. A., "LNG Stratification and Rollover." Paper presented at the API Division of Refining, Philadelphia, PA, May 17, 1973.

This report covers an incident where LNG was stratified in an LNG storage tank during filling and how that stratification subsequently resulted in a rollover of the tank contents and the release of a large quantity of gas. A repetition will be positively prevented by the installation of a jet mixing nozzle that will thoroughly mix offloaded cargo with different composition initial tank heels.

Schaalenkamp, M., Votapek, E., Schwander, R., Fanfan, A., and Nortz, J.M. "Technical Meeting: LNG-Liquefied Natural Gas - Present and Future Importance for Switzerland." (in German), Gas Wasser Abwasser. 61 (10):295-309, 1981.

The technical meeting was held during the opening of a tank plant for LNG in Le Locle, Switzerland. A report is given on the contributions to the following topics: liquefaction of natural gas, transportation of $L N G$ on sea, LNG-terminal, LNG-transportation on roads, isolation of storage tanks, and tendencies and trends in the economical use of LNG in Switzerland.

Schimmelpfennig, K. "Pipework Made of Low Temperature Brittleness Resistant Special Stee1." (in German), Sie und Wir. 3:14-15, 1978.

A description is given of the technical construction of pipeworks which are installed on natural gas liquefaction plants on platforms in the North sea. The technical is based on corrugated tubes made of X5 Cr Ni 189 for the inner and $\mathrm{X} 2 \mathrm{Cr} N \mathrm{i}$ Mo 1812 for the outer tube.

Schintgen, L. "LNG-Cold, An Unused Energy Potential." (in German), Brennst. Wärme Kraft. 32 (6):247-251, 1980.

The paper describes a process of using the refrigeration energy of LNG to produce electric power for an LNG-terminal with a high efficiency.

Schnatz, G.; Flothmann, D. "A ' $K$ '-model and its modification to the dispersion of Heavy Gases" (in English), S. Hartwig (ed.), Heavy Gas and Risk Assessment, 125-139, Battelle-Institut e.V., Frankfurt am Main, Germany, 1980.

Formulas for the modification of the wind and turbulence profiles are shown, which are based on the experimentally gained knowledge from hydrodynamics, meteorology and oceanography, and are transferable to the processes of heavy-gas dispersion. In connection with the entire area of heavy-gas dispersion, the following aspects are mentioned: change of the wind and turbulence profile, shearing of the vapor cloud, heavy-gas diffusion and dispersion as tracer. 
The present day knowledge in the experimental field of heavy-gas dispersion is outlined, and a microturbulent system of equation is introduced which is suitable for simulation of heavy-gas dispersion. The formulas for the modification of the wind and turbulence profile are applied to a simplified dispersion model, and the effect of this modification is discussed by an example.

Schneider, A. L., "Liquified ilatural Gas Safety Research." American Gas Association - Cryogenic Society of America, LNG Terminal and Safety Symposium, San Diego, 1973.

The paper summarizes experimental research programs for safety issues related to LNG transportation and storage.

Schneider, A. L. "Liquefied Natural Gas Safety Research Overview." LNG Terminals and Safety Symposium, pp. 195-271, in Applications of Cryogenic Technology 9, Scholium Internationa 1, Flushing, ilew York, 1979.

A very thorough and comprehensive review is given on LNG research, conducted over the last two decades. For this purpose the research projects are divided into three sections, those dealing with shore-side facilities, those with water transportation, and those independent of land and water.

Schneider, A. L., "LNG Research Overview." Proceedings of the Marine Safety Counci1, 36(3):52-54, 1979.

A condensed overview is given on U.S. Coast Guard sponsored safety projects connected with the marine transportation of LNG. The projects and their main results are listed briefly.

Schneider, A. L., Lind, C. D. and Parnarouskis, M. C., "U.S. Coast Guard Liquefied Natural Gas Research at China Lake," CG-M-03-80, 1980.

The paper presents an overview of the LNG safety research projects that have been sponsored by the U.S. Coast Guard over the last decade. Results of the various projects are briefly outlined.

Schneider, H. "Deflagration of Hydrocarbon/Air Mixtures." (in German), Proc. ICT-Jahrestagung. 455-478, 1979.

On behalf of the German Federal Ministry for Research and Technology and industry, ICT, among other activities, conducted some experimental studies on the deflagration of free, i.e., unconfined gas clouds consisting of hydrocarbon/air and hydrogen/air mixtures. These clouds were simulated by hemispherical plastic balloons with volumes between $0.7 \mathrm{~m}^{3}$ and $262 \mathrm{~m}^{3}$ put on the ground and filled with gas and ignited by means of wire explosions. The studies were mainly concerned with the determination of flame velocities and the shock waves generated during combustion. The paper reports on the experimental results and their interpretation by means of a simple model. 
Schraewer, R. "Design Criteria for Cyrogenic Pipeworks." (in German), Gas Aktue11. 18:3-8, 1979.

To optimize the design of cryogenic pipeworks for the transportation of undercooled cryogenic fluids one has to consider the frictional loss of the flowing liquid and the non-steady influence of isolation in addition to the steady heat flux. Physical models and computer programs are used to describe the non-steady behaviour of cryogenic pipelines (cool-down phase).

Schrödter, W. "Marine Transport and Transhinment of Large Amounts of Liauefied Gas under Safety Aspects." (in German), Hansa. (8):573, 1981; (9):673, 1981 ; and (10):772, 1981 .

Original paper not available at this time.

Schrödter, W. "Aspects of Safety Technoloqy in Ship Transport and Loading of Flammable Liquefied Gases." (in German), Paper presented at a meeting 'Standards of Chemical Safety Technology and their Practical Use' Okt. 1981, Report Bundesanstalt für Materialprüfung, January 1982.

The hazardous potential of LNG and LPG during transportation on ships, loading and unloading is discussed in this article. A brief description is given of the material behaviour after an accidental release and the resulting safety measures.

Schuller, M. R., Murphy, J. C. and Glasser, K. F., "LNG Storage Tanks for Metropolitan Areas." Paper presented at the 4th International LNG Conference, ATgiers, Algeria, June 24-27, 1974.

This article describes in some detail the special design features of the 290,000 BBL storage tank built for Consolidated Edison of New York by the Pittsburg Des Moines Steel Company. The special design features, including a 9\% $\mathrm{Ni}$ outer tank shell and a concrete berm wall around the outside of the tank, were used because of the heavily populated surrounding area and the proximity of the facility to LaGuardia Airport. 
Schulte, K. "The Gas Cloud Explosion Program on the PIL-Project." From Discussion on Explosion Hazards at the 7 th International Colloquium on Gas Dynamics of Explosions and Reactive Systems, ed. H. Wagner, pp. 60-68. MaxPlanck-Institute Für Strömungsforschung, Göttingen, 1979.

The situation under study involved the use of waste heat from a nuclear power plant in a coal gasification process. The close proximity of the two facilities and West Germany's Reactor Safety Guidelines dictate consideration of damage potential to the nuclear power plant from explosion of a gas cloud released from the gasification process. The main areas under study involve: 1) finding the pressure and pressure front shape of realistic gas explosions and 2) determining the behavior of typical structure's expected pressure loadings. The ultimate goal is to develop a representative pressure-time-function or a set of such functions that could be used as the basis for safe design criteria for coal gasification plants utilizing nuclear power plant waste heat.

Schultz, D. "Safety Considerations in Using LP-Gas Engine Fuel." LP-Gas Enqine Fuels. ASTM STP 525. American Society for Testing and Materials, pD. 125-134, 1973.

This paper provides recommendations for the safe use of LP-Gas as an engine fuel. These recommendations are based on the standards published in June 1972. This paper is intended to be a guide to the safe installation and use of LP-gas as an engine fuel. The items covered include: containers, valve and accessories, relief valves, vaporizers, piping, general safety precautions and safety experience.

Schwier, K. "Techniques of an LNG-Line with the Example of the German LNGImports." (in German), Gas U. Wasserfach-Gas/Erdgas. 121(10):468-474, 1980.

This article reports the technical installations which are necessary to transport LNG from the producing to the consuming country, like gas cleaning at the well hole, liquefaction plant at the harbor with additional purification and separation of condensates, tankers and tank constructions, materials, discharge terminal and storage tanks. As an example of such an LNG-line the supply of Germany from Algeria is described.

Science Applications, Inc., LiVG Terninal Risk Assessment Study for Los Angeles, California. SAI-75-614-LJ, for Hestern LIIG Terminal Company, Los Angeles, CA, 1975.

SAI analyzed the potential risk of a proposed LNG import terminal in Los Angeles Harbor. 
Seeger, P.G. "Heat Transfer Due to Radiation and Convection from Tank Fires as Basis for Fire Protection Measures," (in German), Gas u. Wasserfach Gas/Erdqas. 120 (1):25-30, 1979 .

This article discusses the relationships and material constants to calculate the heat transfer due to radiation and convection. In the case of natural gas fires, theoretical and experimental values of heat radiation are in good agreement. The convective heat flux is about $15-20 \%$ of the flux due to emitted radiation from the flame. Fire protection measures are discussed.

Sergeant, R. J. and Robinett, F. E., An Experimental Investigation of the Atmospheric Diffusion and Ignition of Boil Off Vapors Associated With a Spillage of Liquefied flatura1 Gas. TRW Systems Group Report No. 08072-7, to A.G.A., A.G.A. Catalog No. M19715, ilovember 14, 1968.

\begin{abstract}
Results of experimental spills of LNG into scaled earthen dikes are described. Emphasis of this phase of the program was directed toward qualitatively determining the path of the boil-off vapors, quantitatively measuring the gas/air mixture in the surrounding environment, and demonstrating the extent of the flammability with an ignition source. Correlation of the experimental data into empirical form is presented; radiation data were also obtained.
\end{abstract}

Seroka, S. and Bolan, R. J., "Safety Considerations in the Installation of an LNG Tank." Cryogenics and Industrial Gases. pp 22-27, September/October, 1970 .

Design codes and standards for LNG storage tanks are detailed. Diagrams showing instrumentation for a typical tank are included.

Shaheen, E. I. and Vora, M. K., "Worldwide LNG Survey Cites Existing, Planned Projects." 0il and Gas Journal. pp 59-71, June 20, 1977.

This article discusses the various types of LNG facilities and briefly describes several existing facilities. A list of all the LNG facilities worldwide is included.

Shaw, P. and Briscoe, F., Evaporation from Spil1s of Hazardous Liquids on Land and Water. SRD R-100, $197 \overline{8 .}$

Mathematical models for an analytical description of cryogenic liquid spills both on water and on land are being developed and evaluated. Numerical results are given. 
Shell International Research, "Transportation of Liquefied Natural Gas." Chem. Abstr. 66:97298b, iNeth. Appl. 6,506,843, 1966.

An aqueous isopentane emulsion was used as a recyclable thermal carrier for heating or cooling LNG. A solid phase, such as silicagel, was also suggested.

Shinn, J. H., Environmental Issues of the Proposed LNG Spill Tests at Frenchman Flat. UCID-19036, Lawrence Livermore National Laboratory, 1981.

Potential environmental concerns of the magnitude of the LNG tests at the Nevada nuclear test site are discussed. It is concluded that these concerns are only minor and should not prevent the test program to proceed.

Shultz, F. D., "Safety at an LNG Peakshaving Facility." Presented at the ASIIE Winter Heeting, ilew York, ilY, November 17-22, 1974.

Design and operation of the many safety related aspects of Long Island Lighting Company's Holbrook LNG plant is described. Such features include gas detectors, fire protection and vapor dispersion systems, and the emergency shutdown systems.

Sidjak, W., Arctic Pilot Project. Presented to the American Gas Association Transmission Conference, lilontrea1, Quebec, llay 8-10, 1978.

This paper describes a pilot study involving a barge-mounted liquefaction and storage facility in the Arctic. The pilot study is in support of the Arctic Islands LNG project (see above).

Siegwarth, J. D., Radio Frequency Liquid Level Gauging In Propane Tank Car Safety Tests - A FeasibiTity Study. iJBSIR 79-1660, National Bureau of Standards, 1979.

The report presents details of experiments to gauge liquid levels in tank cars using the change in resonant radio frequencies. Precision was tested and the method was recommended for routine tank car gauging. 
Siegwarth, J. D., Younglove B. A. and LaBreigue J. F., "An Evaluation of Commercial Densemeters for Use in LNG." NBS Technical Note \#697, 1977.

Three basic types of densemeters: the vibrating element type, the dielectric cell type, and the displacement type were evaluated for their practicality in measuring the densities in liquid methane and Iiquid methane plus other gas mixtures. Measurements were made over a density range from 400 to $480 \mathrm{~kg} / \mathrm{m}^{3}$, temperature range from $108 \mathrm{~K}$ to $130 \mathrm{~K}$ and pressure range from 1 to 3 bar. All instruments are suitable for low temperature density measurements on a fluid of known composition. Commercialization is hindered by lack of suitable calibration methods.

Siegworth, J. D. "Gage Installation Can Trim Level Measurements Errors Caused by LNG Tank Environments." 0il and Gas Journa1. 79:042-152, 1981.

The large temperature differentials encountered in LNG tank operation are the cause for substantial systematic errors in determining the true volume of LNG contained in such a tank. Calculated corrections are difficult to make. Two special measurement methods (a reference cable and a stilling well) are described which can significantly reduce the systematic errors.

Simanek, J. and Pick, P., "Hydrates of Natural Gas." Plyn. 53:167-9, June 1973.

Crystallographic data was presented concerning the unit cell and crystal dimensions. In natural gas, up to seven components can participate in mixed hydrate formation. Phase diagrams for several of the mixtures were shown.

Simmons, John A., Risk Assessment of Storage and Transport of Liquefied Natural Gas and LP-Gas. Science Applications, Inc., November 25, 1974.

A method for assessing the societal risk of transporting LPG and LNG is described. From an estimated 52 significant accidents per year with LPG tank trucks at the present truck-associated transportation rate of 20 billion gallons of LPG per year, a fatality rate of 1.2 per year is calculated. For the projected 1980 importation of 33 billion gallons by tanker ship, a fatality rate of 0.4 per year is calculated. 
Simplified Methods for Estimating Vapor Concentration and Dispersion Distances for Continuous LIIG Spills into Dikes with Flat or Sloping Floors. A. D. Little, Inc. for American Gas Association, AGA No. X50978, Apri1 1978.

The report describes a set of techniques which allow calculation of dispersion of LNG spilled on a flat or sloped dike floor. Calculations include leakage flow rate, LNG flash vaporization, LNG boiling and vapor overflow, and vapor dispersion.

Sindt, C. F. and Ludtke, P. R., "Characteristics of Slush and Boiling Methane and Methane lixtures." Proceedings of 13th Int. Congr. of the Int. Institute of Refrigeration. pp. 315-320, 1971.

Experiments were performed to determine the boiling behavior of methane and methane mixtures and also of the slush which is formed when vacuum pumping the ullage over the mixture.

Singer, I. A., "The Relationship Between Peak and Miean Concentrations." Journal of the Air Pollution Control Association. 11:336-341, July 1961.

A method of predicting average concentrations has been presented. It has been shown that the simplified normal bivariate distribution describing the average concentration pattern is composed of various short-term periodic distributions which may differ from it significantly. A descriptive, empirical method has been described.

Singer, I. A. and Smith, M. E., "Atmospheric Dispersion of Brookhaven ilational Laboratory." Air and Water Pollution - An International Journal. 10:125-135. 1966.

A variety of data relating to atmospheric dispersion has been obtained at the Brookhaven Laboratory site and its environs. Concentration measurements were made at distances ranging from $10 \mathrm{~m}$ to $60 \mathrm{~km}$. Dispersion patterns developed are discussed in detail and values of the parameters appropriate for various theoretical treatments are summarized.

Slade, D. H., "Atmospheric Dispersion Over Chesapeake Bay." Monthly Weather Review. pp 217-224, June 1962.

It was found that, after the air had traveled for about 7 miles over the water, its direction fluctuations were always less than they had been before reaching the water. The wind speed usually increased as the air crossed the water. The ratio of overland to overwater dispersive capacity varied from less than 5:1, for heating from below, to greater than 35:1 for cooling from below. 
Slagg, H. "Vapor Cloud Explosion Studies in the United States." From Discussion on Explosion Hazards at the 7th International Colloquium on Gas Dynamics of Explosion and Reactive Systems, ed. H. Wagner, pp. 111-113, MaxPlanck-Institute Für Strömungsforschung, Göttinger, 1979.

In the United States, several government agencies and other institutions are involved in programs that contibute to a basic understanding of unconfined explosions. Practical considerations associated with the accidental dispersion of energetic materials dictate the need for including the role of confinement in studies. Buildings, warehouses, ship's hulls, and associated pathways all present an opportunity for confinement to aid in acceleration of a deflagration that may eventually develop into a detonation. Major technical areas under study in the U.S.A include mechanisms that cause flame acceleration, initiation requirements, affect variations in fuel/air ratio, blast effects estimating, and blast scaling.

Slawson, P. R. and Csanady, G. T., "The Effect of Atmospheric Condition on Plume Rise." Journal of Fluid Mechanics. 47:33-49, 1971.

The buoyant rise of chimney plumes is discussed for relatively large distances from the source, where atmospheric turbulence is the dominant cause of mixing (rather than turbulence due to the plume's own upward motion). A simple theory is developed which shows a number of different shapes plumes can have under different atmospheric conditions (particularly in an unstable environment).

Sloan, E., Dendy, Khoury, F. H., and Kobayashi, R., "Water Content of ilethane Gas in Equilibrium with Hydrates." Ind. Eng. Chem. Fundam. 15:318-23, April 1976.

Experimental measurements of water content of methane gas in equilibrium with hydrate were presented at 1000 and 1500 psia for temperatures greater than $-10^{\circ} \mathrm{F}$. The differences between methane and natural gas hydrates were stressed.

Smith, J. M. S., Mathew, R. C. and Cool, J. A. F., "The Safety of Gas Carriers with Particular Reference to the ICS Tanker Safety Guideline (Liquefied Gas)." Presented at Gastech 75, Paris, September 30-October 3, 1975.

This paper provides an overview of the hazards of operating an LNG carrier with particular emphasis on personnel training.

Smith, K. A., Lewis, J. P., Randa11, G. A. and Meldon, J. H., "Mixing and Rollover in LNG Tanks." Paper presented at the Cryogenic Engineering Conference, Atlanta, GA, August 8, 1973.

Criteria and data are presented for deciding whether a specific LNG installation need have both top and bottom fill capacity. In general, a large facility will benefit from such capability if it is to receive a variety of LNG compositions from a variety of ships. It is further shown that the top fill device requires surprisingly careful design in order to assure good mixing at the free surface. 
Smith, K. A. and Reid, R. C., The Effect of Composition on the Boiling of LIIG on Water. M.I.T. LNG Research Center, 1976 Annual Report, Task IV, to the American Gas Association BR 87-6, January 1977.

\begin{abstract}
The results obtained thus far with binary and ternary mixtures indicate that a preferential evaporation of methane does indeed take place, followed by the preferential evaporation of the next more volatile component ethane. Propane is the last component to evaporate. Although a preferential evaporation takes place, the vapors are a mixture very rich in the volatile component but a mixture after all.
\end{abstract}

Smith, K. A. and Reid, R. C., Electrostatics and its Hazards in Petroleum Industry and LiNG Systems. M.I.T. LNG Research Center, 1976 Annual Report, Task V, to the American Gas Association BR 87-6, January 1977.

The paper discusses streaming potentials and sedimentation potentials in relation to static charge generation as a consequence of hydrocarbon flow through pipes.

Smith, K. A. and Reid, R. C., Boiling of LNG on Dike Floor ifaterials. M.I.T. LiIG Research Center, 1976 Annual Report, Task VI, to the American Gas Association BR 87-6, January 1977.

The rate of vaporization of LNG spilled on a number of substrates was measured experimentally. Included in the materials tested: insulated concrete of two densities, soil, sand, pebbles, wet and dry polyurethane. In all cases, the early rate of vaporization could be well correlated with simple, one-dimensional conduction heat transfer.

Snith, II., ed., Recommended Guide for the Prediction of the Dispersion of Airborne Effluents. Published by the American Society of Mechanical Engineers, May 1968.

The guide discusses meteorological fundamentals, airborne effluents, stack height, dispersion and deposition, data sources and experimental methods, and gives calculation methods and examples.

Smith, R. V., "The Influence of Surface Characteristics on the Boiling of Cryogenic Fluids." J. of Eng. for Industry. 91:1217-1221, 1969.

The influence of a solid heating surface on the boiling behavior of liquid helium, hydrogen and nitrogen is being discussed. This is a review article and contains essentially no new information. 
Smolik, V. "Assessment of Cloud Formation of Natural Gas After Release in Crash Accidents." (in Czech), Bezpecna praca 10(5):178-181, 1979.

Safety aspects of the liquefaction, storage and evaporation of natural gas are discussed, especially for the case of massive release of LNG in a crash accident with the following formation and dispersion of an explosive vapor cloud.

Snellink, I. G., "Hazard Assessment of LNG Supply and Storage." Communication of the ietherlands velegation, January 1978.

The author describes a risk analysis of the supply and storage of LNG at a facility near the river Maas on the Dutch coast.

Solberg, D. M., Nylund, J. and Hansen, H. R., "Safety and Reliability of Floating LNG Protection Facilities." Fifth International Conference on LNG, Session III, paper 6, Institute of Gas Technology, 1977.

Safety guidelines for the construction and classification of floating facilities for gas processing, liquefaction, and storage are being reviewed.

Solberg, D. M., J. A. Pappas and E. Skranstad. "Observations of Flame Instabilities in Large Scale Vented Gas Explosions." Paper presented at the 18th International Symposium on Combustion, August 17-22, University of Water100, Canada, 1980.

Experiments on vented gas deflagrations performed in a $35-m^{3}$ prismatic steel module showed that Taylor instabilities may be the dominating mechanism governing the pressure load from even freely vented explosions depending on the point of ignition and venting layout. The pressures obtained were higher than expected based on simple volume scaling of previous explosion tests on laboratory scale. The simple volume scaling of vented gas deflagration based on constant burning speed thus seems to be invalid for vessel volumes at least up to $35 \mathrm{~m}^{3}$ and is furthermore non-conservative.

Solberg, D. M., J. A. Pappas and E. Skramstad. "Experimental Investigations of Flame Acceleration and Pressure Rise Phenomena in Large Scale Vented Gas Explosions." Paper presented at the 3rd International Symposium on Loss Prevention and Safety Promotion in the Process Industries, Basle, 1980.

Existing equations and formulas used to relate maximum pressure-to-vent area are mainly based on small scale laboratory tests and show very large discrepancies. Experiments performed in a $35-\mathrm{m}^{3}$ prismatic steel module show that deflagrations in larger rooms are of much more complex nature and may give higher pressures than expected from small scale tests. Explosions with uncovered vents show several pressure peaks and the maximum pressure rise occurs at a higher gas concentration than the one giving maximum laminar burning velocity. 
Several phenomena which explain the pressure-time history from gas explosions in larger enclosures have been observed. This includes distortion of the flame front by the flow field set up by the venting, confinement and vent area geometry and combustion instabilities. An improved calculation model is presented and estimated values compared to observed ones.

The results of this investigation are useful for the understanding of deflagration processes and for prediction of the loads from deflagrations.

Solberg, D. M. Unconfined Vapor Cloud Explosions-A Prestudy. Report No. 79-0615. Det Norske Veritas, Hovik, Norway, 1979.

This study reviews the hazard potential to offshore facilities from unconfined vapor cloud explosions and examines ways that this hazard can be predicted and reduced by preventive and protective design. Damage potential from an unconfined vapor cloud is determined by the rate of energy release (or flame speed) during explosion. Factors that accelerate the flame increase the damage potential. Additional research to quantitatively define the mechanism of flame acceleration is recommended. Vapor cloud explosions on offshore platforms may be coupled to confined vented explosions. Additional research is needed on situations where a confined explosion propagates to an external vapor cloud with subsequent explosion.

Solomon, B., "Cove Pt. LHG Terminal to Resume Operation After Accident." The Energy Daily. pp. 1-2, October 19, 1979.

A recent accident at the Cove Point, Maryland liquefied natural gas facility is described. Seepage of LNG from a high pressure pump resulted in a gas explosion which killed one employee and critically injured another.

Spangler, C. V., "Storing Gases." U.S. Patent 2,663,626 (to J. F. Pritchard and Co.), 1953.

Natural gas was cooled to slightly above its boiling point and adsorbed on activated carbon or silica gel. Release of adsorbed gas was achieved by contacting heated natural gas with the solid support.

Speir, G. A., "Indonesia's Badak LivG Project Sets New Records." Pipeline and Gas Journal. June 1978.

This article discusses design, construction, startup and operation of the Badak export terminal. The facility liquefies gas for

shipment to Japan.

Srinivason, K., et al., "Effect of Floating Insulation on Free Surface of Cryogenic Liquids in Open Containers." 6th Internat. Cryog. Eng. Conf., pp. 258-262, IPC Science and Technology Press Ltd., Guilford, England, 1976.

The effect of floating insulation materials on the evaporation rate of cryogenic liquids is investigated. Normally, this rate can be reduced by up to $25 \%$. 
Staartjes, R. "Choice of Material for Storage Tanks for LNG Peakshaving Built at the Maas-mouth." (in Dutch), Ingenieur (NL). 88(23):481-485, 1976.

Materials appropriate for inner vessels at cryogenic temperatures are Austenitic nickel steels which show a high notch toughness. Techniques of welding like the MIG (metal inert gas) - method or of testing of fracture tonghness like the COD (crack opening displacement) - method are discussed.

Staffa, V. V. and Jhaveri D.K. "LNG Project Development: Shipping and Terminal Considerations." Adv. Cryo. Eng. 25:730-750, 1979.

A general overview is given on the various technical aspects of LNG projects, such as gas gathering, liquefaction, shipping, receiving terminal, pipeline distribution and also on project financing. It is stated that all LNG technologies are by now well established and that no new technologies are needed.

Staff-Work. Onshore/Offshore $0 i 1$ and Gas Multilinqual Glossary. EUR 6554, Published by Graham \& Trotman Ltd. for the Commission of the European Communities, EUR 6554, 1979.

A glossary of terms concerning the exploration and exploitation of oil and gas resources, in Danish, German, English, French, Italian and Dutch.

Staff Writer. "Thyssengas uses LiNG as Reserve Supply." Pipeline â Gas J. 207 (13):28-30, 1980 .

A mobile LNG trailer is described that can be used to provide continued gas supply for both scheduled and unscheduled emergency interruptions. The full unit consists of the LNG tractor-trailer, a mobile vaporizer, and a portable power supply.

Staff Writer. "LNG Scorecard." Pipeline \& Gas J. 209(13):26-36, 1991.

The latest listing of U.S., Canadian and International peakshaving facilities is presented, including both small and large satellite plants as well as baseload LNG facilities and import/receiving terminals around the world.

Staff Writer. "Worldwide LNG Projects Hit by Price, Contracts." Pipeline \& Gas J. $209(13): 23-24,1981$.

Three-fourths of the world's LNG trade was going to Japan in 1980. Controversy over LNG pricing has affected exports from Algeria to the U.S. A new contract is still under negotiation. 
Stanfil1, I.C., "Startup Experiences and Special Features at Memphis LivG Plant." Presented at the First LNG International Conference, Cnicago, IL, Apri] 7-12, 1968.

This paper describes four major and several minor equipment malfunctions which occurred during startup and the first six months of operation at the Memphis LNG plant. Several process flow diagrams for the Memphis plant are included.

Stein, W., LiNG Firebal1 Thermal Radiation. UCID-13190, Lawrence Livermore Laboratory, 1977.

The highly simplified computational method is presented for the determination of thermal radiation, emanating from a LNG fireball. Quantitative results are given in a series of diagrams.

Stein, W., Vapor Generation from a $40 \mathrm{~m}^{3}$ Instantaneous LIVG Spill into a $100 \mathrm{~m}^{2}$ Diked Soil Area. UCID-18188, Lawrence Livermore Laboratory, 1978.

A simple heat transfer model is presented in the evaporation of LNG spilled into a diked area. Some numerical results are given.

Stein, W., "The Spreading of Differential Boil-Off for a Spill of LNG on a Water Surface." Report A, Liquefied Gaseous Fuels Safety and Environmental Control Assessment Program; A Status Report. DOE/EV-0036, Department of Energy, Washington, DC, 1979.

A computer program is described which calculates pool size, difierential boil-off and spreading rate for LNG spills on water. Results compare favorably with experimental data.

Stein, W. and U. L. Ermak. One-Jimensional Numerical Fluid Dynamics Model of the Spreading of Liquefied Gaseous Fuel (LGF) on Water. Report No. UCRL-530378, Lawrence Livermore Laboratories, Livermore, California, 1980.

A computer model is described which calculates the height and the diameter of a continuous and instantaneous spill of LGF on water. Typical results of the calculations are presented in both tabular and graphical form. However, there are no comparisons with actual test data.

Steinmetz, G. F., "Special Combustion Characteristics and Blending Problems of LNG, SNG, and LPG Gases." Symp. , New Fuels and Advances in Combustion Technologies, pp. 1-14, 1979.

Imported LNG is interchangeable with domestic natural gas if minor changes in the supply facilities and their operation are tolerable and if burners are derated or physically changed. Otherwise, minor problems might arise, which would reduce efficiency and would require more frequent service of the burners. 
Stephan, K., "Evaporation Rate of Liquid Natural Gas in Large Containers." Thermo and Fluid Dynamics. 11:53-61, 1973.

Natural gas is often stored in large isolated metal containers. Heat flow through the bottom, the side wall and the cover to the stored liquid are practically independent from each other due to the large dimensions of such containers. Based on this simplification the evaporation rate of the liquid is calculated by means of the Laplace Transformation and a specific difference equation. With the results it is possible to determine the time after which freezing in the surrounding soil commences. The rate of heat flow to the condensed gas proved to be practically unaffected by the ice-formation in the soil. (in German)

Stephan, K. and Adamek, Th. "Evaporation Losses During the Storage of Low Boiling Gases in Large Vessels." (in German), Waerme-u. Stoffuebertraq. 11:53-61, 1978.

A method for calculating the heat flux of isolated underground LNGstorage tanks is explained. The evaporation rate as a function of time and the influence of ice formation is discussed.

Steward, F. R., "Linear Flame Heights for Various Fuels." Combustion and Flame. $\underline{8}(3): 171-178$, September 1964.

The flame heights of linear diffusion flames for several different fuels have been correlated with a single parameter derived from a model assuming mixing controlled combustion. The assumptions involved are stated clearly.

Steward, F. R., "Prediction of the Height of Turbulent Diffusion Buoyant Flames." Combustion Science and Technology. 2:203-212, 1970.

A mathematical model of a turbulent diffusion buoyant flame based on a number of simplifying assumptions is presented. It was found that the height at which $400 \%$ excess air has been entrained corresponds to the visible flame height according to data taken in our laboratory as well as that presented by a number of other workers.

Stewart, A. "San Diego Gas \& Electric Company LiVG Plants." LiVG Terminals and Safety Symposium, pp. 364-369, in Applications of Cryogenic Technology 9 , Scholium International, Flushing, iNew York, 1979.

The operation of LNG peakshaving plants is described. This includes: cleaning the feed gas, chilling the gas, liquefying the gas, storage, and revaporization. 
Stewart, A. iN. "LNG Research Programs." LiNG Terminals and Safety Symposium, pp. 190-194, in Applications of Cryogenic Technology 9, Scholium International, Flushing, ivew York, 1979.

The objectives for LNG research, sponsored by the Gas Research Institute, are outlined. They are primarily concerned with LNG properties, LNG vapor dispersion, LNG fire control, and basic LNG research being conducted by MIT LNG Research Center.

Stol1, W. and Biederbick, M. "Cryostop-Service: Repairing Liquid Cycles Without Discharging and Shutdown." (in German), Kälte- U. Klimatech. 34(3):108-110, 1981 .
A method is described for repairing pipeline-systems while freezing the transported liquid at the right location. A suitable packing is placed around the pipe and filled with liquid nitrogen. The frozen fuel inside the pipe acts like a closed valve. Some examples are given to demonstrate the practical use of this method.

Strassburg, F.W. "LNG-Storage and Transportation." (in German), europa industrie revue, 14(5):21-24, 1980.

The increasing need of LNG requires the building of transportationand storage tanks of high volume. The construction of such vessels has to follow special guidelines in respect to welding and cutting. New process technologies have been developed to build selfsupporting rectangular, cylindrical and spherical tanks with up to 30-mm wall thickness.

Strehlow, R. A., "Unconfined Vapor Cloud Explosions - An Overview." Paper presented at the 14th Symposium on Combustion. The Combustion Institute,
Pittsburgh, PA, 1973.

The author summarizes the history of accidental vapor cloud explosions, reviews the work that has been done to understand the dispersion, ignition, propagation and blast effects produced, then points out areas for future investigation.

Stroem-01sen, H. "Experiences of the Kockums-Shipyard in Project and Construction of LNG-Transporters." (in French), Bul1. Techn. Bur. Veritas. 62(3):99-103, 1980.

The article briefly describes the tubsystem for the transportation of liquefied gaseous fuels. Advantages of this system are discussed. $A$ report is given on the preparations for the construction of such ships to be used as gas transporters between Alaska and Tokio as well as on the building of two $133,000 \mathrm{~m}^{3}$ tankers. 
Strehlow, R. A. et a1., "On the Measurement of Energy Release Rates in Vapor Cloud Explosions." Combustion Science and Technology. 6:307-312, 1973.

The method is based on the finite amplitude isentropic acoustics of a centered spherical wave and involves the reduction of data from 3 pressure gauges which are measuring the explosion. The method of characteristics is used to back calculate to an effective spherical piston which replaces the explosion so energy release rates of the explosion can be calculated.

Strehlow, R. A. and Baker, W. E., "The Characterization of Accidental Explosions." Prog. Energy Combustion Science. Pergammon Press, 1976.

The authors review actual explosion incidents and classify them into several categories. Basic theory in blast wave damage is also discussed along with the effects of "non-ideal" blast waves. Future areas of research are recommended.

Strehlow, R. A., Luckiatz, R. T., Adamczyk, A. A. and Shimpi, S. A., "The Blast Wave Generated by Spherical Flame." Combustion and Flame. 35(3):297-310, August 1979.

The authors report on their work for determining the overpressures and impulses resulting from reactive fronts. Some results are presented for hydrocarbon mixtures. This paper may have application to blast wave effects estimation.

"Strong Global LNG Trade Growth Seen." 0il and Gas J. 77:36-37, December 1979.

It is expected that world LNG trade will double in the next 5 years, reaching about 3 trillion $\mathrm{cu} f \mathrm{ft} / \mathrm{yr}$ by 1985. However, U.S. import policy will remain uncertain because of safety, siting, liability, and insurance issues.

Stuart, A. "El Paso in the Grip of the Frozen Fuel." Fortune 14: 70-75, July 1980.

The history of EI Pasco Company's LNG venture is outlined and the reasons for its recent downturn are discussed. The article leaves little doubt that political and financial difficulties are responsible and not any technical or safety problems. The outlook for the future is not viewed optimistically.

Stuckly, J. M. and Walker, G., "Hydraulics a Key to Optimizing LNG Pipelines." 0i1 and Gas J. 77(17):68-70, 1979.

By carrying out detailed numerical calculations for the considered LNG pipeline, it is shown that under optimized conditions a liquid carrying pipeline offers improved fuel efficiency when compared with a conventional vapor-phase line. 
Stuckly, J. M. and Walker, G., "LNG Long-Distance Pipelines--A Technology Assessment." 0i1 and Gas J. 77(16):59-63, 1979.

An outline design study for a 1,430-mile LNG pipeline in Northern Canada is described. The tradeoffs between operating temperatures, pressures, pipe diameter, insulation, and material requirements are discussed in some detail. So far no large-diameter, long-distance LNG pipelines have actually been built, but they have received a lot of attention recently.

Study of LNG Safety - Parts I and II. Tokyo Gas Company Ltd., Central Laboratory, February 1971.

This two-part study presents experimental results on LNG evaporation, combustion and dispersion characteristics in a dike, and on LNG evaporation, ice formation, and LNG dispersion on water.

Stuhmiller, J. H. and Ferguson, R. E., Comparison of Numerical Methods for Fluid Flows, EPRI Report iNP-1236, RP 838-1, November 1979.

The numerical dispersion (velocity) and dissipation (amplitude) of initial value data for the transient convection equation (1-D) for fourteen numerical methods are studied. Three initial data profiles are used and results are compared to the analytic answer.

Sturzenegger, E. "Storage and Distribution of LPG." (in German), Dre R Int. 20(12):675-680, 1981 .

This article describes those physical parameters and relationships which are important for the storage and transportation of LPG especially the fuel-vapor phase equilibrium. Programs and methods for the calculation of vapor composition and pressures are given as well as examples of calculations.

Sulzer-Installation "Installation for Reliquefaction of Natural Gas and Petroleum Gas." (in French), Tech. Mod. 68(7/8): 45-46, 1976.

Even the best insulating material cannot prevent that about $0.25 \%$ of the LNG or LPG load of a tanker evaporates per day. The article describes an automatic installation for the reliquefaction of the vapor. 
Sunvala, P. D., "Dynamics of the Buoyant Diffusion Flame." Journal of the Institute of Fuel. 40:492-497, 1967.

A new theoretical treatment of the axial velocity growth and mass concentration decay in a buoyant diffusion flame is presented. It has been found that for the flame lengths of burning of various fuel gases, organic liquids as well as fuel oils, the one-fifth power index for the Froude Number holds good. However, for the flame lengths of burning firewood in cribs, the two-fifths power index for the Froude Number is suggested.

Sutherland, V. and J. E. Hughes, "Subterranean LiNG Storage." Energy Digest. 3:15-17, October 1978 .

The construction of six storage cavities in underground salt formations is described. Each cavity can hold about $60 \times 106 \mathrm{~m}^{3}$ LNG at pressures between 120 and 270 bar.

Sutton, S. B., Overpressure Prediction. UCID-18189, Lawrence Livermore Laboratory, 1977.

A simple calculation is performed to determine the energy within a burning cloud of LNG. This energy is assumed to have the same pressure effect as an energy-equivalent quantity of TNT.

Taki, S. and Fujiwara, T., "ilumerical Analysis of Two-Dimensional ilonsteady Detonators." AINA Journa 1. 16, January 1978.

This paper is a report about the numerical calculation of twodimensional detonation propagation in a confined channel. A simplified chemical kinetics was employed. The method may have application to the study of detonation probabilities for methane-air mixtures.

Tanker Structural Analysis for Minor Collisions. U.S. Coast Guard Report CG-D-72-76. NTIS iNo. AD/A037031, December 1975.

This report describes the work accomplished during the course of the project of the Evaluation of Tanker Structure in Collision. The intent of the report is to present the investigations performed in evaluating the phenomena that contribute to the ability of a longitudinally framed ship, particularly a tanker, to withstand a minor collision. A minor collision is one in which the cargo tanks remain intact. The ability to withstand a minor collision is quantized by the total energy that can be absorbed during the collision. 
Tarifa, C. S., Del Notario, P. P. and Valdes, C. F., Open Fires. Final Report, U.S. Department of Agriculture, Forest Service, Grant FG-SP-114 and 146, May 1967.

An experimental study was made of some basic laws of open fires by utilizing the pool fire techniques. Data were obtained for burning rates, energy balances and flame characteristics, including the influence of fuel type, vessel size and vessel configuration.

Taylor, P. B. and Foster, P. J., "Some Gray Gas Weighting Coefficients for $\mathrm{CO}_{2}-\mathrm{H}_{2} \mathrm{O}$ Soot Mixtures." International Journal of Heat Mass Transfer. 19:13311332,1975 .

Two tables are provided which give 1) the values of constants which specify weighting factors for various soot concentrations applicable in the temperature range 1400 to $2400^{\circ} \mathrm{K}$ and 2) values of constants which specify the gray gas absorption coefficient applicable in the 1200 to $2400^{\circ} \mathrm{K}$ temperature range.

te Riele, P. H. M. "Atmospheric Dispersion of Heavy Gases Emitted at or Near Ground Leve1." Second International Loss Prevention Symposium, 1977: 347-357.

This paper presents a theory developed at Koninklijke/Shell-Laboratorium, Amsterdam (KSLA) for predicting the atmospheric dispersion of heavy gases emitted at or near ground level. The paper showns the validity of the theory by comparing it with available experimental data, and discusses its applicability.

Terry, A. C., "Floating LNG Facilities May Solve Many Problems." Pipeline and Gas Journal. pp. 25-28, June 1977.

This article discusses the history of development of offshore liquefaction facilities. Various generic types of floating facilities are discussed and their potential evaluated.

Thermal Radiation and Overpressure from Instantaneous LiVG Release into the Atmosphere. TRW Systems Group Report No. 08072-4, to A.G.A., April 26, 1968.

The report conclusions express belief that 1) a stoichiometric mixture of natural gas and air at atmospheric pressure will not detonate with a charge of high energy explosive equivalent to 625 grams of TNT; 2) the parameters of charge energy, mixture composition and confining wall geometry should be further investigated. 
Thomas, P. H., "The Size of Flames From Natural Fires." Paper presented at the 9 th International Symposium on Combustion, 1963.

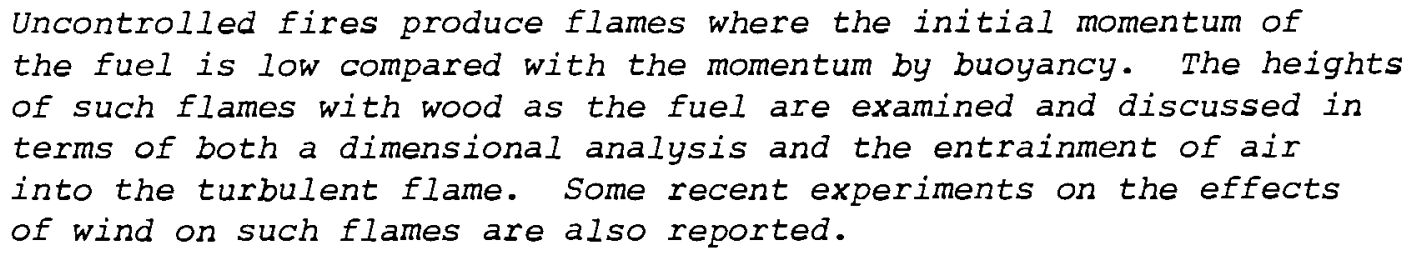

Thomas, P. H., Baldwin, R. and Heselden, A. J. M., "Buoyant Diffusion Flames: Some Measurements of Air Entrainment, Heat Transfer, and Flame Merging." Paper presented at the 10th International Symposium on Combustion, the Combustion Institute, 1965.

Thistledown has been used as a tracer to measure the flow of air toward ethyl alcohol and wood fires $91 \mathrm{~cm}$ in diameter, and a smaller town gas fire. The measured mean axial temperature rise at the mean flame height was about $300^{\circ}$ to $350^{\circ} \mathrm{C}$ for wood and alcohol and $500^{\circ} \mathrm{C}$ for town gas.

Thomas, W. D. The LNG Ship in a Changing Energy Environment in the Proceedings of the Second Ship Technology and Research Symposium, San Francisco, California, May 25-27, 1977.

The paper describes some of the recent developments in LNG containment systems. The author also includes a method for improving the efficiency of the LNG ship from the viewpoint of energy consumption per unit of energy delivered.

Thurley, J., Drouineau, M. and Santoleri, J. J., "Economic Considerations in the Selection Between Fired and Seawater Vaporizers." GasTech Horkshop, Houston, 1979.

Submerged combustion vaporizers for LNG are usually preferred over seawater vaporizer for ecological reasons, even though the latter are more economical. A combination of the two versions appears to be the best overall choice.

Timmerhaus, K. D. and Flynn, T. M., "Safety with Cryogenic Systems." Advances in Cryog. Eng. 23:721-729, 1978.

Safety aspects of cryogenic fluids are discussed from a practical point of view. Rules and suggestions for the safe handling of such fluids are given. 
Tilo. Methods for the Estimation of the Consequences of the Releases of Dangerous Material (Liquid and Gases). TNO-Report 3386, 1979.

A report was made to Directorate-General of Labor of the ministry of Social Affairs dealing with the releases of dangerous liquids and gases. These include outflow, spray releases, evaporation heat radiation from burning pools, and dispersion of natural gas cloud.

Tomkins, B. G., "LNG Plant Computer System: A Conceptual Philosophy." 0 il and Gas J. $77(48): 56-60,1979$.

A computer in an LNG plant must be designed around the plant operating plan. Consideration must also be given to maintenance and safety plants. Suggestions for useful hard and software selections are provided.

Tonnessen, A., Insulated Tanks for Liquefied Gas. U.S. Patent 4,141,465, 1979.

To reduce boil-off in spherical LNG tanks, the tank skirt is supplied with a special low conductivity ring insert, made of 18-8 SS. Such a heat flow resistance can reduce the heat leak through the skirt by about 50 percent.

Tsai, S. S. and Chan, S. H., A General Formulation and Analytical Solution for Multi-Dimensional Radiative Transfer in Non-Gray Gases. A.I.Ch.E., A.S.M.E. Heat Transfer Conference, Salt Late City, Utah, (77-HT-51), August 1977.

The equations of radiative transfer (spectral) are cast into band absorptance from the multidimensional geometries. Optically thick and thin limiting expressions are thus deduced and discussed.

Tsatsaronis, G., "Prediction of Propagating Laminar Flames in llethane, Oxygen, Nitrogen Mixtures." Combustion and Flame. 33:217-239, 1973.

A fundamental analysis of one dimensional flame propagation (including chemical kinetics and transport [processes] of methane flames) is performed. Flame speed, flame structure and pressure effects are enumerated.

"Turbine/Compressor Serves First 50/50 ilethane-Nitrogen Cycle Gas System." Diesel and Gas Turbine Progress.

A unique liquefaction plant at a peakshaving facility is described. Considerable detail, including several photographs, on the refrigerant compressor is provided. 
Turner, D. B., Workbook of Atmospheric Dispersion Estimates. Publication No. 99-AP-26, Public Health Service, 1969.

This workbook presents methods of practical application of the continuous plume dispersion model with a Gaussian distribution to estimate concentrations of air pollutants. Estimates of dispersion are those of Pasquill as restated by Gifford. Emphasis is on the estimation of concentrations from continuous sources for sampling times up to 1 hour.

Tutko, T. J., "How to Design an Integrated Security System for an LiNG Facility." Pipeline and Gas Journal. 121:50-62, July 1979.

The need for a integrated security system at all major LNG facilities is demonstrated. Various suggestions are given as how to best implement such a system.

Uhl, A. E., Amoroso, L. A. and Seitir, R. H., "Safety and Reliability of LiNG Facilities." Presented at the ASME Petroleum Mechanical Engineering and Pressure Vessels and Piping Conference, New Orleans, LA, September 17-21, 1972.

The prime factors behind the fine operational safety and reliability record of LNG facilities are the early definition and understanding of the nature of LNG, the establishment and utilization of relevant codes, the casting and observation of pertinent quality assurance programs, and thorough training of plant operators. This paper discusses each of these factors in detail.

U1denvan, A. P., "The Unsteady Gravity Spread of a Dense Cloud in a Calm Environment," paper presented at the International Technical meeting on Air Pollution Modeling and its Application, NATO-CCMS, Rome, October 26, 1979.

Simplified bulk momentum equations for one dimensional and axisymmetric gravity spreading of dense clouds are presented. Analytical solutions indicate that a steady state is not reached during cloud spreading.

Urtiew, P. A. Flame Propagation in Gaseous Fuel Mixtures in Semiconfined Geometries. UCID-19000, Lawrence Livermore National Laboratory 1981.

This report describes experiments on the flame acceleration mechanism in vapor cloud explosions. It is concluded that turbulence plays a major role in these phenomena. 
U.S. Coast Guard. Experiments Involving Pool and Vapor Fires from Spills of Liquefied National Gas on Water. Report Wo. CG-D-55-79. National Technical Information Service, Springfield, Virginia, 1979.

A series of 16 tests were conducted at the Naval Weapons Center involving the spill and ignition of liquefied natural gas (LNG) on water. Two kinds of fires were studied; namely, pool fires and vapor cloud fires. The principal objective of the tests was to measure the thermal characteristics. The quantities of spilled LNG varied between 3 and $5.5 \mathrm{~m}^{3}$ with spill durations from 30 to $250 \mathrm{~s}$. Thermal radiation from the fires was measured using wide-angle and narrow-angle radiometers and a spectrometer. The data from the tests have been analyzed for pool spread, liquid regression rate, flame heights, thermal radiative output and LNG fire spectra. Models useful for evaluating LNG fire hazards are indicated in the report. Mean flame emissive power measured was about $210 \mathrm{~kW} / \mathrm{m}^{2}$ and estimated flame temperature was $1500 \mathrm{~K} . \mathrm{CO}_{2}, \mathrm{H}_{2} \mathrm{O}$, and soot appear to be the principal radiating species. Vapor cloud burning was close to the ground with a propagating plume fire. The velocity of propagation was function of the wind speed. $A$ peculiar fire halting behavior noticed was observed and possible reasons for the behavior are discussed in the report.

U.S. Comptroller General, Need to Improve Regulatory Review Process for Natural Gas Imports. ID-78-17, General Accounting Office, July 14, 1978.

The article highlights difficulties in the review process for

LNG importation facilities and makes recommendations to congress

and federal agencies to mitigate the impacts.

U.S. General Accounting Office, Information on the U.S. Importation of Liquefied ivatural Gas. EMD-79-48, Warch 22, 1979.

The report deals with questions on LNG consumption in the U.S., the sources and prices for the imported LNG and with its end use by the utility companies. It also addresses size and ownership of the LNG tanker fleet.

"Using LNG Cold Energy More Efficient7y." 0il and Gas Journal 78:174-182, Harch 17, 1980.

Several advanced methods are described that allow a more efficient vaporization of LNG. These include: submerged combustion, seawater vaporization, ethylene plants using LNG for refrigeration, power generation with closed and open gas turbine cycles, and use of multicomponent working fluids.

Valencia-Chavez, J. A. and Reid, R. C., "The Effect of Composition on the Boiling Rates of Liquefied Natural Gas for Confined Spills on Water." Int. J. Heat Mass Transfer. 22:831-838, 1979.

Boiling rates for spills of LNG on a confined area of water (calorimeter) were measured for various $L N G$ compositions. A simplified model was developed which compared well with experimental results. 
Van Breugel, K. "A Designer's Perspective on Cryogenic Storage Systems for Liquefied Industrial Gases." Cryogenics 22:337-334, 1982.

The pros and cons of using concrete for constructing LNG storage vessels are discussed. Areas which have not yet been sufficiently researched are pointed out. The safety features of concrete structures at cryogenic temperatures are evaluated. On balance, it appears that concrete may have certain advantages when compared with steels. The article does not contain any quantitative data, however.

Van Buijtenen, C. J. P., et al., Dispersion and Analysis of Methane in the Atmosphere. $1178-26644,1976$.

An analytical model, based on atmospheric diffusion, has been developed for the dispersion of methane from a large LNG spill. No experimental verification is supplied.

Van Buijtenen, C. J. P. Calculation of the Amount of liethane in the Explosive Region of a Time-Dependent Source. Chemisch Laboratorium Tivo Report 1975-10.

As an extension of the work on instantaneous and continuous sources, a model was developed to calculate the downwind concentrations as functions of time for a time-dependent source. The calculated concentrations are compared with published experimental data.

Van Buijtenen, C. J. P. "Calculation of the Amount of Gas in the Explosive Region of a Vapour Cloud Release in the Atmosphere." J. of Hazardous Materials $3: 201-220,1980$.

In order to evaluate the explosion hazard of a vapor cloud, it is important to know the amount of gas between the flammability limits at any instant and the maximum distance from the source when delayed ignition is possible. This paper discusses the development of a model to calculate these parameters from a Gaussian plume model. The results appear reasonable for neutral gases; however, the author concluded that it is more difficult to establish a model for large amounts of gas that are heavier than air.

Vanderwall, E. M., "Investigation of the Suitability of Gelled Methane for Use in a Jet Engine." NAS 3-14305, iASA CR-72876, 1971.

Methanol gelled cryogenic methane was storable at $-263^{\circ} \mathrm{F}$ for periods exceeding 100 hours with no significant gel structure degradation. The gel could be transferred through properly designed heat exchangers at comparatively high flow rates $(10 \mathrm{lb} / \mathrm{hr}$ ) without clogging. Fuel consumption by jet engines was not excessive due to the gelant. 
Van Horn, A. J. and Wilson, R., Liquefied latural Gas: Safety Issues, Public Concerns, and Decision Making. BNL 22284, Energy and Environmental

Policy Center, Jefferson Physical Laboratory, Harvard Liniversity, November 1976.

The report provides background information on LNG and discusses safety issues, LNG facilities siting disputes, public concern for LNG facilities siting, LNG decision making, and gives recommendations concerning LNG terminal siting facilities.

Vanta, E. B. et al., Detonability of Some Natural Gas-Air Mixtures. Technical Report AFATL-TR-74-80, Air Force Armament Laboratory, Elgin Air Force Base, Apri1 1974.
A bag test method to screen natural gas-air mixtures $(5.2$ to $12.5 \%$ by vol. natural gas) to determine detonability. At the 8.6 to $8.8 \%$ concentration level, erratic, uneven detonations were initiated and explosive charges ranged from 1001 to 1020 grams. Deflagration occurred at all other fuel concentrations. The detonations propagated the length of the bag, but a steady Chapman-Jouguet type wave front was not observed.

Van Tuyen, N. "Study Outlines Problems in Long Distance LNG Dipelines." 0il and Gas Journa1. 78:107-111, 1980.

Use of special high-nickel steels and adequate thermal insulation are required for transporting cryogenic fluids through pipelines. It is shown that LNG pipelines can be both safe and economic to operate. However, original construction costs are higher for cryogenic liquid lines than for gas lines.

Van Ulden, A. P., "On the Spreading of a Heavy Gas Released Near the Ground." Loss Prevention and Safety Promotion in the Process Industries. Bushman, C. H., d. Proceedings of the First International Loss Prevention Symposium. The Hiague/ Delft, The Netherlands, May 28-30, 1974, Elsevier Scientific Publishing Company, 1974.

It is shown that the spreacing of a heavy gas differs essentially from the spreading of a neutral gas. Horizontal spread is increased considerably by gravity effects, whereas vertical spread is limited. calculations are compared with experimental results. 
Varma, R. K., Murgai, M. P. anc Ghildya1, C. D., "Radiative Transfer Effects in Natural Convection Above Fires - General Case." Proc. Roy. Soc., London, A314, 1970.

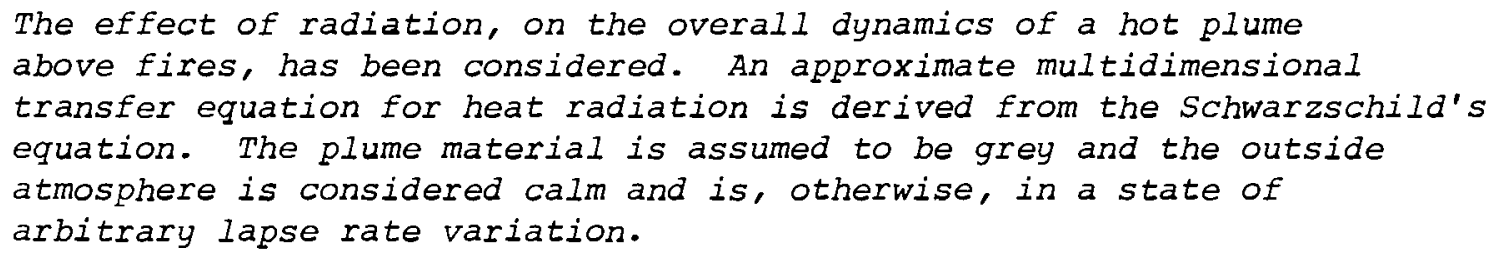

The effect of radiation, on the overall dynamics of a hot plume above fires, has been considered. An approximate multidimensional transfer equation for heat radiation is derived from the Schwarzschild's equation. The plume material is assumed to be grey and the outside atmosphere is considered calm and is, otherwise, in a state of arbitrary lapse rate variation.

Verma, S. B. and Cermak, J. E., "Mass Transfer From Aerodynamically Rough Surface." International Journal of Heat and Mass Transfer. 17:567-579, 1974

\begin{abstract}
Mass transfer rates were determined by directly measuring the actual volume of water evaporated from saturated wavy (sinusoidal) surfaces in micrometeorological wind tunnel. Simultaneous measurements of mean velocity, humidity and temperature distributions were made over these saturated waves.
\end{abstract}

Verneau, A. "The Possibilities of Turbo Expanders in the Gas and 0il Industry." (in French), Gaz d'aujourd'hui. p. 390, 1975.

Different types of turbines and their applications are discussed; among others, the use of the condensable fraction of natural gas and the outlet of underground storages, economical reasoning shows that reimbursement of investments should be possible at least in two years.

Vielvoye, R., "Abu Dhabi Activity Soars, but Government Keeps Lid on Production." 0 il and Gas Journal. p. 74, July 9, 1978.

Included in this article is a discussion of some of the problems which have plagued the Das Island export terminal. These include cracked cryogenic pipelines, corrosion from high-sulfur gas, and a leak in the inner shell of a storage tank which eventually caused a crack in the outer shell.

Vora, M. K., Shaheen, E. I. and Knieves, D. V., "U.S. Energy Future: Higher LiVG Imports Wi11 be Needed." World Oil. pp. 134-148, June 1978.

The future U.S. energy needs and the potential of LNG imports are discussed. It is predicted that LNG could supply $4.7 \%$ of total U.S. energy requirements by 1985 . This would require an import of 4.86 tcf including 1.17 tcf from Alaska. 
Voss, H.-J. and Mergler, K.W. "Visual Observation of Non-luminous Flames in Heating Rooms Using UV-Radiation." (in German), Glastechn. Ber., 51(5):96-103, 1978.

LPG and natural gas flames are quite non-luminous especially with premix burners. A visual observation of flames is necessary to prevent over-heating, furnace destruction or low efficiency. The paper describes the use of the UV band spectrum of oH-radicals, appropriate filter glasses and UV-image converter technique.

Vreedenburger, H., "Steel or Prefab Concrete for Inshore Plants." Chemical Engineering Progress. pp. 82-85, 1979.

The use of steel and concrete in the construction of a floating LNG receiving terminal is discussed. Concrete can offer some advantages in the storage tank design and construction.

Walter, W. "Research and Development Activities of the A.G. 'Wesser' on Large Ice-Breaking Ships." (in German), Hansa. 116(18):1374-1375; 1979.

The EOS-project (ice breaking OBO-ship) to develop the technology of merchant ships for arctic waters is described. Among the project's aims are the study of the mechanical water-ice properties, development of propelling engines, study of weldability of cold brittleness resistent steels, bow-shape and ice-breaking LNG-tankship.

Wakeshima, H. and Takata, K., "On the Limit of Superheat." Journal of the Physical Society of Japan. 13(11):13-1403, November 1958.

A new method was devised in which small drops of a sample liquid are heated as they rise up in the nonsoluble heating liquid with a suitable temperature gradient upward. The limit of superheat was determined for saturated hydrocarbons and polymethylenes.

The agreement between (Doring's) theory and experiment was satisfactory.

Walker, G. Technology Asesssment of Long Distance LNG Pipelines, Phase 7: Novel Applications for LNG Pipelines. NP 2900381, 1977. (microfiche onty)

Six independent studies are compiled which deal with a variety of novel applications of LNG pipelines. The topics include: internally insulated LNG pipelines; LNG freight pipelines; evaporative, nonisothermal, two-phase LNG pipelines; simultaneous electric power/LNG transmission, slush-methane pipelines, formation of a sea-ice protective shield. 
Weber, D., "Electric Power Generation and LiVG Evaporation with the Aid of Gas Turbines ilithin a Closed Cycle Process." CONF 78-155-010, (in German), 1978.
By taking advantage of the low temperature of evaporating LNG, the efficiency of a closed-cycle gas turbine could be substantially increased. This would represent a valuable contribution to energy conservation in LNG evaporating plants.

Weber, 0., "Recovery of Energy from LNG Vaporization." Presented at the Meeting on Industrial Processes: Energy Conservation R and D. pp. 173-189. H. Ehringer, G. Hoyaux (eds.). Washington, DC; European Community Information Service, 1979.

With the proposed cold utilization process of a closed-cycle gas turbine plant, an electrical output of $182 \mathrm{MW}$ is produced with an efficiency of $53 \%$. The specific power generation costs are 0.043 $D M / \mathrm{kWh}$ in baseload operation. With the combination of a closedcycle gas turbine and a diesel engine, an efficiency of $60 \%$ can be achieved.

Weber, D. "The 'Cold' Energy. Gas Turbines in Closed Cycle For LNG-Evanoration." (in German), Energie (BRD). 3C(7):238-241, 1978.

A description is given of the combined process of LNG evaporation and production of electric energy using gas turbines in a closed cycle. The efficiency factor is quite high with a temperature range from -120 to $+720^{\circ} \mathrm{C}$ in the cyclic process.

Weber, D. "Economic Production of Energy and LNG-Evaporation with Enclosed Gas Turbine." (in German), MAN-Forschen Planen Bauen 9:25-31, 1978.

This paper presents an overview of compressors and turbines used for the transportation of LNG in tankers or pipelines. Technical descriptions are given about natural gas turbo compressors for liquefaction plants, screw-type compressors for reliquefaction on LNG-ships, gas turbines in a cloud cycle for LNG evaporation with combined production of energy.

Weith, P.G. "Determination of Calorific Values of Liquefied Hydrocarbons by Capacity Measures." (in German), Gas u. Wasserfach,-Gas/Erdgas. 118(8):31-333, 1977.

The calorific values of liquefied hydrocarbons are often determined calorimetrically though the capacity-densitometric method is more profitable. By this method the proportion of dielectric constant and density of a fuel are measured with a relatively simple apparatus, and the calorific value is calculated. Though the corresponding equation is strictly valid only for nonpolar fluids, the resulting error is negligible in the case of small polarity. 
Welker, J. R., Brown, L. E., Ice, J. N., Martinsen, H. E. and West, H. H., Fire Safety Aboard LNG Vessels. J.S. Coast Guard Report No. CG-D-94-76. NTIC No. AD/A030619. Janiary 1976.

This report presents results of an analytical examination of cargo spill and fire hazard potential associated with the marine handling of liquefied natural gas cargo. Principal emphasis was on cargo transfer operations at receiving terminals, and more speaifically on the LNG tanker's caigo handling and hazard sensing and control equipment and operations.

Welker, J. R., Wesson, H. R. and Brown, L. E., "Use of Foam to Disperse LivG Vapors?" Hydrocarb. Process. pp. 119-120, 1974.

Tests have shown that a blanket of high-expansion foam effectively reduces ground-level methane concentrations downwind of an LNG spill.

Welker, J. R. et a1., "LNG Spi11s: To Burn or ilot to Burn." Paper presented at the A.G.A. Operating Section Distribution Conference, 1969.
This paper concludes that: flammable mixtures from large spills will penetrate a long distance downwind; a major spill should be ignited as soon as possible; a high-expansion foam system offers the best protection by suppressing either LNG evaporation or the burning rate and present standards that specify separation distance irrespective of pool size are meaningless.

Helker, J. R., Pipkin, 0. A. and Sliepcevich, C. M., "The Effect of Wind on Flames." Fire Technology. 1(2):122-219, 1965.

A simplified and improved correlation for the drag coefficient of windblown natural gas flames is given. Experimental results leading to the correlation were obtained in a low-spe zd wind tunnel specifically designed for such studies at the University of Oklahoma North Campus.

Welker, J. R. and Schorr H. P. "LNG Plant Experience Data Base." Paper 79-T-21 in Proceedings of the AGA Operations Section Conference, American Gas Association, 1979 .

Failure rates data on $L N G$ peakshaving plants were selected from information supplied by 25 plant operators. Most failures reported did not affect plant safety and caused only short-term interruption of normal operations. 
Welker, J. R. and Sliepcevich, C. M., "Bending of Wind-Blown Flames From Liquid Pools." Fire Technolojy. 2, 1966.

The bending of a flame by wind influences the amount of heat transferred by radiation and convection, the fuel burning rate, and the flame spread rate. To what extent will a flame be bent by wind? The author presents correlations of data taken from liquid pool fires, which enable us to predict flame bending and trailing for large fires.

Welker, J. R., West, H. H., Mento, M. A. and Ice, J. N., A Survey of the Effectiveness of Control liethods for Fires in Some Hazardous Chemical Cargoes. U.S. Coast Guard Report CG-D-64-76. NTIS No. AD/A026300, ilarch 1976.
Assessment of fire safety of marine bulk chemical carriers was attempted. It is recommended that standard fire control test methods be developed together with standardized test data col- lecting and reporting methods and that large-scale fire tests be made on chemicals from different families to attempt to develop methods of correlation with smal1-scale test results. If a reliable correlation can be developed, small-scale tests could be used in the future with more confidence to both predict behavior of chemical cargoes under fire conditions and to assess large fire extinguishing effectiveness.

Wesson, H. R. "LiVG Fire Training Schools." LNG Terminals and Safety Symposium, pp.340-345, in Applications of Cryogenic Technology 9. Scholium International, Flushing, ilew York, 1979.

The paper presents a summary of the training materials presented and the type of fire training problems used at two nationally known fire training schools that specialize in LNG fire fighting.

Wesson, H. R., Lott, J. L., Feldman, R. and Closiler, J. J., "Thermal Performance of a Fire Resistant Coating Applied to Prestressed Concrete." 1978 Operating Section Proceedings, American Gas Association, Montrea1, Quebec, i.ay 1978.

The fire resistance of coatings designed to protect weakening of prestressing wire in cryogenic tanks is tested. Degree of protection with coating thickness is discussed.

Wesson, H. R., Welker, J. R. and Brown, L. E., "Control LNG-Spill Fires." Hydrocarb. Process. 51:61-64, December 1972.

Control of LNG-spill fires is obtained by application of high expansion foam. Follow-up with dry chemical fire extinguishers will quickly extinguish the fire. 
Wesson, H. R., J. R. Welker, L. E. Brown, "Control of LNG Spill Fires on Land." Advances in Cryog. Engg., 20: i51-163, 1974.

The effects of high expansion foam and of commercially available dry chemical agents on LNG fires have been evaluated in a guantitative way. Both fire control and vapor dispersion were investigated at various application rates of the agents.

West, H. H., Brown, L. E. and Welker, J. R., "Vapor Dispersion, Fire Control, and Fire Extinguishment for LNG Spil1s." NTIS iNo. AD/A023505, pp. 509-518, Proceedings of the Fourth International Symposium on Transport of Hazardous Cargoes by Sea and Inland Waterway. Jacksonville, FL, October 26-30, 1975.

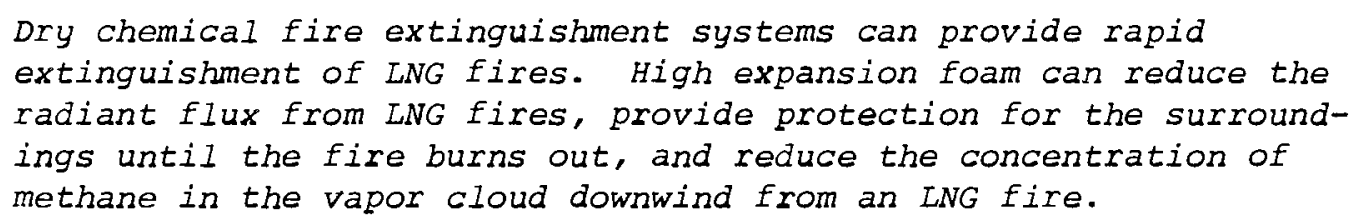

West, H. H., Brown, L. E. and Welker, J. R., "Vapor Dispersion Fire Control and Fire Extinguishment for LNG Spil1s." The Combustion Institute, 1975 Spring Technical Meeting. San Antonio, Texas, 1975.

The paper reports results on $A G A$ tests of $L N G$ evaporation and pool fire radiation reductions by foam application. Tests also demonstrated flame extinguishment by dry chemicals if applied a short time after pool fire ignition.

Westbrook, C. K., A Generalized ICE Method for Chemically Reactive Flows in Combustion Systems. LCRL-78915, Rev. 1, Lawrence Livermore Lab., August 1977.

The ICE method is modified to allow the pressure calculated at a new time step to include the effects of changes in internal energy and species over that time step. This is important for reactive flows in which the change in temperature and/or species contributes significantly to changes in pressure.

westbrook, C. K., "An Analytical Study of the Shock-Tube Ignition of Mixtures of ilethane and Ethane." Comb. Sci.\& Techn. 20:5-17, 1979.

The results of a detailed analytical study of the ignition of methane/ ethane mixtures show good agreement with previous shock tube experiments. Even small amounts of ethane, as found in LNG, will drastically reduce the ignition delay times of pure methane. 
Westbrook, C. and Haselman, L., Chemical Kinetics of LNG Detonations. UCRL-82293, Lawrence Livermore Laboratory, February 1979.

The authors of this paper theoretically investigate the effect of ethane on the detonability of methane. Small amounts of ethane were found to significantly increase the possibility of a detonation occurring. The chemical kinetics of the reaction mechanism are also presented.

Jestbrook, C. K., Modeling of Laminar Flames in Mixtures of Vaporized Liquefied ilatural Gas (LNG) and Air." UCID-13540, 1980.

A simplified chemical kinetics submodel is described which analytically represents the fuel/air burning in a large LNG spill.

Westbrook, C. K. 1982. "Chemical Kinetics of Hydrocarbon 0xidation in Gaseous Detonations." Combust. \& Flame. 46:191-210.

A detailed kinetics model has been developed to describe the mechanism for the transition to detonation in hydrocarhon/air mixtures. A criterion has evolved to quantify the susceptibility of the various hydrocarbons to develop detonation in their vapor phase.

Weston, H. and Brown, L.E., "Analyze Fire Protection System." Hydrocarbon Processing. pp. 89-92, August 1977.

This paper outlines a systems approach to fire safety and gives an example application to LNG Fire control.

Wethenbach, H. G. "Ausbreitung von Flammen an zylindrischen Behältern (Tanks) für flüssige Kohlenwasserstoffe." (Spreading of Flames on Cylindrical, Liquid Hydrocarbons Tanks.) Gas-Wasserfach, Gas Erdgas. 112:383-386, August 1971.

Storage of LNG can take place either in surface - or underground tanks. Either solution requires adequate safety and fire prevention measures. For storage of LNG, the same criteria concerning fires apply as for liquid petroleum products.

Wiekema, B. J. "Vapor Cloud Explosion Mode1." Journal of Hazardous Materials. $\underline{3}: 221-232,1980$.

In the paper, a model is presented which makes it possible to estimate the overpressure and positive phase duration as a function of distance from the explosion center. The type of explosions considered are deflagation and detonation although detonation is unlikely for all but the most highly combustible materials. The model assumes a hemispherical cloud lying on the ground and ignition is at the center. The results of the study identified three regions based on overpressure and position phase duration. Each region is valid for a particular fuel-air mixture of a different reactivity. 
Wilcox, D. C., "Model for Fires With Low Initial Momentum and Nongray Thermal Radiation." AIAA Journal. 13(3):381-386, March 1975.

A new ambient-air entrainment law accounts for rapid fluid acceleration from initially low velocity at a liquid pool, to higher velocities established under buoyant rise of the combustion products. Radialradiation heat transfer is computed with the exact radiation transport equation. Fire-model predictions fall within scatter of experimental flame-height and spectral-radiation data for LNG fires.

Wilcox, D. C., Non-Gray Thermal Radiation From a Flame Above a Pool of Liquid Natural Gas. Report by TRW Systems to A.G.A., A.E.A. Catalog No. M19714, February 1971.

This report indicates that a) spectral distribution of the radiation heat flux vector can be calculated, b) minimal data are required to extrapolate from small to large fires, c) an important scaling relationship may have been uncovered, and d) the flame model and associated computer program represent a solid foundation for investigation of radiation properties of a large LNG fire.

Williams, F. A., Combustion Theory - The Fundamental Theory of Chemically Reacting Flow Systems. Addision-Wesley Publishing Company, Inc., 1965.

Chapter 2 discusses Rankine-Hugoniot relations and pages 25-27 the properties of the Hugoniot curve.

Wissmiller, I. L. and Mattocks, E. O., "How to Use LIV Safely." Pipeline and Gas Journal. March 1972.

This article provides a general description of LNG equipment and facilities and how they are designed and operated for safety.

Withrington., J. K., "Analytical Methods for Verifying the Structural Integrity of LIVG Carriers." LNG 3 - International Conference on Liquefied ilatural Gas, Washington DC, September 24-28, 1972.

This paper identifies some of the structural problems that might occur with a very rapid increase in the size of LNG carriers and advocates the adoption of additional analytical methods to be used in conjunction with the normal procedures of the Classification Societies. 
Witte, L. C. and Cox, J. E., INonchemical Explosive Interaction of LNG and Water. ASME Preprint 71-WA/HT-31, 1972.

When LNG contacts water, an explosive incident may occur due to extremely rapid production of LNG vapor as heat is transferred from the surrounding water. Pertinent literature is summarized on similar reported explosions when hot molten materials contact cool liquids. Fragmentation of the LNG is believed to be the triggering mechanism for explosive vapor formation. Recent results of fragmentation research are presented.

Witte, L. C., Cox, J. E. and Bouvier, J. E., "The Vapor Explosion." Journal of Metals. 22:39-44, February 1970.

The article reviews the four theories of entrapment, violent boiling, shell theory, and Weber Number Effects. A common factor exists in that when molten material is fragmented prior to liquid contact, explosion danger is lessened.

Witte, L. C., Vyas, T. J. and Gelabert, A. A., "Heat Transfer and Fragmentation During Molten-Metal/Water Interactions." Journal of Heat Transfer. 95:521-527, Hovember 1973 .

This study indicates strongly that fragmentation occurs when a sample is molten and fragmentation is a response to an external stimulus. Alternate causes of fragmentation are proposed and are predicated upon the initial collapse of a vapor film around the molten metal.

Wolanski, P., Kaufman C. F., Sichel M. and Nicholls J. A. "Detonation of Methane/Air Mixtures." Proc. 18th Symp. (Internat.) on Combustion, pp. 1651$1660,1981$.

It has been shown that detonations of pure methane/air mixtures can be consistently generated in long tubes with a sufficiently large initiation energy. But since this energy is very high, the possibility of initiating a spherical detonation is extremely remote. This result substantiates earlier findings.

Wolf, Sidney 11., "Liquefied Natural Gas." The Bulletin of the Atomic Scientists. 25, Chicago, December 1978.

Wolf presents a review of LNG import questions including safety, security, and price applicable at the time of publication. 
Wood, B. D., Blackshear, P. L., Jr, and Eckert, E. R. G., "Mass Fire Model: An Experimental Study of the lieat Transfer to Liquid Fuel Burning From a Sand-filled Pan Burner." Combustion Science and Technology. 4:113-129, 1971 .

Heat flux data and the radiation heat flux data indicate that radiation contributes between 20 and 40 percent of the thermal load to the fuel surface for the methanol flame. For the acetone flame, approximately 40 to 60 percent of the total heat flux is radiation during the two steady burning rate periods.

Woolers, R. G., ilarine Transportation of LNG and Related Products. Cornell ilaritime Press, Cambridge, MD, 1975.

This book describes aspects of marine transport of LNG including ship design, container design, control systems, and a description of hazards and LNG importation. The hazards section describes experiments performed by the Bureau of Mines to determine the effects of LNG spillage on water.

Yamanouchi, N., and Nagasawa, H., "Using LNG Cold for Air Separation." Chem. Eng. Progr. 75(7):78-32, 1979.

By using the cryogenic energy contained in LNG, liquid oxygen, liquid nitrogen and liquid argon can be produced at a $40 \%$ saving in power consumption. In the same process $L N G$ is evaporated. Three plants based on this principle are already operating in Japan, and a fourth one is under construction.

Yamazaki, D., Yokoyama, it, and Hino, M., "Storing and Transportation of Hydrocarbon Gases." Chem. Abstr. 80:85438q. Japan Kokai 73-92, 401 (to Mitsubishi Heavy Industries, Ltd.), 1973.

Natural gas was contacted with aqueous aliphatic amine solutions to obtain the hydrate. The hydrate product had a vapor pressure of $35 \mathrm{~kg} / \mathrm{cm}^{2}$ at $40^{\circ} \mathrm{F}$.

Yang, K., "Explosive Interaction of Liquefied ivatural Gas and Organic Liquids." ivature. 243:221-222, 1973.

Small scale experiments are described in which LNG is poured into organic liquids. In some cases resulting reactions were rather violent, indicating the possibility of vapor explosions. 
Yilmaz, B. S., Clarke, S. F. and Westwater, J. M., Heat Transfer From Water in Film Boiling to an Lpper Layer of Paraffinic Hydrocarbon. ASIIE paper 76-HT-24, 1976.

Laboratory experiments have been performed to measure the flux from a layer of water in the state of film boiling to a superimposed layer of various types of hydrocarbons.

Yumoto, T., "Heat Transfer From Flame to Fuel Surface in Large Pool Fires." Combustion and Flame. 17:108-110, 1971.

The study was made to obtain experimentally the ratio of radiation and convection transfers to total heat transfer from the flame to the fuel surface in the range where the burning rate has a constant value regardless of pan diameter.

Zagoruchenko, V. A. and Gyske, D. N. "Determination of the Specific Volume of a Mixture of Liquefied Saturated Hydrocarbons Transported in Liquefied Gaseous Fue1 Tankers." (in Russian), Sud. Mash. I. Mckh. Nauchno-tekhn. Sb. 6:116-119, 1975.

The loading of tankers designed for the transport of various liquefied gaseous fuels makes it necessary to determine the specific volume of the mixtures of liquefied saturated hydrocarbons. An equation is given to calculate the specific volume for different concentrations and temperatures. For propane-n-decane, ethane-n-pentane, methane-ndecane and ethylene-n-heptane, it is shown that the calculated values are in very good agreement with experimental data.

Zainn, C. W. and Clayton, H. A., Recovery of ilatural Gas Liquids by Partial Condensation. J.S. Patent 4,142,876, 1979.

A complex control scheme is proposed which sets the minimum temperature of the natural gas stream to the separator, allowing for the recovery of natural gas liquid by partial condensation of the inlet feed stream.

Zeeuwen, J. P., Schippers, J. "Unconfined Vapor Cloud Explosion Modeling and Estimation of Structural Damage as the Consequences of Explosions in Hazard Analysis and Risk Evaluation." Third Incernational Loss Prevention Symposium, $1980,7 / 515-7 / 541$.

A model is presented that estimates peak overpressure and positive phase duration of the pressure wave caused by an unconfined vapor cloud explosion. The kind of loading and the structural elements of the exposed structure are taken into account in the estimation of the expected degree of damage and the probability that this damage will occur. 
Zeeuwen, J. P. "Description of Research Related to Vapor Cloud Explosions in the Netherlands." From Discussion on Explosion Hazards at the 7 th International Colloquium on Gas Dynamics of Explosions and Reactive Systems, ed. H. Wagner, pp. 79-80, Max-Planck-Institute Für Strömungsforschung, Göttingen, 1979.

Research is underway to improve a previously developed model which can be used to predict blast overpressure characteristics from the amount and kind of fuel present in a vapor cloud and structures in the vicinity of the vapor cloud. Studies are concerned with flame acceleration and transition to detonation and the influence of obstacles on flame fronts.

Zeman, 0. The uynamics and Modeling for Heavier-than-Air, Cold Gas Releases. UCRL 15224, 1980.

A new analytical model for the spreading of heavier-than-air LNG vapors is presented. dispersion by mixing with air is included. No test data are available that would quantitatively verify the model.

Zischka, H. "Investigation on Propulsion and Propelling Enqine of Ice-Breaking Ships under Extreme Conditions of Operation." (in German), Schiff u. Hafen. 33 (2):35-42, 1981 .

This article describes the problems of developing merchant ships for arctic waters, especially the design of an ice-breaking LNG-tanker. The consequences of the extreme environmental conditions on the operational systems of the ship are discussed, like power and technique of the propelling engine.

Zuber, K., "LiVG Facilities - Engineered Fire Protection Systems." Fire Technology. 12:41-48, 1976.

Dry chemical fire extinguishers used in conjunction with high expansion foam have been used successfully in tests to extinguish LNG spill fires.

Zubiate, R., Pomonik, G. and Mostarda, S., "Single Point Mooring System for Floating LNG Plant." Ocean Industry. pp. 75-78, November 1978.

The advantages of portable floating offshore LNG terminals are discussed as a preface to a description of a mooring system for such a facility. 
No. of

Copies

10 J. M. Cece (EP-323)

Office of Environmental

Protection, Safety and

Emergency Preparedness

U.S. Department of Energy

Wash ington, D.C. 20545

10 H. F. Walter (EP-35)

Office Of Environmental

Protection, Safety and

Emergency Preparedness

U.S. Department of Energy

Washington, D.C. 20545

12 DOE Technical Information Center

P. J. Anderson

Inst itute of Gas Technology

3424 South State Street

Chicago, IL 60616

S. Atallah

Gas Research Institute

8600 West Bryn Mawr Avenue

Chicago, IL 60631

A. C. Barre 11

Major Hazards Assessment Un it

Health and Safety Executive

25 Chape 1 Street

London, NW1 5DT, UK

L. E. Bell

Western LNG Terminal Associates

700 South Flower Street

Suite 3300

Los Angeles, CA 90017

F. Bodurtha

DuPont Company

Louviers Building 1351

Wi lmington, DE 19898
No. of

Copies
W. J. Bradford
01 in Corporation
120 Long Ridge Road
Stamford, CT 06904
C. P. Buck ley
Boston Gas Company
One Beacon Street
Boston, MA 02108

A. M. Clarke

Algonquin Gas Transmission Company

1284 Soldiers Field Road

Boston, MA 02135

W. E. Coe, Jr.

Southern Energy Company

P.0. Box 1367

Savannah, GA 31402

R. I. Cole

American Gas Association

1515 Wilson Boulevard

Arlington, VA 22209

G. Co lonna

U.S. Coast Guard (G-DMT-1)

2100 Second Street, S.W.

Washington, D.C. 20593

R. Danielson

Bay State Gas Company

120 Roya 11 Street

Canton, MA 02021

R. E. Dehart, I I

Union Carbide Corporation

P.0. Box 8361

South Charleston, WV 25303 
No. of

Copies

W. Denn is

Office of Pipeline Safety

Regulations

4007 th Street, S.W.

Washington, D.C. 20590

L. C. Doelp

Corporate Engineering

Air Products and Chemicals

Allentown, PA 18105

E. Drake

Arthur D. Little, Inc.

Acorn Park

Cambridge, MA 02140

F. Edeskuty

Los Alamos Scientific Laboratory

P.0. Box 1663

Los Alamos, NM 87545

J. Edge 11

Bulk Plant Operations

Columbia Hydrocarbon

Corporation

1600 Dublin Road

Columbus, $\mathrm{OH} 43215$

T. Eichler

IIT Research Institute

10 West 35 th Street

Chicago, IL 60616

H. K. Fauske

Fauske and Associates, Inc. 16070 West 83rd Street

Burridge, IL 60521

J. A. Fay

Department of Mechanical

Engineering

Massachusetts Institute of Technology

Cambridge, MA 02139
No. of

Copies

\author{
J. P. Frazier \\ Natural Gas Pipeline Company \\ of America \\ 122 South Michigan Avenue \\ Chicago, IL 60603
}

\section{S. Fujinami}

Tankage Designing Section

Kawasaki Heavy Industries, LTD

118 , Futatsuzuka, Noda-shi,

Chiba 278, JAPAN

M. Futana

No. 3 Group Chemical Plant and Mach inery Department $B$

Mitsub ishi Heavy Industries, LTD

118, Ichigaya Tomihisa-Cho, Sh injuku-ku

Tokyo 162, JAPAN

W. Geiger

Battelle-Institute e.V.

Am Roemerhof 35

6000 Frankfurt am Ma in 90

FEDERAL REPUBLIC OF GERMANY

D. Gideon

Battelle Columbus Laboratories

$505 \mathrm{King}$ Avenue

Columbus, $\mathrm{OH} 43201$

E. G. Graham

British Gas Corporation

326 High Holborn

London WC17PT, ENGLAND

J. Havens

College of Engineering

University of Arkansas

227 Engineering Building

Fayetteville, AR 72701

E. W. Hofer

Process Engineering Manager

Allied Corporation

P.0. Box 2105R

Morristown, NJ 07960 
No. of

Copies

W. J. Hogan

Lawrence Livermore Laboratory

P.0. Box 808

Livermore, CA 94550

R. Holden

Pacific Gas and Electric Company

77 Beale Street, Room 2971

San Francisco, CA 94106

C. C. Hong

Columbia Gas System Service Corporation

1600 Dub Tin Road

Columbus, $\mathrm{OH} 43215$

D. Igo

Transportation Research

Department of Transportation

4007 th Street, S.W.

Washington, D.C. 20590

W. C. Kohfeldt

Exxon Chemical Company

P.0. Box 271

Florham Park, NJ 07932

J. K. Lathrop

National Fire Protection Association

470 At lantic Avenue

Boston, MA 02210

J. A. Lawrence

Vice President and Manager of Nitrogen Operations

CF Industries, Inc.

Salem Lake Drive

Long Grove, IL 60047

D. J. Lewis

Imperial Chemical Industries, LTD

Mond Division, Research and Deve lopment Department

P.0. Box 7 Winnington

Northwich Cheshire, CW8 4DJ, UK
No. of

Copies

J. P. Lew is

Project Technical Liaison Associates, Inc.

4201 FM 1960 West, Suite 240

Houston, TX 77060

C. D. Lind

Code 3262

U.S. Naval Weapons Center

China Lake, CA 93555

G. Logan

Phillips Chemical Company

Seneca Building

Bartlesville, OK 74004

W. E. Martinsen

Energy Ana lysts Inc.

2001 Priest ley Avenue

P.0. Box 1508

Norman, OK 73070

Y. Matsui

Systems Department

Toyo Eng ineering Corporation

12-10, Higashi-funabashi 6-chome

Funabashi-shi, Chiba 273, JAPAN

R. N. Meroney

Fluid Mechanics and Wind Engineering Program

Department of Civil

Engineering

Colorado State University

Fort Collins, CO 80523

R. Morrison

Boston Gas Company

One Beacon Street

Boston, MA 02108

R. Norton

Distrigas, Inc.

125 High Street

Boston, MA 02110 
No. of

Copies

0. Ok awa

Chiyoda Chemical Engineering Company

P.0. Box 10

Tsurumi, Yokohama 230, JAPAN

J. C. Pace, Jr.

Long Is land Lighting Company

175 East 01d Country Road

Hicksville, NY 11801

H. Pasman

Prins Maurits Laboratory TNO

Techno logical Research

P.0. Box 45

2280 AA Rijswikj, NETHERLANDS

W. H. Penn

Tennessee Gas Pipeline Company

P.0. Box 2511

Houston, TX 77001

A. W. Perry

Trunk line LNG Company

Highway 384 and Lincoln Road

P.0. Box 6327

Lake Charles, LA 70606

H. W. Peter

Brook lyn Union Gas Company

195 Montague Street

Brook lyn, NY 11201

R. E. Petsinger

CNG Services, Inc.

2000 0xford Drive

Bethel Park, PA 15102

C. N. Petterson

Northwest Natural Gas Company 123 Northwest Flanders Street

Portland, OR 97209

T. Raines

Alabama Gas Corporation

P.0. Box 721

Pinson, AL 35126
No. of

Copies

P. Raj

Technology and Management Systems, Inc.

102 Drake Road

Burlington, MA 01803

R. C. Reid

Department of Chemical

Engineering

Massachusetts Institute of Technology

Cambridge, MA 02139

M. I. Rudnicki

Aerojet Energy Conversion Company

P.0. Box 13222

Sacramento, CA 95813

A. Salvador $i$

Gaz de France

Direction des Etudes et Techniques Nouve 1 les

Department des Etudes Cryogenics, Industrielles et Metallurgiques

23, rue Philibert-Delorme

Par is -17 , FRANCE

L. Santman

Materials Transportation Bureau

U.S. Department of Transportation

400 7th Street, S.W.

Washington, D.C. 20590

L. Sarkes

American Gas Association

1515 Wi lson Bou levard

Arlington, VA 22209

H. P. Schorr

Brooklyn Union Gas Company

195 Montague Street

Brooklyn, NY 11201

P. Schreurs

Katholieke Universite it Leuven

CIT

De Croylaan 2

B. 3030 Leuven

THE NETHERLANDS 
No. of

Copies

R. F. Schwab

Manager, Process Safety and Loss Prevention

Allied Corporation

P.0. Box 2332R

Morristown, NJ 07960

P. Seay

Technical Division

Office of Hazardous Materials Regulations

Materials Transportation Bureau 400 Seventh Street, S.W.

Washington, D.C. 20590

J. D. Shefford

British Gas Corporation

59 Bryanston Street

Marble Arch

London W1A2AZ, ENGLAND

R. B. Smith

Battelle Columbus Laboratories

$505 \mathrm{King}$ Avenue

Columbus, $\mathrm{OH} 43201$

J. K. Speckha ls

Columbia LNG Corporation

20 Montchan in Road

Wilmington, DE 19807

H. Stevens

Northwet Pipeline Corporation

P.0. Box 30

Umatilla, OR 97882
No. of

Copies

R. Tatge

CV International, Incorporated 2741 Toledo Street, Suite 208

Torrance, CA 90503

S. K. Wak ami ya

Product Engineering Division

National Bureau of Standards

Department of Commerce

Washington, D.C. 20234

W. Walls

National Fire Protection Association

470 Atlantic Avenue

Boston, MA 02210

J. R. Welker

Applied Technology Corporation

P.0. Box FF

Norman, OK 73070

S. J. Wiersma

Gas Research Institute

8600 West Bryn Mawr Avenue

Chicago, IL 60631

W. W. Wilson

San Diego Gas and Electric Company

P.0. Box 1831

San Diego, CA 92112

R. Zalosh

Factory Mutual Research

1151 Boston-Providence Turnpike

Norwood, MA 02062

B. Sweedler ONSITE

National Transportation Safety Board 800 Independence Avenue

Washington, D.C. 20591

DOE Rich land Operations

J. Tatematsu

Technology Transfer Institute

Kyodo Building

3-1, Akasaka 4-chome, Minato-ku

Tokyo 105, JAPAN

H. E. Ransom

25 Pac ific Northwest Laboratory

W. J. Bair

H. J. Bome lburg

C. A. Counts 
No. of

Copies

C. E. Cowan

W. E. Davis

J. G. DeSteese (10)

P. J. Pelto
No. of

Copies

R. E. Rhoads

L. D. Williams

Library (5)

Publishing Coordination (2) 
Toehnical Report Documentation Page

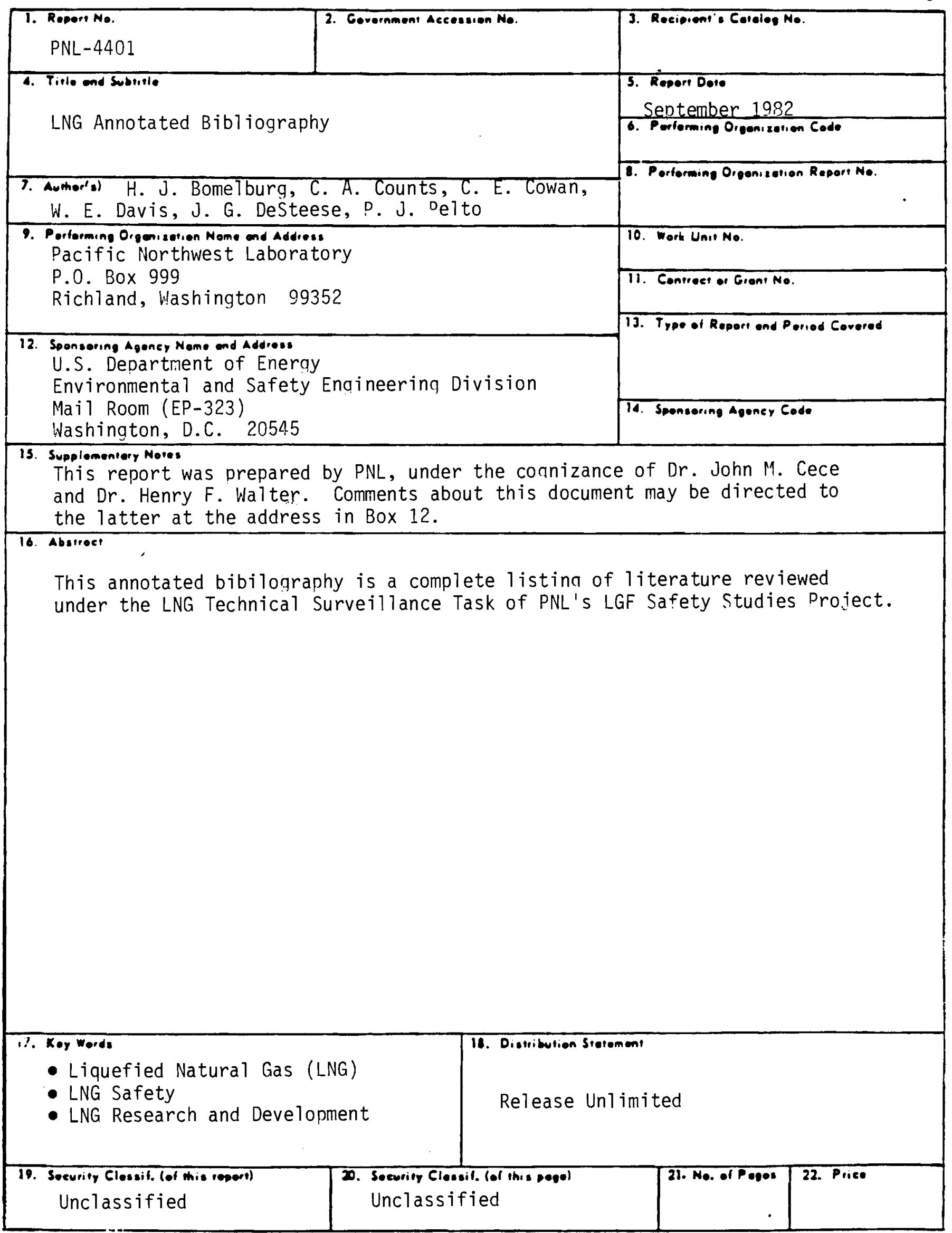


